\title{
HALOGENATED 1'-METHYL-1,2'-BIPYRROLES (MBPS) IN THE NORTHWESTERN ATLANTIC
}

\author{
By \\ Kristin C. Pangallo \\ B.S., Bates College, 2002 \\ Submitted in partial fulfillment of the requirements for the degree of \\ Doctor of Philosophy \\ at the \\ MASSACHUSETTS INSTITUTE OF TECHNOLOGY \\ and the \\ WOODS HOLE OCEANOGRAPHIC INSTITUTION \\ September 2009 \\ (c) 2009 Kristin C. Pangallo \\ All rights reserved. \\ The author hereby grants to MIT and WHOI permission to reproduce and \\ to distribute publicly paper and electronic copies of this thesis document in \\ whole or in part in any medium now known or hereafter created.
}

Signature of Author

Joint Program in Oceanography/Applied Ocean Science and Engineering Massachusetts Institute of Technology and Woods Hole Oceanographic Institution

June 26, 2009

Certified by

Dr. Christopher M. Reddy

Thesis Supervisor

Accepted by

Prof. Roger E. Summons

Chair, Joint Committee for Chemical Oceanography Massachusetts Institute of Technology/Woods Hole Oceanographic Institution 


\title{
HALOGENATED 1'-METHYL-1,2'-BIPYRROLES (MBPS) IN THE NORTHWESTERN ATLANTIC
}

\author{
By
}

\author{
Kristin C. Pangallo
}

\begin{abstract}
Submitted to the MIT/WHOI Joint Program in Oceanography on June 26, 2009, in partial fulfillment of the requirements for the degree of Doctor of Philosophy in the field of Chemical Oceanography
\end{abstract}

\section{THESIS ABSTRACT}

Halogenated 1'-methyl-1,2'-bipyrroles (MBPs) are a distinctive class of marine organic compounds. They are naturally produced, they have a unique carbon structure, they are highly halogenated, and they bioaccumulate in upper trophic levels. MBPs share many characteristics with persistent organic pollutants (POPs), and may prove to be useful natural analogues for these anthropogenic compounds. Further, their unique structure suggests that their biosynthetic organism(s) may have new genes to add to current knowledge of biosynthetic chemistry. The objectives of this dissertation were to further clarify the environmental distribution of MBPs, to examine whether MBPs biomagnify, and to investigate possible origins of these compounds through their stable nitrogen isotopic signatures.

Results from these investigations have shown that over 40 highly brominated MBP congeners are present in marine mammals, fish, and squid from the Northwestern Atlantic Ocean. The most abundant MBPs do appear to biomagnify through the food web to reach the concentrations observed in marine mammals. This additional evidence affords greater confidence in the use of MBPs as natural analogues for POPs. However, differences in the environmental chemistry of MBPs and anthropogenic compounds are also evident, and may be due to these compounds' different origins, or to the capacity of degradative enzymes to act upon them. Finally, compound-specific nitrogen isotope analyses on MBPs isolated from dolphin blubber show that these compounds are dramatically enriched in ${ }^{15} \mathrm{~N}$ relative to other biosynthetic organic compounds. This enrichment is likely a signal imparted during biosynthesis, and may assist in elucidating the organism(s) and mechanism(s) responsible for the biosynthesis of MBPs. 
To my grandmother,

Rachel B. Watkins,

whose strength, independence, and courage have always inspired me.

And, to my parents,

Diane and Robert Smith,

whose love and support make all things possible. 


\section{ACKNOWLEDGEMENTS}

The years spent working towards a Ph.D. can be tedious and difficult, or can inspire a more sophisticated fascination with your discipline. Your Ph.D. advisor can make all the difference, and I was incredibly fortunate to be advised by Dr. Christopher M. Reddy. Chris, you have made the past five years a time of exciting opportunities, memorable events, and enlightening discussions. More than that, you have made this crazy journey a lot of fun. I appreciate equally your high professional standards and your genuine warmth, compassion, and friendship. Thank you, Chris, for your dedication to your work and students, for the hours of instruction and discussion, for your confidence and trust, and for giving me the tools and inspiration to build my own career.

I have greatly benefited from the knowledge and generosity of my committee. Timothy Eglinton co-advised me during my first two years in the Joint Program and continues to contribute his thoughtfulness and experience, for which I am very grateful. I was privileged to take Sarah O'Connor's class on the biosynthesis of natural products, and was delighted when she agreed to serve on my committee. Sarah has offered a valuable perspective on my work, and welcomed me into her lab for a portion of my research. Thank you, Sarah, for the opportunities that you have provided. Tracy Mincer joined the WHOI faculty in my final year as a graduate student, but has provided unique and valuable insights into the synthesis and chemical ecology of marine natural products. I am delighted that he was able to serve on my committee. Philip Gschwend has gone beyond the duties of a committee member, offering me full access to his lab and instruments in Parsons. Even more critically, he has been exceptionally generous with his time, providing comments and feedback on my ideas and publications. His class on environmental organic chemistry changed the way I approach scientific questions, and had a considerable impact on my dissertation. Thank you for challenging me to improve as a scientist, and for assisting me on the ongoing journey. I feel incredible fortunate that Mark Hahn chaired my thesis defense. Thank you for performing all of the work of the thesis chair, for your exceptional perspective on xenobiotic compounds in marine mammals, and for generously giving your time and advice on both my thesis and future research plans.

I would probably still be trying to get instruments and methods working, were it not for Bob Nelson, Daniel Montluçon, Li Xu and Sean Sylva. They were always there to answer questions, make suggestions, offer miraculous solutions, and provide ironic commentary on day-to-day life in Fye. Sean, I must thank you especially, you were one of the first people I met at WHOI and you have been a constant source of guidance and a wonderful friend over the past seven years. Whether it was rebuilding the freeze-drier so I could finish my thesis, teaching me how to troubleshoot a GC-MS, or simply using your magic touch to 
get something working again, you were always there. Seriously, I'd still be on sample number 2 without you.

Chapter 5 of this dissertation would not have been possible without collaboration with Thomas Hofstetter and Jakov Bolotin of the ETH in Zürich, Switzerland. Their expertise in compound-specific stable nitrogen isotope analyses is second only to their warmth and hospitality. Thank you both for all of your work on our project, and for making my trip to Zürich both educational and extremely fun.

I am certain that the Academic Programs Offices for the MIT/WHOI Joint Program is thanked in every thesis, and this one is no exception. Julia Westwater, Marsha Gomes, Valerie Caron, Christine Charette, Ronni Schwartz, Jim Price and Jim Yoder, thank you for making the Joint Program an unbelievable experience. Literally unbelievable - friends of mine in other graduate programs cannot believe the financial, logistical and emotional support that you offer us. I will be forever grateful for your hard work on our behalf, and for your friendship through it all.

There are a few more groups of WHOI employees that I must thank. They were my nightly company in Fye, my late-night rides back to Winding Lane, and my morning rides into work. We would solve the world's problems over a 5minute car ride or coffee break, and they helped lighten the burden of long hours and hard work. Specifically, I want to extend my sincere appreciation to WHOI's custodial staff, security staff, and the shuttle drivers. I will especially miss my conversations with Rose (Clark) and already miss joking around with Tony (Fye). Commuting will never be the same without morning rides and local commentary from Bob, and on evening rides home I will miss the lively banter and recipe exchange with John. And the security staff - thank you for the doorto-door service, the late night conversations, and your reassuring presence (especially in the pre-dawn hours one fall day in 2007). Students at WHOI are lucky to have such a wonderful community of co-workers.

I started at WHOI as a research technician, and that experience is what led me to pursue my Ph.D. (and probably helped get me into the Joint Program), so I have to thank the people who hired me: Dr. Kai-Uwe Hinrichs, and NOSAMS. Working in Kai's lab was an excellent introduction to the world of oceanography and organic geochemistry. It was a delightful bonus that the people in our lab group became dear friends, many of whom I have continued to work with as a graduate student. And I was extremely fortunate to start off the Chemical Oceanography program after having worked at NOSAMS. Trying to wrap my mind around all the isotope chemistry was significantly easier with all that I learned from the people there. Specifically, I want to thank Dr. John Hayes, Dr. Ann McNichol, Al Gagnon, Mary Lardie and, especially, Dana Gerlach for sharing their knowledge, experience, and friendship. 
The organic chemists in Fye are a rowdy bunch, which makes working there thoroughly entertaining. The second summer I worked on this project I was privileged to work with Matthew Poyton, then an undergraduate student at Providence College. Matt, you were an enormous help, but more than that, you were wonderful company, thank you. Helen Fredricks has a heart and a candy drawer that are both seemingly bottomless. Thank you for teaching me how to Bligh\&Dyer, and more importantly, thank you for being such a dear and constant friend. Eoghan and James, I will always look back on our days in the trailer with fondness - not that I want to move back in. You have helped me stay upbeat during the past few years with your senses of humor and creative schemes: Christmas decorations, movie nights, and beer hours, to name a few. And Eoghan, I will always remember and appreciate your support for UMAP.

Within Fye Lab is an enclave of brilliant women working to understand the fate of organic contaminants - the Reddy graduate students past and present. Helen White offered direct and wise advice on negotiating graduate school, and has continued to provide mentoring well after our free lunches came to an end. Karin Lemkau has brightened up our lab with her smiles and her cleanliness, both are wholeheartedly appreciated by me! And Fye would never be the same without Emily Peacock, my labmate and officemate, who provides welcome distraction as we discuss everything from politics to Chihuahua sporting events. (And, on that note, thank you to Rose and Demi for their love and affection, and for cleaning up all my crumbs.) Emily, you have been a constant source of support and assistance, thank you for everything.

As a commuting student I spent an enormous portion of the past 5 years in student housing at 512 Winding Lane. Thank you to all the wonderful women with whom I lived - you made 512 a place that I enjoyed returning to every night. I am so glad to have found good friends in my long-time roomies Stacy DeRuiter, Rachel Horowitz, and Jessie Kneeland. Thank you for your company, friendship, and recipes.

There are three JP women who have a special place in my heart: Laura Hmelo, Naomi Herrera, and Desirée Plata. You were my companions for countless hours of problem sets, navigating the general exams, and the ups and downs of research. Thank you all for generously sharing your knowledge, expertise, and friendship. Laura, thank you for the hours of conversation, for always being able to make me laugh, and for keeping me grounded in reality. Naomi, thank you for being a fabulous driver, roommate extraordinaire, and sounding board on every conceivable topic. Desirée, my academic Irish twin, you continue to inspire me with your creativity, intelligence, and principles. Thank you for all of your advice, laughs, and for being a true confidant.

Any success that I find in life has its roots in my loving and supportive family. I am particularly lucky in that I actually have two such families: the Smiths and the Pangallos. Matteo, Nettie, Karen, and Sal, I can never thank you 
enough for everything that you have done for me over the past 5 years while I've pursued my degree. Although we have only been 'legally' family for the past 2 years, I always knew that I had family in Salem, and that you were there for me under any circumstance. Thank you. My siblings, Lindsey Smith and Michael Smith, have to be credited with teaching me how to develop and support an argument. You two were the best teachers. Mike, thank you for inspiring me to look at the world from a different perspective and for all the music (I've been listening to it as I have written this dissertation). Lindsey, you inspire me to make my work relevant, to use any gifts I have to better people's lives, and to always place family first. Thank you for all that you've taught me.

This dissertation is dedicated to my grandmother, Rachel B. Watkins, and to my parents, Diane and Robert Smith. Nana, I have dedicated this dissertation to you because I aspire to your example. You were the first women in our family to study science. You are always up for learning something new. You are independent in mind and spirit. And you continually demonstrate incredible strength, courage and resiliency. Thank you for always inspiring me, and all those who meet you. And thank you to my Mom and Dad. A few lines of thanks are hardly sufficient for all that you have given me. Thank you for providing me with every opportunity, for letting me explore any interest, and for your unwavering faith in me. Mom, thank you for sharing your love of learning, for teaching me to read (that has really come in handy), for demonstrating the impact an excellent teacher can have, and for your unerringly good advice. Dad, thank your for introducing me to boats and the wonders of the ocean, for encouraging my curiosity in the world, and for exemplifying high moral and professional standards. Mom and Dad, I am so proud to be your daughter.

My final thank you is to my husband, Dominick Pangallo. A simple 'thank you' can hardly encompass the extent of my gratitude. Thank you for your steadying presence. Thank you for always being so supportive, especially when I was away for weeks, months, and years at a time. Thank you for being a single parent to our furry menagerie. Thank you for proof-reading and editing papers which were written in, more or less, another language. Thank you for including me in your life and bringing me joy every day. For all of this, and for so much more, I thank you and I love you.

This dissertation was made possible with funding provided by the National Science Foundation, through their Graduate Research Fellowship Program and OCE grant number 0550486 (PI: Dr. Christopher M. Reddy), and by The Seaver Institute, the J. Seward Johnson Fund, the Virginia Walker Smith Fund, and the WHOI Ocean Ventures Fund. 


\section{TABLE OF CONTENTS}

Thesis Abstract 3

Dedication $\quad 5$

Acknowledgements $\quad 7$

Table of Contents $\quad 11$

Chapter 1. An introduction to halogenated 1'-methyl-1,2'-

bipyrroles (MBPs) 19

History $\quad 19$

Structure and Properties $\quad 21$

Relevance $\quad 22$

Relevance: Natural Analogues to POPs 23

Summary 29

Objectives $\quad 30$

References $\quad 32$

Figures 36

Chapter 2. Expanding the range of halogenated 1'-methyl-1,2'-

bipyrroles (MBPs) using GC/ECNI-MS and

GCXGC/TOF-MS 39

Abstract 39

1. Introduction $\quad 40$

2. Methods 42

2.1 Samples 42

2.2 Sample extraction and purification $\quad 42$

2.3 Production of an MBP standard solution 43

$2.4 \mathrm{GC} / \mathrm{ECNI}-\mathrm{MS}$ procedures 44

2.5 GC×GC/TOF-MS procedures $\quad 45$

3. Results and Discussion 46

3.1 Tentative identification of halogenated $1^{\prime}$ methyl-1,2'-bipyrroles by GC/ECNI-MS 46

3.2 Further evidence of partially halogenated congeners of the halogenated 1'-methyl1,2'-bipyrroles by GC×GC/TOF-MS 49

4. Conclusions 53

Acknowledgements $\quad 54$

References $\quad 55$

Figures and Tables $\quad 58$

Chapter 3. Distribution patterns suggest biomagnification of
halogenated 1'-methyl-1,2'-bipyrroles (MBPs)

Abstract $\quad 65$ 
1. Introduction 66

2. Experimental 68

2.1 Sampling $\quad 68$

2.2 HOC extraction and purification $\quad 68$

2.3 Detection and quantification by
GC/ECNI-MS

3. Results and Discussion $\quad 71$

3.1 Age dependence of contaminant
concentrations

3.2 Maternal transfer of contaminants $\quad 77$

3.3 Comparison of nutritionally-compromised
and healthy individuals

3.4 Interspecies differences $\quad 80$

Acknowledgements $\quad 82$

References $\quad 83$

$\begin{array}{ll}\text { Figures and Tables } & 87\end{array}$

Brief $\quad 93$

Supplemental Information $\quad 94$

Chapter 4. Marine natural products, the halogenated 1'-methyl1,2'-bipyrroles (MBPs), biomagnify in a Northwestern Atlantic food web 107

$\begin{array}{ll}\text { Abstract } & 107\end{array}$

1. Introduction 108

2. Methods 108

2.1 Sampling 110

2.2 HOC extraction and purification $\quad 111$

2.3 Detection and quantification by

GC/ECNI-MS 113

2.4 Quality control of MBP quantification $\quad 115$

2.5 Stable isotope analysis $\quad 115$

3. Results and Discussion 116

3.1 MBP concentrations 116

3.2 MBP distributions in non-mammalian samples 117

3.3 Stable isotope results $\quad 118$

3.4 Trophic level assessment by $\delta^{15} \mathrm{~N} \quad 118$

3.5 Evidence for biomagnification of MBPs 120

3.6 Pinniped anomaly 122

3.7 Differences between MBPs and CB-153 125

Acknowledgements 127

Figures and Tables $\quad 128$

$\begin{array}{ll}\text { Chapter } 4 \text { Appendix } & 139\end{array}$ 
References

Chapter 5. $\delta^{15} \mathrm{~N}$ enrichment suggests possible source for halogenated 1'-methyl-1,2'-bipyrroles (MBPs)

Abstract

1. Introduction 147

2. Methods 149

2.1 Samples 149

2.2 MBP isolation from blubber $\quad 150$

2.3 Bulk stable nitrogen isotope analyses $\quad 152$

2.4 Compound-specific nitrogen isotope analyses

2.5 Quality controls 152

2.5.1 GC-C-IRMS 152

2.5.2 Extraction and purification

procedure

153

2.6 Nomenclature 154

3. Results and Discussion 154

3.1 MBPs enriched in ${ }^{15} \mathrm{~N}$

3.2 Origin of enrichment 156

3.2.1 Fractionation during degradation $\quad 157$

3.2.2 Enriched pre-cursors and biosynthesis 160

3.3 A hypothesis for MBPs origins $\quad 162$

Acknowledgements 164

Figures and Tables $\quad 165$

$\begin{array}{ll}\text { References } & 169\end{array}$

Chapter 6. Conclusions and Future Directions 177

Appendix 185 


\section{TABLE OF FIGURES}

Chapter 1. An introduction to halogenated 1'-methyl-1,2'bipyrroles (MBPs)

Figure 1. General structure of MBPs 35

Figure 2. Illustration of biomagnification 35

Figure 3. Structures of compounds similar to MBPs 36

Chapter 2. Expanding the range of halogenated 1'-methyl-1,2'-

bipyrroles (MBPs) using GC/ECNI-MS and GC $\times$ GC/TOF-MS

Figure 1. General structure of MBPs

60

Figure 2. Summed ion GC chromatograms of MBP standard solution and blubber extract

Figure 3. Mass spectra of $\mathrm{MBP}-\mathrm{Br}_{7}, \mathrm{MBP}^{-\mathrm{HBr}_{6}}$, and $\mathrm{MBP}-\mathrm{H}_{2} \mathrm{Br}_{5}$ from ECNI-MS and TOF-MS

Figure 4. Partial GC $\times$ GC/TOF-MS chromatograms of MBP standard solution and blubber extracts

Chapter 3. Distribution patterns suggest biomagnification of halogenated 1'-methyl-1,2'-bipyrroles (MBPs)

Figure 1. Lipid-normalized concentrations of MBP$\mathrm{Br}_{6} \mathrm{Cl}-b$ and $\mathrm{CB}-153$ in the blubber of 13 common dolphins vs. their length

Figure 2. Lipid-normalized concentrations of MBPs and CB-153 in the blubber of an Adult Female vs. Juvenile Male common dolphins found stranded together

Figure 3. The mean (18 odontocetes) of liver concentrations relative to blubber concentrations (both lipid-normalized) of $\mathrm{MBP}-\mathrm{Br}_{6} \mathrm{Cl}$ and $\mathrm{CB}-153$.

Figure S1. The general structure of MBPs

Chapter 4. Marine natural products, the halogenated 1'-methyl1,2'-bipyrroles (MBPs), biomagnify in a Northwestern Atlantic food web

Figure 1. Partial summed ion chromatogram of the Silver Hake 153, highlighting three newly tentatively identified $\mathrm{MBP}-\mathrm{Br}_{6} \mathrm{Cl}$ congeners

Figure 2. Distribution of MBPs and CB-153 in select non-mammalian samples.

Figure 3. Plots of the natural log of MBP and CB-153 (lipid-normalized) concentrations versus trophic level, showing biomagnification 
Figure 4. Plots of Br7-MBP-79 and CB-153 versus MBP$\mathrm{Br}_{6} \mathrm{Cl}-b$.

Figure 5. Plots of MBP-Br 6 Cl- $b$ and $\mathrm{CB}-153$ versus $\delta^{13} \mathrm{C}$ in mammals and non-mammals.

Chapter $5 . \delta^{15} \mathrm{~N}$ enrichment suggests possible source for halogenated 1'-methyl-1,2'-bipyrroles (MBPs)

Figure 1. General structure of MBPs

Figure 2. Linearity test of GC-C-IRMS system at low signal amplitudes.

Figure 3. Box plots of $\delta^{15} \mathrm{~N}$ ranges of MBPs and compound classes from a literature review

Figure 4. Selected pathways of pyrrole biosynthesis

Figure 5. Box plots of $\delta^{15} \mathrm{~N}$ ranges of selected amino acids from a literature review 


\section{TABLE OF TABLES}

Chapter 2. Expanding the range of halogenated 1'-methyl-1,2'bipyrroles (MBPs) using GC/ECNI-MS and GC $\times$ GC/TOF-MS

Table 1. MBPs identified in $0.5 \mathrm{~g}$ of lipid from the blubber of a common dolphin (D. delphis).

Chapter 3. Distribution patterns suggest biomagnification of halogenated 1'-methyl-1,2'-bipyrroles (MBPs)

Table 1. Species, gender and maturity distributions for the 25 samples analyzed

Table 2. Lipid-normalized concentrations of MBPs and CB-153 in the blubber and liver of all samples

Table S1. Descriptions of individual mammals included in this study

Table S2. GC/ECNI-MS relative retention times and quantification ions of compounds discussed 98

Table S3. Concentrations of MBPs and CB-153 in individual blubber samples

Table S4. Detection of MBPs not quantified in blubber

Table S5. Concentrations of MBPs and CB-153 in individual liver samples

Table S6. Detection of MBPs not quantified in liver

Chapter 4. Marine natural products, the halogenated 1'-methyl1,2'-bipyrroles (MBPs), biomagnify in a Northwestern Atlantic food web

Table 1. Description of additional mammals included in this study

Table 2. Lipid-normalized concentrations of MBPs and CB-153 in non-mammalian samples

Table 3. Lipid-normalized concentrations of MBPs and CB-153 in additional mammal samples

Table 4. Stable isotope ratios and calculated trophic levels for all samples

Table 5. Regression equations, significance level, food web magnification factor and $\log \mathrm{K}_{\mathrm{ow}}$ for MBPs and CB-153

Table 6. Correlation matrix for MBP and CB-153 lipidnormalized concentrations

Appendix A. Mass of the total lipid extract (TLE), dry mass, and wet mass for all non-mammalian samples 
Chapter 5. $\delta^{15} \mathrm{~N}$ enrichment suggests possible source for halogenated 1'-methyl-1,2'-bipyrroles (MBPs)

Table $1 . \delta^{15} \mathrm{~N}$ of four individual MBPs isolated from the blubber of three common dolphins 


\section{CHAPTER 1}

\section{An introduction to halogenated 1'-methyl-1,2'-bipyrroles (MBPs)}

History

Ten years ago, Environmental Science $\mathcal{E}$ Technology published a research article suggesting that a highly halogenated contaminant isolated from seabird eggs, tetrabromodichloro-1,1'-dimethyl-2,2'-bipyrrole, was naturally produced [1]. The natural origin of this compound was confirmed in 2004 [2], and provided the first evidence that halogenated natural products (HNPs) bioaccumulate in upper trophic levels in the same manner as anthropogenic contaminants. Since then, a few other classes of HNPs have been shown to bioaccumulate in these higher trophic level organisms. One such class is the halogenated 1'-methyl-1,2' -bipyrroles (MBPs) [3, 4].

Investigations into MBPs began in 1999 when an unknown contaminant with the molecular formula $\mathrm{C}_{9} \mathrm{H}_{3} \mathrm{Cl}_{7} \mathrm{~N}_{2}$, initially called $\mathrm{Q} 1$, was detected in marine samples [3]. Shortly thereafter it was determined that Q1 was identical to compounds detected but unidentified in samples dating back to the 1980s [5]. When the structure was determined in 2002, as an N,C1-linked bipyrrole with chlorine atoms occupying all ring carbons (Figure 1) [6], it had been detected in a variety of samples worldwide, including seabird eggs, marine mammal blubber, 
human breast milk (from women with diets rich in blubber) and Antarctic air [3, 7-10]. No compounds with this structure had ever been commercially produced, and it was only found in marine samples; thus, MBPs were believed to be naturally produced in marine ecosystems. The organism (or organisms) responsible for MBP biosynthesis has yet to be identified.

Although the perchlorinated MBP congener was detected in 1999, brominated congeners were not detected until 2006 [4]. The highly brominated heptabromo-, hexabromochloro-, hexabromo-, and pentabromochloro-1'-methyl1,2'-bipyrroles (MBP-Br7, $\mathrm{MBP}-\mathrm{Br}_{6} \mathrm{Cl}, \mathrm{MBP}-\mathrm{Br}_{6}$, and $\mathrm{MBP}-\mathrm{Br}_{5} \mathrm{Cl}$, respectively) were found to be more abundant than the perchlorinated congener, Q1, in the blubber of marine mammals from the Northwestern Atlantic [4, 11]. The lag between the detection of Q1 and the brominated congeners likely resulted from a combination of the geographic distribution and the chemical stability of the different congeners. The procedure for the initial isolation of Q1 used sulfuric acid to remove the lipid matrix [3], conditions under which the highly brominated congeners were unstable [4]. Further, much of the work on Q1 was accomplished in the Pacific and Southern Oceans, locations where highly chlorinated MBPs dominate the MBP distribution [12]. With the detection of the brominated congeners in the Atlantic, it became clear that MBPs consist of a family of compounds that have the same carbon backbone but different halogenation patterns; it was not yet proven that they were produced naturally. 
As of 2006, the evidence for MBPs as natural products consisted of a number of observations [4,5]. MBPs had no known industrial source, either intended or inadvertent (e.g., dioxins are an unintended byproduct of industrial processes [13]). MBPs have only been found in marine samples; a critical point, since all anthropogenic compounds ultimately have terrestrial sources. MBPs shared structural similarities to other marine HNPs, specifically the bipyrrole structure. As mentioned previously, the natural product found to bioaccumulate in higher trophic level organisms was a halogenated bipyrrole [1]. A marine bacteria, Pseudoalteromonas luteoviolacea (originally classified as a Chromobacterium), is known to produce a perbrominated bipyrrole [14, 15]. A natural source for MBPs was confirmed through their detection in whale oil archived prior to the onset of industrial halogenation [16].

Structure and Properties

MBP structure consists of two nitrogen-containing, aromatic, fivemembered rings, with up to seven halogens (either bromine or chlorine) on the ring carbons (Figure 1). This structure results in two properties of MBPs that make them environmentally relevant: persistence and lipophilicity. MBPs have high octanol-water partition coefficients $\left(\mathrm{K}_{\mathrm{ow}}\right)$, as estimated from their molecular structure $\left(\log \mathrm{K}_{\mathrm{ow}}=6.6-8.3[16]\right)$. Kow values use octanol as a representative of organic matrices to predict the partitioning of chemicals between an organic 
phase and water. MBPs are aromatic, and relatively non-polar and non-volatile, characteristics that result in MBPs concentrating in organic matrices, like blubber, rather than aqueous reservoirs or air. The persistence of these molecules partially stems from their high $\mathrm{K}_{\mathrm{ow}}$ values. When partitioned into storage tissues, such as blubber, there is limited opportunity for metabolism [17]. Their persistence is also due to their high degree of halogenation. Halogens form strong bonds with carbon because of their high electronegativity. Additionally, the lipophilicity of organic molecules tend to increase with the number of halogens. This is due to halogens' large size and their low affinity for forming hydrogen bonds with water [18]. Thus MBPs, which are concentrated in blubber and highly halogenated, have little opportunity for degradation and are likely difficult to metabolize.

\section{Relevance}

When initially discovered, MBPs were considered remarkable for two reasons: their high degree of halogenation and the unusual $\mathrm{N}, \mathrm{C} 1$-linkage of the pyrrole moieties. They remain unusual in these characteristics among known natural products today. These characteristics are particularly relevant to researchers studying the cycling and fate of persistent organic pollutants and those developing new pharmaceutical therapeutics. 
Relevance: Natural Analogues to POPs

Persistent organic pollutants (POPs) are a group of chemicals defined (and regulated) under the United Nations Environment Program's Stockholm Convention on Persistent Organic Pollutants (2001) as compounds that “...possess toxic properties, resist degradation, bioaccumulate and are transported, through air, water and migratory species, across international boundaries and deposited far from their place of release, where they accumulate in terrestrial and aquatic ecosystems..." [13] Two chemical characteristics that define POPs, halogenation and lipophilicity, are shared by MBPs. These similarities are potentially useful when considering the long term cycling of halogenated compounds. As natural products, MBPs likely evolved with their ecosystem, and have presumably been 'in production' for a very long time. Anthropogenic POPs have only been produced and emitted into the environment in recent decades, and thus their long-term fate is unclear. By using MBPs and other HNPs as model compounds, we can more clearly understand the routes and reservoirs important to the fate of POPs in the environment. For example, by recognizing which structural moieties are enzymatically degraded in natural products, and which are removed through abiotic processes (such as photodegradation or surface-mediated catalysis), we can better predict the fate of pollutants containing the same or similar structures. Additionally, HNPs that only have a marine source may help gauge the seafood-based contribution to 
human uptake of POPs. This pathway is a concern, but its relative contribution is difficult to assess, as POPs are present in both terrestrial and marine food sources. Transfers of marine HNPs into human tissues have previously been demonstrated [9] and may offer a method for disentangling the two POP vectors.

The utility of MBPs to act as natural analogues for POPs depends on a thorough understanding of the environmental distribution of MBPs and the controls on their cycling and fate. An important difference between these types of compound is their geographic origin. Although POPs have only been produced on land, POPs are ubiquitous pollutants and are now present in both terrestrial and marine ecosystems [13]. Thus, they have multiple inputs to the marine ecosystem, e.g., rivers, dust, aerosols, and freely diffusible gasses. MBPs are natural products that have only been detected in marine samples or samples closely tied to the marine food web $[5,12,19]$. It is likely that they are made by a specific organism or group of organisms, and thus their source is much more geographically limited than that of the POPs. From this source difference, it is likely that MBPs and POPs enter the marine food web differently. This may impact the availability of the compounds for bioaccumulation, biomagnification, and biotic and/or abiotic degradation. Therefore, their sources may ultimately result in different distributions in marine biota.

For use as natural analogues to POPs, it is also necessary that the mechanisms known to be important in POP cycling are also relevant to MBPs. 
An important control on POP cycling is biomagnfication, which is the increase of the lipid-normalized concentration of a contaminant with trophic level [20]. Previous work has established that biomagnification can occur for hydrophobic compounds with octanol/water partition coefficients exceeding $10^{4}$ [21]. Additionally, biomagnfiying compounds must be persistent to avoid any appreciable abiotic or enzymatic degradation. Contaminant concentrations increase in each trophic level (Figure 2) because persistent compounds are not significantly metabolized during digestion and contaminant fugacities increase as prey is digested [22]. This increase in fugacity during digestion explains how contaminants are transferred against the apparent thermodynamic fugacity gradient.

It is important to note that biomagnification and bioaccumulation are different concepts and are not interchangeable. Bioaccumulation is equilibrium partitioning between biota and the surrounding environment, and can occur through inhalation, ingestion, and/or absorption [18]. Biomagnification acts through ingestion and results in top predators with contaminant concentrations that are much higher than what would be expected based on equilibrium partitioning between the surrounding environment (i.e., water, soil, or sediment) and biotic tissues [18].

Biomagnification is a concern for POPs. Indeed, the high concentrations of POPs in top predators are partially responsible for the concerns and strict 
regulation of these compounds [13]. As of 2006, when this study began, it was unclear whether the high concentrations of MBPs found in marine mammal blubber resulted from biomagnification. Based on the concentrations observed, the chemical properties of MBPs, and the detection of MBPs in one sample of a marine mammal prey species [16], biomagnfication was suspected. In order to show that biomagnification occurs, however, the lipid-normalized concentration increase with trophic level must be demonstrated.

\section{Relevance: Pharmaceutical Therapeutics}

The development of pharmaceutical agents began with the isolation of bioactive compounds from environmental samples. For example, quinine was 'discovered' by western medicine by noting that indigenous populations of South America used cinchona bark (a source of quinine) to treat fevers [23]. Although drug development turned away from natural products in recent decades, there is a renewed interest in naturally produced compounds for novel therapeutic agents [24]. This interest has focused significant attention on marine sources. Marine sources were, until recently, largely ignored, and in this brief period of renewed interest they have already proven a rich source of novel bioactive compounds [25]. One route of recent drug development is the use of biosynthetic pathways to produce or to assist in the production of complex chemical structures [26]. The novel pyrrole linkage and the highly halogenated 
nature of MBPs suggest that the organism(s) responsible for their biosynthesis may contribute new mechanisms to our growing 'library' of biosynthetic chemistry. Additionally, many organisms that produce secondary metabolites (compounds not required for primary metabolism, but which benefit the producing organism) synthesize more than one type of compound [27, 28]; for example, the marine bacterium that produces $3,3^{\prime}, 4,4^{\prime}, 5,5^{\prime}$-hexabromo-2, $2^{\prime}$ bipyrrole also produces other brominated pyrrole structures and biosynthetically-unrelated polysaccharides [14, 29]. Identification of the producing organisms of MBPs may result in the discovery of yet more novel bioactive compounds. In order to fully realize the therapeutic potential of MBPs, we must identify their biosynthetic origins.

Although the producer(s) of MBPs has yet to be identified, there are organisms known to produce structurally similar compounds. The N,C1-linkage in MBPs has not been previously observed linking two pyrrole rings. However, there are a few biosynthetic examples of the N,C1-linkage between other fivemembered, nitrogen-containing, bicyclic ring systems (Figure 3). Two lily species are known to produce bicyclic systems with this linkage, Lilium hasnonii [30] and Lilium candidum [31]; Wasabi japonica produces a bi-indole system linked through its 5-membered rings [32]. In a broader search of all chemical literature, the motif is also present in $\mathrm{N}$-fused porphyrins [33], azofullerenes [34], 
pyrrolodiazines [35], compounds for drug development [36], and pyrrollic sensors [37].

Two additional bipyrrole types have been described in the literature that have C1,C1- and N,C2-linkages (Figure 3). The C1,C1-linked bipyrroles include another class of biomagnifying marine natural products, halogenated 1,1'dimethyl-2,2'-bipyrroles [38]. Although their origin is unknown, a halogenated bipyrrole of similar structure (the aforementioned 3,3',4,4',5,5'-hexabromo-2,2'bipyrrole) has been isolated from a marine bacterium [14] now identified as Pseudoalteromonas luteoviolacea [15]. A group of gram-positive bacteria commonly known as actinomycetes also produce bipyrroles: the $\mathrm{C} 1, \mathrm{C} 1$-linked prodigiosin series of natural products are produced by Streptomyces species $[39,40]$, and marine actinomycete strain $\mathrm{CNQ}-418$ produces the $\mathrm{N}, \mathrm{C} 2$-linked marinopyrroles [41].

In addition to the unusual carbon backbone, MBPs are halogenated, and their halogenation appears geographically dependent: chlorinated congeners dominate the MBP distributions in the Pacific and Southern Oceans \{Vetter, 2007 \#422\}, while highly brominated congeners dominate in the Northwestern Atlantic \{Teuten, 2006 \#35;Pangallo, 2008 \#454\}. (Thus far no iodinated MBPs have been reported in any environmental samples.) This halide-specificity suggests that the halogenases involved in MBP biosynthesis may also have specific geographic distributions. Of the three classes of known halogenases that 
target aromatic rings, vanadium-dependent haloperoxidases have shown the greatest halide specificity \{Blasiak, 2009 \#873\}. However, both heme-dependent haloperoxidases and flavin-dependent halogenases are also capable of both brominating and chlorinating aromatic rings, and many questions remain regarding the halide specificity of the halogenase enzymes \{Blasiak, $2009 \# 873$ \}.

\section{Summary}

When the research for this dissertation was initiated, in the summer of 2006, we knew of 7 MBP congeners that were present in the blubber of marine mammals $[5,16]$ : the perchlorinated $\mathrm{Q} 1$, the perbrominated $\mathrm{MBP}-\mathrm{Br} 7$, one congener of $\mathrm{MBP}-\mathrm{Br}_{6} \mathrm{Cl}$, one congener of $\mathrm{MBP}_{-} \mathrm{Br}_{6}$, and three congeners of $\mathrm{MBP}$ $\mathrm{Br}_{5} \mathrm{Cl}$. We knew that these compounds were natural by virtue of their presence in whale oil archived prior to the onset of industrial halogenation [16]. Q1 was the most abundant MBP detected in samples from Australia and the Southern Ocean, while the highly brominated congeners dominated the MBP distribution in samples from the Northwestern Atlantic $[4,11,16]$. MBPs had also been identified in squid [4] and the breast milk of women who had diets rich in blubber [9], suggesting that MBPs could undergo trophic transfer. However, it was not yet certain whether they biomagnified.

To facilitate discussion of the MBPs, Vetter et al. [12, 42] suggested a numbering system for the MBPs based on the system developed for the 
anthropogenic polychlorinated biphenyls (PCBs) [43]. In this system the perchlorinated Q1 is given the acronym MBP-79, and the perbrominated MBP$\mathrm{Br}_{7}$ is termed $\mathrm{Br}_{7}-\mathrm{MBP}-79$. This is the nomenclature that will be used for these two compounds for Chapters 4-6. Chapters 2 and 3 are already published [19, 44], and use $\mathrm{MBP}^{-\mathrm{Cl}_{7}}$ and $\mathrm{MBP}-\mathrm{Br}_{7}$ for $\mathrm{MBP}-79$ and $\mathrm{Br}_{7}-\mathrm{MBP}-79$, respectively. For further details on nomenclature please see Chapter 3.

\section{Objectives}

The objectives of this dissertation were to further clarify the environmental distribution of MBPs, to determine whether MBPs biomagnify, and to investigate possible origins of these compounds through their stable nitrogen isotopic signatures. The following four chapters each delve into one or more of these areas. Chapter 2 dramatically expands the number of MBPs present in blubber, most of which were detected at trace abundances. A comparison of analytical techniques for MBP analysis (gas chromatography/electron capture negative ion mass spectrometry and comprehensive two-dimensional gas chromatography/time of flight mass spectrometry) is also presented in this chapter. To further explore the environmental distribution of MBPs, Chapter 3 describes the MBP content of blubber and liver from a wide variety of marine mammals. (Additional information regarding the lipid content of the samples from this chapter is 
included in the Appendix to the thesis.) This chapter presents strong evidence for MBP biomagnification by comparing MBP distribution patterns with those of a PCB known to biomagnify. The comparisons also illustrate differences in the cycling of the natural MBPs and anthropogenic PCB. These themes are further explored in Chapter 4, which demonstrates that lipid-normalized MBP concentrations do indeed increase with trophic level. Finally, Chapter 5 presents the measurement of compound-specific nitrogen isotope ratios for four individual MBPs and discusses the implications of the remarkable enrichment that was found. Chapter 6 summarizes the results and suggests future directions for research on MBPs. 


\section{References}

1. Tittlemier, S. A.; Simon, M.; Jarman, W. M.; Elliott, J. E.; Norstrom, R. J., Identification of a novel $\mathrm{C}_{10} \mathrm{H}_{6} \mathrm{~N}_{2} \mathrm{Br}_{4} \mathrm{Cl}_{2}$ heterocyclic compound in seabird eggs. A bioaccumulating marine natural product? Environmental Science E Technology 1999, 33 (1), 26-33.

2. Reddy, C. M.; Xu, L.; O'Neil, G. W.; Nelson, R. K.; Eglinton, T. I.; Faulkner, D. J.; Norstrom, R.; Ross, P. S.; Tittlemier, S. A., Radiocarbon evidence for a naturally produced, bioaccumulating halogenated organic compound. Environmental Science E Technology 2004, 38 (7), 1992-1997.

3. Vetter, W.; Alder, L.; Palavinskas, R., Mass spectrometric characterization of Q1, a $\mathrm{C}_{9} \mathrm{H}_{3} \mathrm{Cl}_{7} \mathrm{~N}_{2}$ contaminant in environmental samples. Rapid Communications in Mass Spectrometry 1999, 13 (21), 2118-2124.

4. Teuten, E. L.; Pedler, B. E.; Hangsterfer, A. N.; Reddy, C. M., Identification of highly brominated analogues of Q1 in marine mammals. Environmental Pollution 2006, 144, 336-344.

5. Vetter, W., Marine halogenated natural products of environmental relevance. Reviews of Environmental Contamination and Toxicology 2006, 188, 1-57.

6. Wu, J.; Vetter, W.; Gribble, G. W.; Schneekloth, J. S.; Blank, D. H.; Gorls, H., Structure and synthesis of the natural heptachloro-1 '-methyl-1,2 '-bipyrrole (Q1). Angewandte Chemie-International Edition 2002, 41 (10), 1740-1743.

7. Vetter, W.; Weichbrodt, M.; Scholz, E.; Luckas, B.; Oelschlager, H., Levels of organochlorines (DDT, PCBs, toxaphene, chlordane, dieldrin, and HCHs) in blubber of South African fur seals (Arctocephalus pusillus pusillus) from Cape Cross/Namibia. Marine Pollution Bulletin 1999, 38 (9), 830-836.

8. Weichbrodt, M.; Vetter, W.; Scholz, E.; Luckas, B.; Reinhardt, K., Determination of organochlorine levels in Antarctic skua and penguin eggs by application of combined focused open-vessel microwave-assisted extraction, gelpermeation chromatography, adsorption chromatography, and GC/ECD. International Journal of Environmental Analytical Chemistry 1999, 73 (4), 309-328.

9. Vetter, W.; Alder, L.; Kallenborn, R.; Schlabach, M., Determination of Q1, an unknown organochlorine contaminant, in human milk, Antarctic air, and further environmental samples. Environmental Pollution 2000, 110 (3), 401-409.

10. Vetter, W.; Scholz, E.; Gaus, C.; Muller, J. F.; Haynes, D., Anthropogenic and natural organohalogen compounds in blubber of dolphins and dugongs (Dugong dugong) from northeastern Australia. Archives of Environmental Contamination and Toxicology 2001, 41 (2), 221-231.

11. Teuten, E. L.; Saint-Louis, R.; Pedler, B. E.; Xu, L.; Pelletier, E.; Reddy, C. M., Expanding the range of brominated Q1 analogues. Marine Pollution Bulletin 2006, 52, 578-582. 
12. Vetter, W.; Gaul, S.; Olbrich, D.; Gaus, C., Monobromo and higher brominated congeners of the marine halogenated natural product 2,3,3',4,4',5,5'heptachloro-1'-methyl-1,2'-bipyrrole (Q1). Chemosphere 2007, 66, 2011-2018.

13. Program, U. N. E., Stockholm Convention on Persistent Organic Pollutants. Program, U. N. E., Ed. Stockholm, Sweden, 2001; p 43.

14. Andersen, R. J.; Wolfe, M. S.; Faulkner, D. J., Autotoxic antibiotic production by a marine Chromobacterium. Marine Biology 1974, 27 (4), 281-285.

15. Gauthier, G.; Gauthier, M.; Christen, R., Phylogenetic analysis of the genera Alteromonas, Shewanella, and Moritella using genes-coding for smallsubunit ribosomal-RNA sequences and division of the genus Alteromonas into 2 genera, Alteromonas (emended) and Pseudoalteromonas Gen-Nov, and proposal of 12 new species combinations. International Journal of Systematic Bacteriology 1995, 45 (4), 755-761.

16. Teuten, E. L.; Reddy, C. M., Halogenated organic compounds in archived whale oil: A pre-industrial record. Environmental Pollution 2007, 145 (3), 668-671.

17. Montie, E. W.; Fair, P. A.; Bossart, G. D.; Mitchum, G. B.; Houde, M.; Muir, D. C. G.; Letcher, R. J.; McFee, W. E.; Starczak, V. R.; Stegeman, J. J.; Hahn, M. E., Cytochrome P4501A1 expression, polychlorinated biphenyls and hydroxylated metabolites, and adipocyte size of bottlenose dolphins from the Southeast United States. Aquatic Toxicology 2008, 86 (3), 397-412.

18. Schwarzenbach, R. P.; Gschwend, P. M.; Imboden, D. M., Environmental Organic Chemistry. Second ed.; John Wiley \& Sons, Inc.: Hoboken, New Jersey, 2003; p 1313.

19. Pangallo, K.; Nelson, R. K.; Teuten, E. L.; Pedler, B. E.; Reddy, C. M., Expanding the range of halogenated 1'-methyl-1,2'-bipyrroles (MBPs) using GC/ECNI-MS and GC $\times$ GC/TOF-MS. Chemosphere 2008, 71, 1557-1565.

20. Rasmussen, J. B.; Rowan, D. J.; Lean, D. R. S.; Carey, J. H., Food chain structure in Ontario lakes determines PCB levels in Lake Trout (Salvelinus namaycush) and other pelagic fish. Canadian Journal of Fisheries and Aquatic Sciences 1990, 47, 2030-2038.

21. Thomann, R. V.; Connolly, J. P.; Parkerton, T. F., An equilibrium model of organic chemical accumulation in aquatic food webs with sediment interaction. Environmental Toxicology and Chemistry 1992, 11, 615-629.

22. Gobas, F. A. P. C.; Wilcockson, J. B.; Russell, R. W.; Haffner, G. D., Mechanism of biomagnification in fish under laboratory and field conditions. Environ. Sci. Technol. 1999, 33 (1), 133-141.

23. Kaufman, T. S.; Rúveda, E. A., The quest for quinine: those who won the battles and those who won the war. Angewandte Chemie International Edition 2005, 44 (6), 854-885.

24. Quinn, R. J.; Carroll, A. R.; Pham, N. B.; Baron, P.; Palframan, M. E.; Suraweera, L.; Pierens, G. K.; Muresan, S., Developing a drug-like natural product library. Journal of Natural Products 2008, 71 (3), 464-468. 
25. Williams, P. G., Panning for chemical gold: marine bacteria as a source of new therapeutics. Trends in Biotechnology 2009, 27 (1), 45-52.

26. Van Lanen, S. G.; Shen, B., Microbial genomics for the improvement of natural product discovery. Current Opinion in Microbiology 2006, 9 (3), 252-260.

27. Garson, M. J., Ecological perspectives on marine natural product biosynthesis. In Marine Chemical Ecology, McClintock, J. B.; Baker, B. J., Eds. CRC Press LLC: Boca Raton, FL, 2001; pp 71-114.

28. Ehrenreich, I. M.; Waterbury, J. B.; Webb, E. A., Distribution and diversity of natural product genes in marine and freshwater cyanobacterial cultures and genomes. Applied and Environmental Microbiology 2005, 71 (11), 7401-7413.

29. Gauthier, M. J.; Flatau, G. N., Antibacterial activity of marine violetpigmented Alteromonas with special reference to production of brominated compounds. Canadian Journal of Microbiology 1976, 22 (11), 1612-1619.

30. Ori, K.; Mimaki, Y.; Mito, K.; Sashida, Y.; Nikaido, T.; Ohmoto, T.; Masuko, A., Jatropham derivatives and steroidal saponins from the bulbs of Lilium hansonii. Phytochemistry 1992, 31 (8), 2767-75.

31. Haladova, M.; Eisenreichova, E.; Buckova, A.; Tomko, J.; Uhrin, D.; Ubik, K., Dimeric pyrroline alkaloids from Lilium candidum. Collection of Czechoslovak Chemical Communications 1991, 56 (2), 436-438.

32. Somei, M.; Tanimoto, A.; Orita, H.; Yamada, F.; Ohta, T., Syntheses of wasabi phytoalexin (methyl 1-methoxyindole-3-carboxylate) and its 5-iodo derivative, and their nucleophilic substitution reactions. Heterocycles 2001, 54 (1), 425-432.

33. Mlodzianowska, A.; Latos-Grazynski, L.; Szterenberg, L.; Stepien, M., Single-boron complexes of $\mathrm{N}$-confused and $\mathrm{N}$-fused porphyrins. Inorg. Chem. (Washington, DC, U. S.) 2007, 46 (17), 6950-6957.

34. Xu, X.; Xing, Y.; Shang, Z.; Wang, G.; Cai, Z.; Pan, Y.; Zhao, X., Systematic investigation of the molecular behaviors of heterofullerenes C48X2 $(X=B, N)$. Chem. Phys. 2003, 287 (3), 317-333.

35. Minguez, J. M.; Vaquero, J. J.; Alvarez-Builla, J.; Castano, O.; Andres, J. L., Pyrrolodiazines. 5. Synthesis, structure, and chemistry of pyrrolo[1,2c]pyrimidine. Dipolar cycloaddition of pyrrolo[1,2-c]pyrimidinium ylides. Journal of Organic Chemistry 1999, 64 (21), 7788-7801.

36. Ghorab, M. M.; Noaman, E.; Ismail, M. M. F.; Heiba, H. I.; Ammar, Y. A.; Sayed, M. Y., Novel antitumor and radioprotective sulfonamides containing pyrrolo[2,3-d]pyrimidines. Arzneim. Forsch. 2006, 56 (6), 405-413.

37. Shevchuk, S. V.; Lynch, V. M.; Sessler, J. L., A new terpyrrolic analogue of dipyrrolylquinoxalines: an efficient optical-based sensor for anions in organic media. Tetrahedron 2004, 60 (49), 11283-11291.

38. Tittlemier, S. A.; Fisk, A. T.; Hobson, K. A.; Norstrom, R. J., Examination of the bioaccumulation of halogenated dimethyl bipyrroles in an Arctic marine food 
web using stable nitrogen isotope analysis. Environmental Pollution 2002, 116 (1), 85-93.

39. Cerdeño, A. M.; Bibb, M. J.; Challis, G. L., Analysis of the prodiginine biosynthesis gene cluster of Streptomyces coelicolor A3(2): new mechanisms for chain initiation and termination in modular multienzymes. Chemistry $\mathcal{E}$ Biology 2001, 8 (8), 817-829.

40. Williamson, N. R.; Simonsen, H. T.; Ahmed, R. A. A.; Goldet, G.; Slater, H.; Woodley, L.; Leeper, F. J.; Salmond, G. P. C., Biosynthesis of the red antibiotic, prodigiosin, in Serratia: identification of a novel 2-methyl-3-n-amylpyrrole (MAP) assembly pathway, definition of the terminal condensing enzyme, and implications for undecylprodigiosin biosynthesis in Streptomyces. Molecular Microbiology 2005, 56 (4), 971-989.

41. Hughes, C. C.; Prieto-Davo, A.; Jensen, P. R.; Fenical, W., The marinopyrroles, antibiotics of an unprecedented structure class from a marine Streptomyces sp. Organic Letters 2008, 10 (4), 629-631.

42. Vetter, W.; Jun, W.; Althoff, G., Non-polar halogenated natural products bioaccumulated in marine samples. I. 2,3,3 ',4,4 ',5,5 '-heptachloro-1 '-methyl-1,2 'bipyrrole (Q1). Chemosphere 2003, 52 (2), 415-422.

43. Mills III, S. A.; Thal, D. I.; Barney, J., A summary of the 209 PCB congener nomenclature. Chemosphere 2007, 68 (9), 1603-1612.

44. Pangallo, K. C.; Reddy, C. M., Distribution patterns suggest biomagnification of halogenated 1'-methyl-1,2'-bipyrroles (MBPs). Environmental Science \& Technology 2009, 43 (1), 122-127.

45. Tittlemier, S. A.; Blank, D. H.; Gribble, G. W.; Norstrom, R. J., Structure elucidation of four possible biogenic organohalogens using isotope exchange mass spectrometry. Chemosphere 2002, 46 (4), 511-517. 


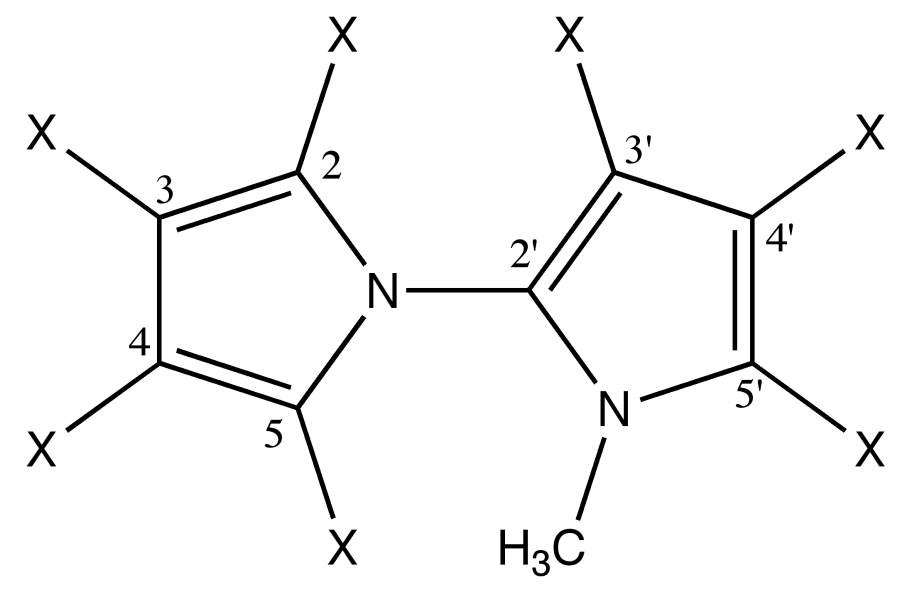

Figure 1. The general structure of MBPs, where $\mathrm{X}$ represents $\mathrm{Br}, \mathrm{Cl}$ or $\mathrm{H}$.
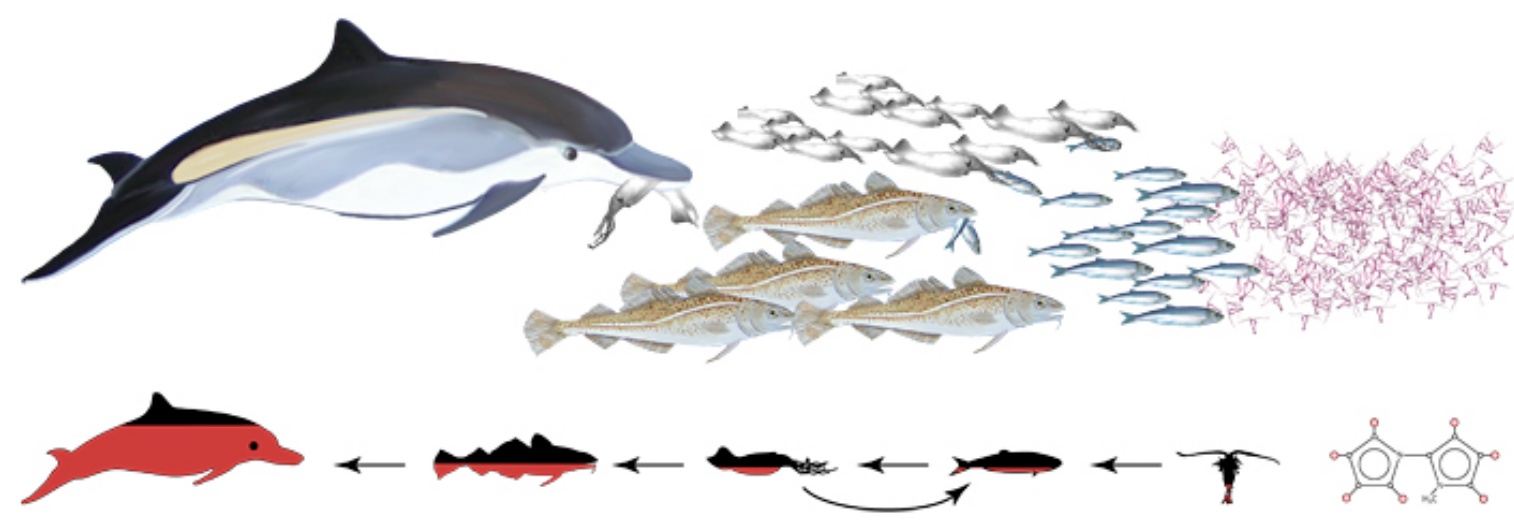

Figure 2. A visual representation of biomagnification of MBPs. The concentration of MBPs in each trophic level is represented in red. (E. Paul Oberlander, WHOI) 


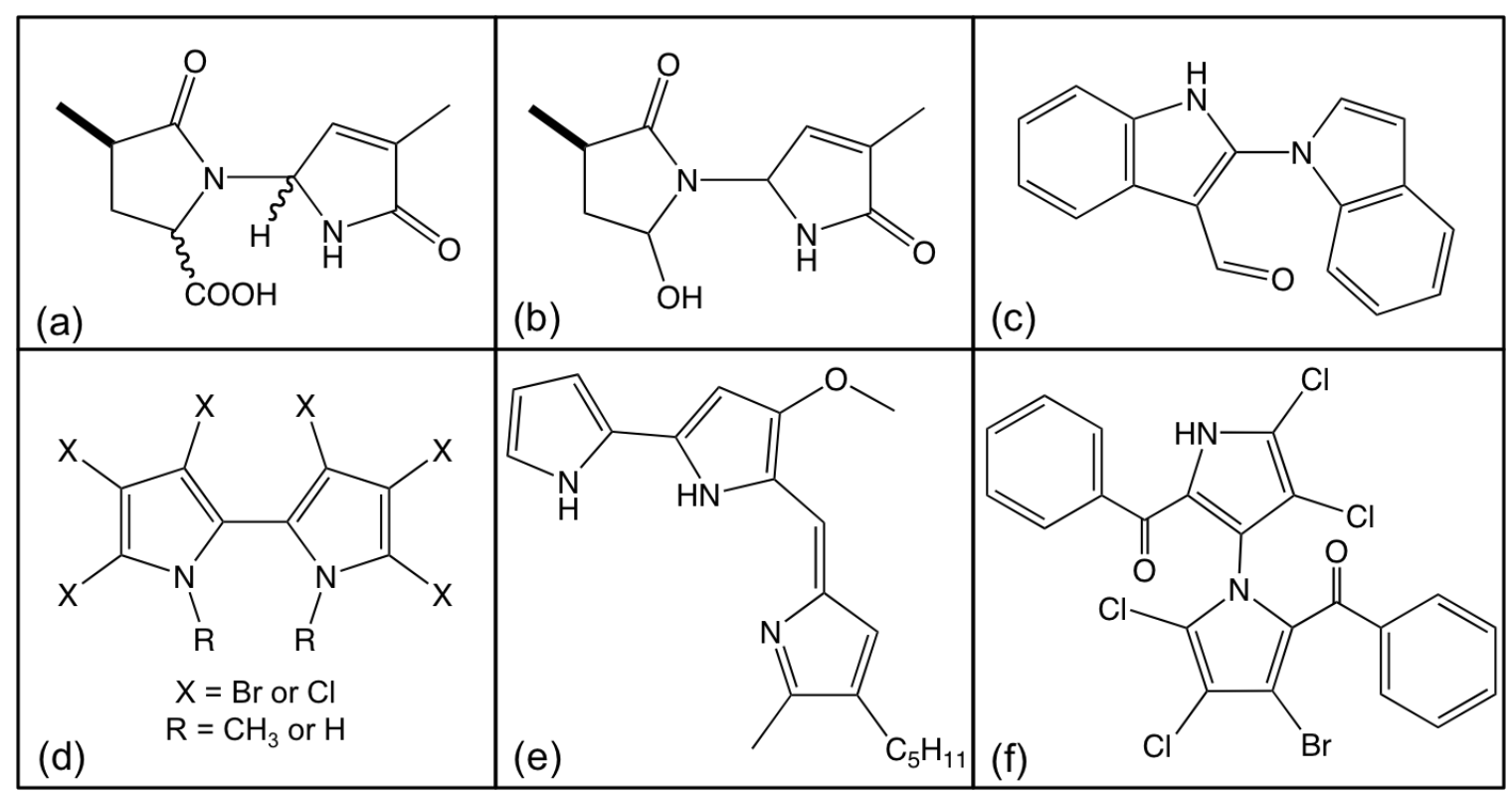

Figure 3. Structures of compounds similar to the MBPs: (a) 1-(2,5-dihydro-4-methyl-5-oxo- $1 \mathrm{H}-$ pyrrol-2-yl)-4-methyl-5-oxo-proline isolated from Lilium hansonii [30]; (b) 1,5-dihydro-5-hydroxy3,4'-dimethyl-[1,2'-Bi-2H-pyrrole]-2,5'(1'H)-dione isolated from Lilium candidum [31]; (c) [1,2'-bi$1 \mathrm{H}$-indole]-3'-carboxaldehyde isolated from Wasabi japonica [32]; (d) $\mathrm{X}=\mathrm{Br}$ or $\mathrm{Cl}, \mathrm{R}=\mathrm{CH}_{3}$ :

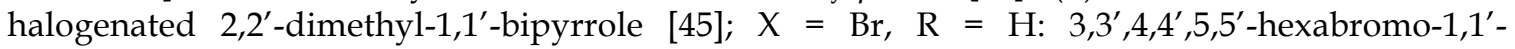
bipyrrole [14]; (e) Prodigiosin [40]; (f) (-)-marinopyrrole B [41]. 


\title{
CHAPTER 2
}

This manuscript appeared in:

Chemosphere (2008), 71, 1557-1565

It is reprinted here with permission of the publisher

\section{Expanding the range of halogenated 1'-methyl-1,2'-bipyrroles (MBPs) using GC/ECNI-MS and GC $\times$ GC/TOF-MS}

\author{
Kristin Pangallo, Robert K. Nelson, Emma L. Teuten, \\ Byron E. Pedler and Christopher M. Reddy
}

\begin{abstract}
Halogenated 1'methyl-1,2'-bipyrroles (MBPs) have been identified worldwide in marine mammals. Here we present the tentative identification of previously undetected MBP congeners in Delpinus delphis blubber using gas chromatography/electron capture negative ion mass spectrometry (GC/ECNIMS) and comprehensive two-dimensional gas chromatography/time-of-flight mass spectrometry (GC×GC/TOF-MS). This is the first report of 26 isomers, only two of which are perhalogenated, one with bromine and one with chlorine. The presence of numerous partially halogenated congeners suggests that they are either biosynthesized concomitantly with their perhalogenated counterparts or that their dehalogenation products can also bioaccumulate. The newly found compounds fit the geographic trend that has been previously noted. That is,
\end{abstract}


samples from the Atlantic Ocean are dominated by the more brominated congeners while those from the Pacific are dominated by the more chlorinated congeners.

\section{Introduction}

Halogenated natural products (HNPs) are a class of secondary metabolites found in environmental matrices [1]. Most of the HNPs currently known have been identified in organisms that produce high quantities of secondary metabolites or that concentrate the bioactive compounds of their prey in their own tissues [2]. However, a select subset of HNPs bioaccumulates in the tissues of higher trophic-level organisms at trace concentrations in similar patterns to persistent organic pollutants (POPs). Several lines of evidence support the classification of these compounds as natural products, for example, radiocarbon dating $[3,4]$ and their presence in pre-industrial, archived whale oil [5]. Classes of HNPs shown to bioaccumulate include the polybrominated phenoxyanisoles [4, 6], polybrominated dibenzo- $p$-dioxins [7], 1,1'-dimethyl-2,2'-bipyrroles (DMBPs) [8] and halogenated 1'-methyl-1,2'-bipyrroles (MBPs) [9-11]. These compounds have been thoroughly reviewed in recent publications by Covaci et al. [12] and Vetter [1]. Like the POPs, bioaccumulating HNPs are available for human uptake [13-15] and at least one such compound is present in human breast milk [16]. 
Organisms responsible for synthesizing most of these compounds have not been identified. Nevertheless, these HNPs are of great interest to environmental chemists and toxicologists since they have similar physical and chemical properties to POPs [17]. In fact, it may be that the degradative mechanisms used in POP remediation originally evolved to degrade HNPs [18]. Hence, they can be used as models to help understand the cycling and environmental fate of POPs $[3,19]$.

Recently published research has shown that bioaccumulative MBPs (Figure 1) include more than 20 congeners of mixed halogenation (containing bromine and chlorine) in addition to the perchlorinated and perbrominated MBPs [10, 11]. Unlike POPs, these compounds appear to have a specific geographic distribution: the more highly-chlorinated derivatives tend to dominate in the South Pacific [11] and the more highly-brominated derivatives tend to dominate in the North Atlantic $[10,20]$. Of the more than 20 MBPs described, most are perhalogenated (i.e., 7 halogens). Four hexahalogenated MBP derivatives of mixed halogenation have been measured in blubber from animals stranded along the North American coast [10], as well as in archived whale oil from the 1920s [5]. Six hexachlorinated MBPs have been detected as photolytic transformation products of $\mathrm{MBP}-\mathrm{Cl}_{7}$ (formerly referred to as Q1) [21], of which 5 were detected in marine biota samples that contain large amounts of $\mathrm{MBP}_{-} \mathrm{Cl}_{7}[21,22]$. 
Here we report the presence of additional MBP congeners in the blubber of a common dolphin (Delphinus delphis) stranded along the east coast of North America. Out of $43 \mathrm{MBP}$ congeners that we report here, 26 have not been detected previously. Possible implications of these compounds are also discussed.

\section{Methods}

\subsection{Samples}

The blubber of a D. delphis fatally stranded in January 2006 in Orleans, MA was obtained from the Cape Cod Stranding Network (identification number: CCSN06-013Dd).

\subsection{Sample extraction and purification}

The blubber was homogenized in a blender and the lipids were obtained by filtration through a glass fiber filter with a nominal pore size of $0.7 \mu \mathrm{m}$. To quantify the MBPs, the cetacean oil was spiked with an internal standard, $3,3^{\prime}, 4,4^{\prime}, 5,5^{\prime}$-hexachloro-1,1'-dimethyl-2,2'-bipyrrole (DMBP-Cl $)_{6}$, which is not found in environmental samples and was synthesized for us by Drs. David Blake and Gordon Gribble of Dartmouth College [23]. The majority of lipids were removed by gel permeation chromatography (GPC) on an OI Analytical GPC Autoprep 2000. The 700-mm glass column was packed with $60 \mathrm{~g}$ of Envirobeads SX-3 in 1:1 hexane:dichloromethane. One gram of lipid was solvated to $10 \mathrm{~mL}$ 
with 1:1 hexane:dichloromethane, and $5 \mathrm{~mL}$ of this solution was injected into the GPC. The column was eluted with 1:1 hexane:dichloromethane at $5 \mathrm{~mL} \mathrm{~min}^{-1}$, and MBPs were collected between 16 and 55 minutes. Column chromatography was then used to isolate MBPs from other organic molecules and remove any residual lipids. Fully-activated, 100-200 mesh, Fisher silica gel (8 g) was packed in hexane and topped with fully-activated, 20-325 mesh, Fisher neutral alumnia (5 g) in a 1-cm i.d. column. The column was eluted with $100 \mathrm{~mL}$ hexane and then $100 \mathrm{~mL}$ of 95:5 hexane:dichloromethane. The MBPs were collected between 50$200 \mathrm{~mL}$ of the total eluent. For reference, polychlorobiphenyls (PCBs) were collected in the first $50 \mathrm{~mL}$.

\subsection{Production of an MBP standard solution}

Due to the lack of synthetic standards, we isolated the four previously identified [10] MBP isomers from $D$. delphis blubber to use as reference and calibration standards. They were purified by preparative capillary gas chromatography (PCGC) [24]. Briefly, after $\sim 70$ injections onto a PCGC using a CP-Sil 5CM column $(60 \mathrm{~m} \times 0.25 \mathrm{~mm}$ i.d. $0.25 \mu \mathrm{m}$ film thickness $)$, the individual MBPs were rinsed from their respective U-tubes with dichloromethane. The solvent was removed and the mass of each collected MBP was determined. The purity of the isolated compounds was verified by gas chromatography coupled to a flame ionization detector ( $>99 \%)$. These compounds were analyzed by gas chromatography high-resolution mass spectrometry (GC-HRMS) $[5,10]$ and 
nuclear magnetic resonance (NMR) spectroscopy [20]. The mass of the collected compounds was determined, and a solution was prepared containing $6 \mathrm{ng} \mu \mathrm{L}^{-1}$ of each MBP and $4 \mathrm{ng} \mu \mathrm{L}^{-1}$ of the synthetic standard, $\mathrm{DMBP}-\mathrm{Cl}_{6}$.

\subsection{GC/ECNI-MS procedures}

Compounds were tentatively identified by gas chromatography mass spectrometry using electron capture negative ion mass spectrometry (GC/ECNIMS) with an Agilent 6890N series GC interfaced to an Agilent 5973 network mass selective detector. Extracts were injected in splitless mode and separated by a J \& W Scientific DB-XLB column $(60 \mathrm{~m} \times 0.25 \mathrm{~mm}$ i.d., $0.25 \mu \mathrm{m}$ film thickness $)$ using He as a carrier gas at a constant flow rate of $1.1 \mathrm{~mL} \mathrm{~min}^{-1}$. The oven program was: initial temperature of $50{ }^{\circ} \mathrm{C}$, followed by a temperature increase at $20^{\circ} \mathrm{C}$ $\min ^{-1}$ to $115{ }^{\circ} \mathrm{C}$ and held for 10 minutes, then a $2{ }^{\circ} \mathrm{C} \mathrm{min}^{-1}$ increase to $320{ }^{\circ} \mathrm{C}$, which was held for 15 minutes. Methane was used as a reagent gas, and the source and transfer lines were maintained at $150{ }^{\circ} \mathrm{C}$. Spectra were acquired in full scan mode, and the data was analyzed for the mass-to-charge $(\mathrm{m} / \mathrm{z})$ ratios representative of the possible MBP congeners. The molecular ions, fragmentation patterns, and relative retention times were used in tandem to detect MBPs congeners. The tentative identification was verified by comparison of the isotope ratios in the molecular ion clusters to theoretical ratios. Due to differences in response factors [21], only the MBPs present in the standard solution (described previously) were quantified. We used two methods to report 
the amount of each MBP not quantified. For isomers of the MBPs in the standard solution, we used the response factors of the quantified MBPs to estimate the concentrations of their isomers in the blubber extract. Response factors have been shown to vary within an order of magnitude for the hexachlorinated MBPs [21], and thus only one significant figure is reported. For the remaining MBPs, their abundance was reported relative to that of $\mathrm{MBP}-\mathrm{Br}$. As a method blank, vegetable oil was extracted and analyzed for MBPs; none were detected.

\subsection{GC $\times G C / T O F-M S$ procedures}

Each extract was analyzed on a GC×GC/TOF-MS system that employed a dual stage cryogenic modulator (Leco, Saint Joseph, Michigan) installed in an Agilent $6890 \mathrm{~N}$ gas chromatograph configured with a 7683B series split/splitless auto-injector, two capillary gas chromatography columns, and a time of flight mass spectrometeric detection system. Each extract was injected in splitless mode and the purge vent was opened at 0.5 minutes. The inlet temperature was $300{ }^{\circ} \mathrm{C}$. The first-dimension column and the dual stage cryogenic modulator reside in the main oven of the GC. The second-dimension column is housed in a separate oven installed within the main GC oven. The first-dimension column was a nonpolar Restek Rtx-5 Crossbond, $(10 \mathrm{~m} \times 0.18 \mathrm{~mm}$ i.d., $0.2 \mu \mathrm{m}$ film thickness) that was programmed to remain isothermal at $95{ }^{\circ} \mathrm{C}$ for 5 minutes and then ramped from 95 to $250{ }^{\circ} \mathrm{C}$ at $1.25{ }^{\circ} \mathrm{C} \mathrm{min}-1$. Compounds eluting from the first dimension column were cryogenically modulated on deactivated fused silica 
$\left(0.5 \mathrm{~m} \times 0.11 \mathrm{~mm}\right.$ i.d.). The modulator cold-jet gas was dry $\mathrm{N}_{2}$ that was chilled with liquid $\mathrm{N}_{2}$. The thermal modulator hot-jet air was set to be $75{ }^{\circ} \mathrm{C}$ above the temperature of the main GC oven. The hot jet was pulsed for 1.5 seconds every 15 seconds with a 6-second cooling period between stages. Second-dimension separations were performed on a $50 \%$ phenyl polysilphenylene-siloxane column (SGE BPX50, $0.70 \mathrm{~m} \times 0.10 \mathrm{~mm}$ i.d., $0.1 \mu \mathrm{m}$ film thickness) that was programmed to remain isothermal at $120^{\circ} \mathrm{C}$ for 5 minutes and then ramped from 120 to $275{ }^{\circ} \mathrm{C}$ at $1.25{ }^{\circ} \mathrm{C} \mathrm{min}-1$. The carrier gas was $\mathrm{He}$ at a constant flow rate of $1.1 \mathrm{~mL} \mathrm{~min}{ }^{-1}$.

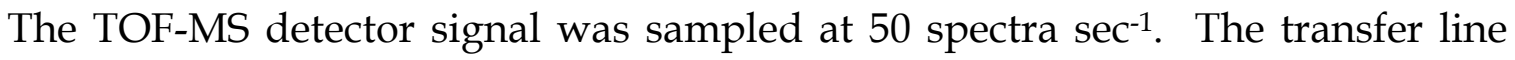
from the second oven to the TOF-MS was deactivated fused silica $(0.5 \mathrm{~m}$ length, $0.18 \mathrm{~mm}$ i.d.), which was held at a constant temperature of $295^{\circ} \mathrm{C}$. The TOF-MS source temperature was $230^{\circ} \mathrm{C}$ and the detector voltage was $1575 \mathrm{~V}$.

\section{Results and Discussion}

3.1 Tentative identification of halogenated 1'-methyl-1,2'-bipyrroles by GC/ECNIMS

A variety of compounds derived from the 1'-methyl-1,2'-bipyrrole backbone (Figure 1) have been measured at trace concentrations in the tissues of marine mammals $[10,11,20,25]$. These compounds have been analyzed by GCHRMS [10], NMR spectroscopy [20, 21], and, for the perchlorinated congener, comparison with a synthetic standard [26]. These congeners span the full range 
of possible halogenation patterns, from perchlorinated [26] to perbrominated [10]. Previous to this effort, ten partially halogenated congeners have been tentatively identified: three isomers of pentabromochloro-1'-methyl-1,2'bipyrrole (MBP- $\mathrm{HBr}_{5} \mathrm{Cl}$ ) and one isomer of hexabromo-1'-methyl-1,2'-bipyrrole (MBP-HBr $)[5,10]$, and six isomers of hexachloro-1'-methyl-1,2'-bipyrrole (MBP$\left.\mathrm{HCl}_{6}\right)[21,22] .{ }^{1}$

We hypothesized that there were additional partially halogenated MBPs present in D. delphis blubber. To guide us in searching for these compounds, we used the MBP standard solution that was isolated by PCGC. The latter was first injected on our GC/ECNI-MS. Briefly, the four MBP congeners in our standard solution elute in the order expected based on their masses; the smaller, partially halogenated compounds elute first and are followed by the more massive perhalogenated MBPs (Figure 2a, Table 1). Also, the MBPs containing chlorine elute prior to MBPs that have the same degree of halogenation, but contain solely bromine. The mass spectrum of every MBP is dominated in the higher mass range $(>350 \mathrm{~m} / \mathrm{z})$ by the sequential loss of either a bromine or chlorine atom. In our standard solution, the mass spectra of the two hexahalogenated isomers are very similar to the perhalogenated MBP standards (example: Figure 3a and 3b);

\footnotetext{
${ }^{1}$ Saint-Louis and Pelletier (2005) published evidence for partially halogenated 1'-methyl$1,2^{\prime}$ 'bipyrroles in marine mammal liver tissue, but identified them as halogenated naphthols. More recently, Teuten et al. (2006c) presented evidence in collaboration with Saint-Louis and Pelletier that these compounds had been misidentified and were tentatively identified MBPs.
} 
they have the same fragmentation patterns, but their molecular ions are lower corresponding to their decreased molecular weight. In this way, predicting the molecular ions and the fragmentation patterns of partially halogenated derivatives is straightforward.

Employing the knowledge gained from analyzing the MBP standard solution, we found $43 \mathrm{MBP}$ isomers within the blubber of this D. delphis, 28 of which were partially halogenated isomers (Figure $2 \mathrm{~b}$, Table 1 ). In addition to using mass spectral evidence, we had the added confidence that all of these compounds eluted in our expected silica gel fraction (and not with less polar compounds like PCBs).

This is the first report of $\mathrm{MBP}-\mathrm{HBr}_{4} \mathrm{Cl}_{2}, \mathrm{MBP}-\mathrm{HBr}_{3} \mathrm{Cl}_{3}, \mathrm{MBP}-\mathrm{H}_{2} \mathrm{Br}_{5}, \mathrm{MBP}-$ $\mathrm{H}_{2} \mathrm{Br}_{4} \mathrm{Cl}, \mathrm{MBP}-\mathrm{H}_{2} \mathrm{Br}_{3} \mathrm{Cl}_{2}, \mathrm{MBP}-\mathrm{H}_{3} \mathrm{Br}_{4}$ and $\mathrm{MBP}-\mathrm{H}_{3} \mathrm{Br} r_{3} \mathrm{Cl}$ isomers (Table 1). It is also the first finding of polychlorinated MBP congeners in samples from the North Atlantic, which may be amongst those previously identified by Vetter et al. (2007). Additionally, this is the first detection of two more isomers of MBP$\mathrm{Br}_{6} \mathrm{Cl}$, previously only one isomer had been detected $[10,11]$. The partially halogenated compounds display the same fragmentation pattern as the MBPs in the standard solution (Figure 3) and have the correct molecular ions for the proposed molecular formulas. The molecular and fragment ions in the mass spectra also display the distinct halogen isotope pattern expected for their molecular formula. For example, Figure 3 a-c shows the isotopic patterns for the 
molecular ions of $\mathrm{MBP}-\mathrm{Br}_{7}, \mathrm{MBP}-\mathrm{HBr}_{6}$ and $\mathrm{MBP}-\mathrm{H}_{2} \mathrm{Br}_{5}$. Finally, these compounds follow the elution order established by previously identified MBPs; the less halogenated and more chlorinated derivatives elute earlier (Figure 2, Table 1).

Using calibration solutions of the $\mathrm{MBP}$ standards $\left(\mathrm{MBP}-\mathrm{Br}{ }_{7}, \mathrm{MBP}-\mathrm{Br}{ }_{6} \mathrm{Cl}\right.$, $\mathrm{MBP}-\mathrm{HBr}_{6}$ and $\left.\mathrm{MBP}-\mathrm{HBr}_{5} \mathrm{Cl}\right)$, the concentrations of these four isomers within the blubber extract were quantified (Table 1). Due to the lack of quantification standards, the other MBPs were not quantified but were estimated (section 2.4). The previously characterized isomer of $\mathrm{MBP}^{-} \mathrm{Br}_{6} \mathrm{Cl}$ is the most abundant congener. However, the sum of the $\mathrm{MBP}-\mathrm{HBr}{ }_{5} \mathrm{Cl}$ isomers exceeds that of the $\mathrm{MBP}-\mathrm{Br}_{6} \mathrm{Cl}$ isomers. The novel MBPs that we detected were all present at low abundances relative to the previously characterized congeners. The MBP concentrations reported here are similar to those observed in other samples of $D$. delphis blubber from Cape Cod [10].

3.2 Further evidence of partially halogenated congeners of the halogenated 1'-methyl1,2'-bipyrroles by GCXGC/TOF-MS

GC $\times \mathrm{GC}$ is an analytical technique that separates complex mixtures based on both their volatility and, most often, their polarity. Hence, GCxGC has often been used to resolve compounds that co-elute in one-dimensional gas chromatography (in which elution is based primarily on a compound's volatility). However, we drew upon a different property of GCxGC for the 
tentative identification of MBP isomers, that structurally similar compounds tend to elute along lines in GCxGC space. This pattern has been observed for many chemical classes, such as long chain ketones [27] and PCBs [28]. Moreover, this empirical observation is corroborated by established chemical concepts: a theoretical analysis shows that a compound family (i.e., a set of compounds that have a common parent structure, but which have varying numbers/patterns of a certain substituent group) exhibits a linear free energy relationship in the GCxGC two-dimensional retention index space [29]. Consequently, a compound family will also elute along a line or a monotonic curve in the GCxGC retention time space. This tendency has been exploited to find previously unidentified compounds of the same class in complex mixtures. For example, Xu et al. (2001) showed that long chain ketones $\left(\mathrm{C}_{35-39}\right)$ eluted along two distinct lines in $\mathrm{GC} \times \mathrm{GC}$ space due solely to the position of the carbonyl group; methyl ketones aligned on one diagonal and ethyl ketones aligned on a parallel line just below the methyl ketones. Additionally, by following the elution lines of the known long chain ketones, previously unknown ketones were identified [27]. Consequently we expected MBPs to elute in a line in GC×GC space. If an unidentified peak falls on the elution line of the set of known MBP standards, this constitutes important corroborative evidence that the unidentified peak is also an MBP.

To expand our search for MBPs, we analyzed the MBP standard solution and the dolphin extract via GCxGC/TOF-MS. Before introducing any GCxGC 
data, it is important to understand how to interpret these chromatograms. Briefly, elution along the $\mathrm{x}$-axis is volatility-based, mimicking retention patterns of one-dimensional gas chromatography. Elution along the y-axis is polaritybased, with the more highly polar components eluting later in the chromatogram. We first analyzed the standard solution in order to determine where the MBPs elute in GCxGC space (Table 1, Figure 4a). Clearly, the four MBPs of the calibration solution exhibit a diagonal trend, with the more halogenated compounds eluting later along both axes.

Using a similar approach to that which we employed with GC/ECNI-MS, we also detected numerous MBPs by GCxGC/TOF-MS in the blubber extract (Figures $3 \mathrm{~d}-\mathrm{f}$ and $4 \mathrm{~b}$, Table 1). MBPs were recognized by the fragmentation patterns and isotope ratios in their mass spectra, and that they aligned in GCxGC space with the MBPs in the standard solution (with the exception of two isomers, described below). A comparison of mass spectra for the sample compounds with ECNI-MS and TOF-MS is shown (Figure 3); as expected, the electron impact of TOF-MS (Figure 3d-f) displays greater fragmentation than the softer chemical ionization of ECNI-MS (Figure 3a-c). The molecular ion clusters and the major fragment ions are otherwise unchanged.

The diagonal elution pattern in GC×GC space that was established by the standard solution extends to the newly found derivatives. Importantly, MBP-Br7 and its brominated congeners align on one diagonal, and $\mathrm{MBP}_{-} \mathrm{Br}_{6} \mathrm{Cl}$ and 
congeners containing one chlorine align along a second, lower, parallel diagonal. This provides strong supporting evidence for the tentative identification of these new compounds as MBPs $[27,29]$. There are two exceptions to the diagonal alignment; one isomer each of $\mathrm{MBP}-\mathrm{HBr} 5 \mathrm{Cl}$ and $\mathrm{MBP}-\mathrm{H}_{2} \mathrm{Br} 4{ }_{4} \mathrm{Cl}$ elute later (higher) in the second dimension than would be expected from the general trend. In GCxGC analysis of PCBs, it has been noted that non-ortho and mono-ortho PCBs elute later in the second dimension than PCBs fully halogenated in the ortho position [28]. Upon applying the observations of PCB elution in GC $\times$ GC space, it is likely that these two outlying MBPs are partially halogenated MBP congeners with at least one hydrogen atom in position $2,3^{\prime}, 5$ or $5^{\prime}$.

The presence of partially halogenated MBPs that do not contain a halogen in the ortho position is important because they may be more toxic then other MBPs containing ortho-halogens. Previous research has shown that the perchlorinated congener binds the aryl hydrocarbon receptor and induces cytochrome P450 activity [30]. This receptor has been shown to bond effectively with planar molecules, such as 2,3,7,8-tetrachlorodibenzo- $p$-dioxin (TCDD) [31]. Thus, understanding the non- and mono-ortho MBP congeners, which can approach a more planar configuration, is critical in evaluating MBP toxicity.

Many of the congeners detected in this sample by GC/ECNI-MS were not detected with GCxGC/TOF-MS (Table 1). These congeners were present at extremely low abundances when detected by GC/ECNI-MS. The selectivity of 
ECNI-MS may allow for a higher signal-to-noise ratio, thus facilitating identification of minute quantities of these compounds. However, GC $\times \mathrm{GC}$ is superior to one-dimensional GC with respect to resolving co-eluting compounds and providing structural evidence. Thus, combining GC×GC-TOF/MS with GCECNI/MS allows for detecting novel congeners and quantifying known compounds for many types of compounds classes.

\section{Conclusions}

By using GC/ECNI-MS in tandem with GCxGC/TOF-MS, we have tentatively identified 26 new partially halogenated MBP congeners. The novel MBP congeners were highly brominated and detected in the blubber of a $D$. delphis fatally stranded on Cape Cod, MA, USA. The concentration of many of the less halogenated isomers is very small, which may explain why these compounds have been previously overlooked. GC×GC/TOF-MS analysis proved very useful in providing support for our tentative identification of the new congeners by GC/ECNI-MS. In two-dimensional space it is clear that newly characterized compounds elute along the same set of lines as previously identified MBPs. Although this identification is still tentative, the presence of such a large number of isomers is notable. Structural confirmation of the tentatively identified compounds will require isolation of the individual 
compounds, full structural elucidation by NMR spectroscopy and/or x-ray crystallography, and, ideally, comparison with a synthetic standard.

Although the task is challenging, full identification of the MBP congeners present in environmental matrices will be important in attempts to understand their toxicity, their biosynthetic pathway, and their cycling in the environment. As of yet we do not know the identity of the producing organism or why we do not detect the many other possible MBP isomers. For example, although there are 24 possible $\mathrm{MBP}-\mathrm{HBr}_{5} \mathrm{Cl}$ isomers, only six have been reported to date. Putting constraints on the factors that determine which MBPs are present in the environment can provide insight into the production, transport, and fate of all halogenated organic compounds in marine ecosystems. For example, the presence of such a large number of diverse isomers may be evidence for dehalogenation as a degradative mechanism for these bioaccumulating natural products. Further work must be accomplished to confirm this theory, but the data presented herein is compelling.

\section{Acknowledgments}

We thank the Cape Cod Stranding Network for the D. delphis sample provided for this research, Sean Sylva and $\mathrm{Li} \mathrm{Xu}$ for their assistance in the laboratory, and J. Samuel Arey for editing this manuscript. We are also grateful to the anonymous reviewers for their valuable insights. This work was 
supported by The Seaver Institute and the National Science Foundation (OCE-

0550486 and the Graduate Research Fellowship Program).

\section{References}

1. Vetter, W., Marine halogenated natural products of environmental relevance. Reviews of Environmental Contamination and Toxicology 2006, 188, 1-57.

2. Faulkner, D. J., Marine natural products. Natural Product Reports 2000, 17 (1), 7-55.

3. Reddy, C. M.; Xu, L.; O'Neil, G. W.; Nelson, R. K.; Eglinton, T. I.; Faulkner, D. J.; Norstrom, R.; Ross, P. S.; Tittlemier, S. A., Radiocarbon evidence for a naturally produced, bioaccumulating halogenated organic compound. Environmental Science \& Technology 2004, 38 (7), 1992-1997.

4. Teuten, E. L.; Xu, L.; Reddy, C. M., Two abundant bioaccumulated halogenated compounds are natural products. Science 2005, 307 (5711), 917-920.

5. Teuten, E. L.; Reddy, C. M., Halogenated organic compounds in archived whale oil: A pre-industrial record. Environmental Pollution 2007, 145 (3), 668-671.

6. Haglund, P. S.; Zook, D., R.; Buser, H.-R.; Hu, J., Identification and quantification of polybrominated diphenyl ethers and methoxy-polybrominated diphenyl ethers in Baltic biota. Environmental Science and Technology 1997, 31 (11), 3281-3287.

7. Haglund, P.; Malmvarn, A.; Bergek, S.; Bignert, A.; Kautsky, L.; Nakano, T.; Wiberg, K.; Asplund, L., Brominated Dibenzo-p-Dioxins: A New Class of Marine Toxins? Environ. Sci. Technol. 2007, 41 (9), 3069-3074.

8. Tittlemier, S. A.; Simon, M.; Jarman, W. M.; Elliott, J. E.; Norstrom, R. J., Identification of a novel $\mathrm{C}_{10} \mathrm{H}_{6} \mathrm{~N}_{2} \mathrm{Br}_{4} \mathrm{Cl}_{2}$ heterocyclic compound in seabird eggs. A bioaccumulating marine natural product? Environmental Science \& Technology 1999, 33 (1), 26-33.

9. Vetter, W.; Jun, W.; Althoff, G., Non-polar halogenated natural products bioaccumulated in marine samples. I. 2,3,3 ',4,4',5,5 '-heptachloro-1 '-methyl-1,2 'bipyrrole (Q1). Chemosphere 2003, 52 (2), 415-422.

10. Teuten, E. L.; Pedler, B. E.; Hangsterfer, A. N.; Reddy, C. M., Identification of highly brominated analogues of Q1 in marine mammals. Environmental Pollution 2006, 144, 336-344.

11. Vetter, W.; Gaul, S.; Olbrich, D.; Gaus, C., Monobromo and higher brominated congeners of the marine halogenated natural product 2,3,3',4,4',5,5'heptachloro-1'-methyl-1,2'-bipyrrole (Q1). Chemosphere 2007, 66, 2011-2018. 
12. Covaci, A.; Voorspoels, S.; Ramos, L.; Neels, H.; Blust, R., Recent developments in the analysis of brominated flame retardants and brominated natural compounds. Journal of Chromatography A 2007, 1153 (1-2), 145-171.

13. Vetter, W.; Stoll, E., Qualitative determination of bioaccumulative halogenated natural products in food and novel food. European Food Research and Technology 2002, 215 (6), 523-528.

14. Tittlemier, S. A., Dietary exposure to a group of naturally produced organohalogens (halogenated dimethyl bipyrroles) via consumption of fish and seafood. Journal of Agricultural and Food Chemistry 2004, 52 (7), 2010-2015.

15. Covaci, A.; Voorspoels, S.; Vetter, W.; Gelbin, A.; Jorens, P. G.; Blust, R.; Neels, H., Anthropogenic and Naturally Occurring Organobrominated Compounds in Fish Oil Dietary Supplements. Environ. Sci. Technol. 2007, 41 (15), 5237-5244.

16. Vetter, W.; Alder, L.; Kallenborn, R.; Schlabach, M., Determination of Q1, an unknown organochlorine contaminant, in human milk, Antarctic air, and further environmental samples. Environmental Pollution 2000, 110 (3), 401-409.

17. Tittlemier, S. A.; Braekevelt, E.; Halldorson, T.; Reddy, C. M.; Norstrom, R. J., Vapour pressures, aqueous solubilities, Henry's Law constants, and octanol/water partition coefficients of a series of mixed halogenated dimethyl bipyrroles. Chemosphere 2004, 57 (10), 1373-1381.

18. Vetter, W.; Gribble, G. W., Anthropogenic persistent organic pollutants lessons to learn from halogenated natural products. Environmental Toxicology and Chemistry 2007, 26 (11), 2249-2252.

19. Stapleton, H. M.; Dodder, N. G.; Kucklick, J. R.; Reddy, C. M.; Schantz, M. M.; Becker, P. R.; Gulland, F.; Porter, B. J.; Wise, S. A., Determination of HBCD, PBDEs and MeO-BDEs in California sea lions (Zalophus californianus) stranded between 1993 and 2003. Marine Pollution Bulletin 2006, 52 (5), 522-531.

20. Teuten, E. L.; Saint-Louis, R.; Pedler, B. E.; Xu, L.; Pelletier, E.; Reddy, C. M., Expanding the range of brominated Q1 analogues. Marine Pollution Bulletin 2006, 52, 578-582.

21. Gaul, S.; Vetter, W., Photolytic dehalogenation of the marine halogenated natural product Q1. Chemosphere 2007, In Press, Corrected Proof.

22. Hackenberg, R.; Looser, R.; Froescheis, O.; Beck, H.; Neissner, R.; Jarman, W. M.; Ballschmiter, K. In Does the definition of POPs have to be expanded? Global occurance of natural POPs?, ACS National Meeting, Division of Environmental Chemistry, San Diego, CA, Trehy, M. L., Ed. San Diego, CA, 2001; pp 128-135.

23. Gribble, G. W.; Blank, D. H.; Jasinski, J. P., Synthesis and identification of two halogenated bipyrroles present in seabird eggs. Chemical Communications 1999, (21), 2195-2196.

24. Teuten, E. L.; Johnson, C. G.; Mandalakis, M.; Asplund, L.; Gustafsson, O.; Unger, M.; Marsh, G.; Reddy, C. M., Spectral characterization of two 
bioaccumulated methoxylated polybrominated diphenyl ethers. Chemosphere 2006, 62 (2), 197-203.

25. Vetter, W.; Alder, L.; Palavinskas, R., Mass spectrometric characterization of Q1, a $\mathrm{C}_{9} \mathrm{H}_{3} \mathrm{Cl}_{7} \mathrm{~N}_{2}$ contaminant in environmental samples. Rapid Communications in Mass Spectrometry 1999, 13 (21), 2118-2124.

26. Wu, J.; Vetter, W.; Gribble, G. W.; Schneekloth, J. S.; Blank, D. H.; Gorls, H., Structure and synthesis of the natural heptachloro-1 '-methyl-1,2 '-bipyrrole (Q1). Angewandte Chemie-International Edition 2002, 41 (10), 1740-1743.

27. Xu, L.; Reddy, C. M.; Farrington, J. W.; Frysinger, G. S.; Gaines, R. B.; Johnson, C. G.; Nelson, R. K.; Eglinton, T. I., Identification of a novel alkenone in Black Sea sediments. Organic Geochemistry 2001, 32 (5), 633-645.

28. Korytár, P.; Leonards, P. E. G.; de Boer, J.; Brinkman, U. A. T., Highresolution separation of polychlorinated biphenyls by comprehensive twodimensional gas chromatography. Journal of Chromatography A 2002, 958 (1-2), 203-218.

29. Arey, J. S.; Nelson, R. K.; Reddy, C. M., Disentangling Oil Weathering Using GC\&\#215;GC. 1. Chromatogram Analysis. Environ. Sci. Technol. 2007.

30. Vetter, W.; Hahn, M. E.; Tomy, G.; Ruppe, S.; Vatter, S.; Chahbane, N.; Lenoir, D.; Schramm, K. W.; Scherer, G., Biological activity and physicochemical parameters of marine halogenated natural products 2,3,3' ',4,4',5,5'-heptachloro-1 '-methyl-1,2 '-bipyrrole and 2,4,6-tribromoanisole. Archives of Environmental Contamination and Toxicology 2004, 48 (1), 1-9.

31. Hahn, M. E., Aryl hydrocarbon receptors: diversity and evolution. Chemico-Biological Interactions 2002, 141 (1-2), 131-160. 
Table 1. MBPs identified in $0.5 \mathrm{~g}$ of lipid from the blubber of a common dolphin (D. delphis). Congeners in bold are previously detected MBPs and were components of the standard solution. The listed ion $( \pm 0.5)$ was used in finding the MBPs and for quantification. Only MBPs that were part of the standard solution (in bold) were quantified, concentrations of their isomers were estimated. For MBPs identified but for which no isomer was quantified the abundance relative to that of $\mathrm{MBP}-\mathrm{Br}_{7}$ is presented: $(+++)$ for a relative abundance of $>10 \%,(++)$ for $<10 \%$ and $(+)$ for $<1 \%$. Congeners not detected by $\mathrm{GC} \times \mathrm{GC} / \mathrm{TOF}-\mathrm{MS}$ are indicated by a (-).

\begin{tabular}{|c|c|c|c|c|c|c|}
\hline Compound & $\begin{array}{c}\left(x-1 \text { '-methyl-1, } 2^{\prime}-\right. \\
\text { bipyrrole) } \\
x=\end{array}$ & $\begin{array}{l}\text { Ion } \\
(\mathrm{m} / \mathrm{z})\end{array}$ & $\begin{array}{c}\text { GC- } \\
\text { ECNI/MS } \\
\text { Retention } \\
\text { Time } \\
\text { (minutes) } \\
\end{array}$ & $\begin{array}{l}\text { Lipid } \\
\text { Conc. } \\
\text { (ng/g } \\
\text { lipid) }\end{array}$ & $\begin{array}{c}\text { GCxGC } \\
\text { Retention } \\
\text { Time } 1 \\
\text { (seconds) }\end{array}$ & $\begin{array}{c}\text { GCxGC } \\
\text { Retention } \\
\text { Time } 2 \\
\text { (seconds) }\end{array}$ \\
\hline $\mathbf{M B P}-\mathrm{Br}_{7}$ & heptabromo- & 697.7 & 97.643 & 2550 & 5795 & 9.99 \\
\hline $\mathrm{MBP}-\mathrm{Br}_{6} \mathrm{Cl}$ & hexabromochloro- & 653.7 & 93.426 & 40 & - & - \\
\hline $\mathrm{MBP}-\mathrm{Br}_{6} \mathrm{Cl}$ & hexabromochloro- & 653.7 & 93.648 & 40 & - & - \\
\hline $\mathrm{MBP}^{-\mathrm{Br}_{6}} \mathrm{Cl}$ & hexabromochloro- & 653.7 & 93.849 & 3480 & 5495 & 9.09 \\
\hline MBP-HBr 6 & hexabromo- & 619.7 & 85.945 & 80 & - & - \\
\hline $\begin{array}{l}\text { MBP-HBr } 6 \\
\text { d }\end{array}$ & hexabromo- & 619.7 & 86.554 & 1260 & 4820 & 8.58 \\
\hline MBP- $-\mathrm{HBr}_{6}$ & hexabromo- & 619.7 & 91.118 & 90 & - & - \\
\hline MBP-HBr 6 & hexabromo- & 619.7 & 94.044 & 200 & - & - \\
\hline $\begin{array}{l}\text { MBP- } \\
\mathrm{HBr}_{5} \mathrm{Cl} \text { c }\end{array}$ & pentabromochloro- & 575.7 & 81.860 & 400 & 4430 & 7.60 \\
\hline $\begin{array}{l}\mathrm{MBP}- \\
\mathrm{HBr} 5 \mathrm{Cl}\end{array}$ & pentabromochloro- & 575.7 & 82.085 & 70 & 4505 & 7.88 \\
\hline $\begin{array}{l}\mathrm{MBP}- \\
\mathrm{HBr}{ }_{5} \mathrm{Cl}\end{array}$ & pentabromochloro- & 575.7 & 82.370 & 30 & - & - \\
\hline $\begin{array}{l}\mathrm{MBP}- \\
\mathrm{HBr}_{5} \mathrm{Cl} \text { a }\end{array}$ & pentabromochloro- & 575.7 & 82.668 & 2360 & 4490 & 7.94 \\
\hline $\begin{array}{l}\mathrm{MBP}- \\
\mathrm{HBr}_{5} \mathrm{Cl} \text { b }\end{array}$ & pentabromochloro- & 575.7 & 87.174 & 500 & 4850 & 9.51 \\
\hline $\begin{array}{l}\mathrm{MBP}- \\
\mathrm{HBr} r_{5} \mathrm{Cl}\end{array}$ & pentabromochloro- & 575.7 & 90.378 & 500 & 5120 & 8.90 \\
\hline $\mathrm{MBP}-\mathrm{Br}_{5} \mathrm{Cl}_{2}$ & pentabromodichloro- & 609.8 & 89.321 & + & - & - \\
\hline $\mathrm{MBP}-\mathrm{Br}_{5} \mathrm{Cl}_{2}$ & pentabromodichloro- & 609.8 & 89.550 & ++ & - & - \\
\hline $\mathrm{MBP}-\mathrm{Br}_{5} \mathrm{Cl}_{2}$ & pentabromodichloro- & 609.8 & 89.776 & ++ & - & - \\
\hline $\mathrm{MBP}-\mathrm{Br}_{4} \mathrm{Cl}_{3}$ & tetrabromotrichloro- & 565.6 & 85.368 & ++ & - & - \\
\hline $\mathrm{MBP}-\mathrm{Br}_{4} \mathrm{Cl}_{3}$ & tetrabromotrichloro- & 565.6 & 85.621 & + & - & - \\
\hline $\mathrm{MBP}-\mathrm{H}_{2} \mathrm{Br}_{5}$ & pentabromo- & 539.8 & 73.870 & +++ & 3695 & 7.12 \\
\hline $\mathrm{MBP}-\mathrm{H}_{2} \mathrm{Br}_{5}$ & pentabromo- & 539.8 & 78.844 & ++ & - & - \\
\hline $\mathrm{MBP}-\mathrm{H}_{2} \mathrm{Br}_{5}$ & pentabromo- & 539.8 & 79.331 & ++ & - & - \\
\hline $\mathrm{MBP}-\mathrm{H}_{2} \mathrm{Br}_{5}$ & pentabromo- & 539.8 & 81.157 & +++ & 4310 & 8.00 \\
\hline $\begin{array}{l}\mathrm{MBP}- \\
\mathrm{HBr}_{4} \mathrm{Cl}_{2}\end{array}$ & tetrabromodichloro- & 531.8 & 77.785 & + & - & - \\
\hline $\begin{array}{l}\text { MBP- } \\
\mathrm{HBr}_{4} \mathrm{Cl}_{2}\end{array}$ & tetrabromodichloro- & 531.8 & 78.100 & +++ & - & - \\
\hline $\begin{array}{l}\mathrm{MBP}- \\
\mathrm{HBr}_{4} \mathrm{Cl}_{2}\end{array}$ & tetrabromodichloro- & 531.8 & 78.394 & ++ & - & - \\
\hline MBP- & tetrabromochloro- & 495.8 & 69.623 & ++ & 3365 & 6.39 \\
\hline
\end{tabular}




\begin{tabular}{|c|c|c|c|c|c|c|}
\hline $\begin{array}{l}\mathrm{HBr}_{4} \mathrm{Cl} \\
\mathrm{MBP}- \\
\mathrm{HBr}_{4} \mathrm{Cl}\end{array}$ & tetrabromochloro- & 495.8 & 69.750 & +++ & - & - \\
\hline $\begin{array}{l}\mathrm{MBP}- \\
\mathrm{HBr}_{4} \mathrm{Cl}\end{array}$ & tetrabromochloro- & 495.8 & 74.705 & ++ & - & - \\
\hline $\begin{array}{l}\mathrm{MBP}- \\
\mathrm{HBr}_{4} \mathrm{Cl}\end{array}$ & tetrabromochloro- & 495.8 & 75.232 & +++ & 3815 & 8.17 \\
\hline $\begin{array}{l}\mathrm{MBP}- \\
\mathrm{HBr}_{4} \mathrm{Cl}\end{array}$ & tetrabromochloro- & 495.8 & 77.174 & +++ & 4010 & 7.17 \\
\hline $\begin{array}{l}\mathrm{MBP}- \\
\mathrm{HBr}_{4} \mathrm{Cl}\end{array}$ & tetrabromochloro- & 495.8 & 78.021 & + & - & - \\
\hline $\begin{array}{l}\text { MBP- } \\
\mathrm{HBr}_{3} \mathrm{Cl}_{3}\end{array}$ & tribromotrichloro- & 485.7 & 73.751 & ++ & - & - \\
\hline $\mathrm{MBP}-\mathrm{Br}_{2} \mathrm{Cl}_{5}$ & dibromopentachloro- & 475.7 & 72.158 & + & - & - \\
\hline $\mathrm{MBP}-\mathrm{Br}_{2} \mathrm{Cl}_{5}$ & dibromopentachloro- & 475.7 & 76.770 & + & - & - \\
\hline $\mathrm{MBP}-\mathrm{H}_{3} \mathrm{Br}_{4}$ & tetrabromo- & 461.7 & 68.025 & + & - & - \\
\hline $\begin{array}{l}\mathrm{MBP}- \\
\mathrm{H}_{2} \mathrm{Br}_{3} \mathrm{Cl}_{2}\end{array}$ & tribromodichloro- & 451.9 & 64.790 & + & - & - \\
\hline $\begin{array}{l}\mathrm{MBP}- \\
\mathrm{H}_{2} \mathrm{Br}_{3} \mathrm{Cl}_{2}\end{array}$ & tribromodichloro- & 451.9 & 65.519 & + & - & - \\
\hline $\mathrm{MBP}-\mathrm{BrCl}_{6}$ & bromohexachloro- & 431.8 & 72.371 & + & - & - \\
\hline $\mathrm{MBP}-\mathrm{BrCl}_{6}$ & bromohexachloro- & 431.8 & 72.959 & + & - & - \\
\hline $\mathrm{MBP}-\mathrm{BrCl}_{6}$ & bromohexachloro- & 431.8 & 73.078 & + & - & - \\
\hline $\begin{array}{l}\text { MBP- } \\
\mathrm{H}_{3} \mathrm{Br}_{3} \mathrm{Cl}\end{array}$ & tribromochloro- & 417.7 & 63.793 & + & - & - \\
\hline $\mathrm{MBP}-\mathrm{Cl}_{7}$ & heptachloro- & 385.9 & 68.420 & +++ & - & - \\
\hline
\end{tabular}

${ }^{a}$ Previously identified as $\mathrm{MBP}-\mathrm{HBr}_{5} \mathrm{Cl}$ Isomer A, Teuten and Reddy (2007).

${ }^{b}$ Previously identified as $\mathrm{MBP}-\mathrm{HBr}_{5} \mathrm{Cl}$ Isomer $\mathrm{B}$, Teuten and Reddy (2007).

${ }^{c}$ Previously identified as $\mathrm{MBP}-\mathrm{HBr}_{5} \mathrm{Cl}$ Isomer $\mathrm{C}$, Teuten and Reddy (2007).

${ }^{\mathrm{d}}$ Previously identified isomer of MBP- $\mathrm{HBr}_{6}$, Teuten and Reddy (2007). 


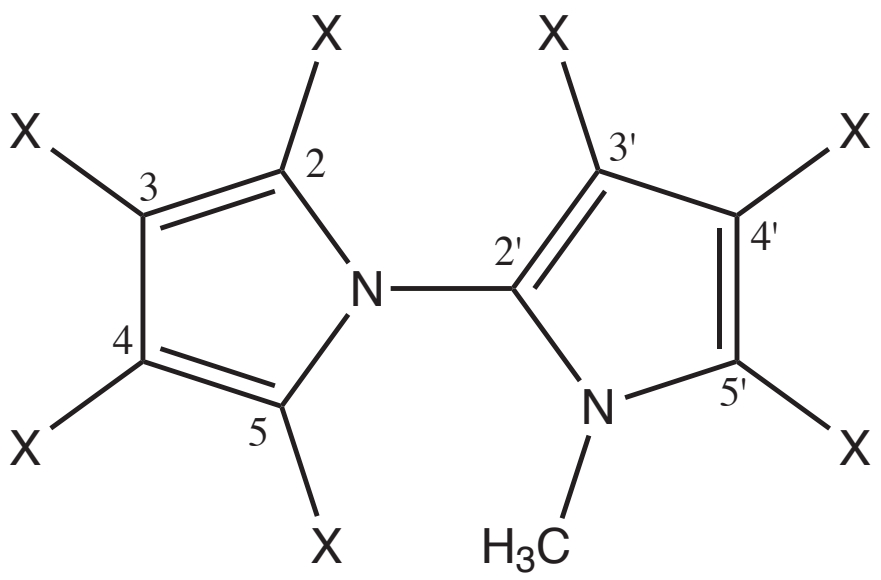

Figure 1. The structure of the halogenated 1'-methyl-1,2'bipyrroles is shown with the carbon atoms numbered. The atoms labeled $\mathrm{X}$ can be $\mathrm{H}, \mathrm{Br}$ or $\mathrm{Cl}$. The nomenclature system used in this paper will indicate the number of $\mathrm{H}$, $\mathrm{Br}$ and $\mathrm{Cl}$ on the ring system by subscripts. For example, the heptachlorinated congener is referred to as $\mathrm{MBP}_{-} \mathrm{Cl}_{7}$, and the congener containing a hydrogen, five bromines and a chlorine on the ring system is called $\mathrm{MBP}-\mathrm{HBr}_{5} \mathrm{Cl}$. 


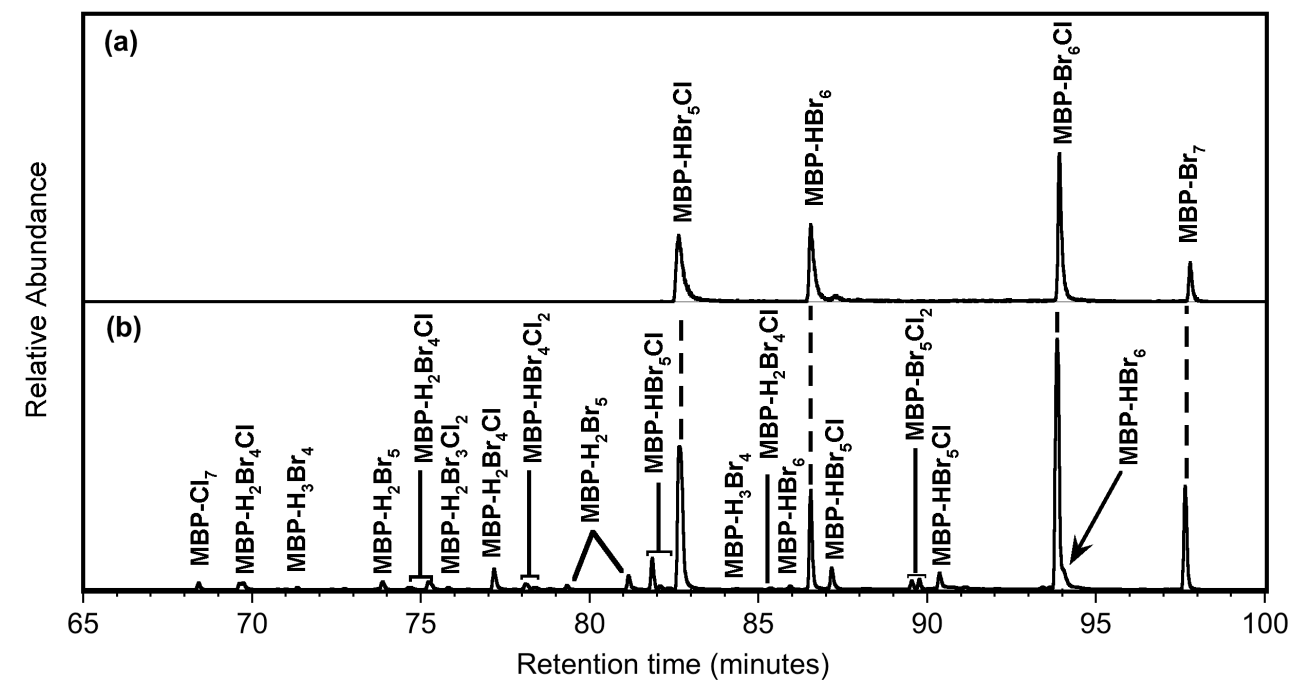

Figure 2. The summed ion chromatograms of the (a) MBP standard solution and the (b) blubber extract from CCSN06-013Dd are presented. Peaks that are visible at this scale are identified. The summed chromatograms result from summation of the following ions $( \pm 0.5)$ : 697.7, 653.7, 619.7 and 575.7 (MBP standard solution); 697.7, 653.7, 619.7, 609.8, 575.7, 565.6, 539.8, 531.8, 495.8, 485.7, 461.7, 451.7, 431.8, 417.7 and 385.9 (blubber extract). 

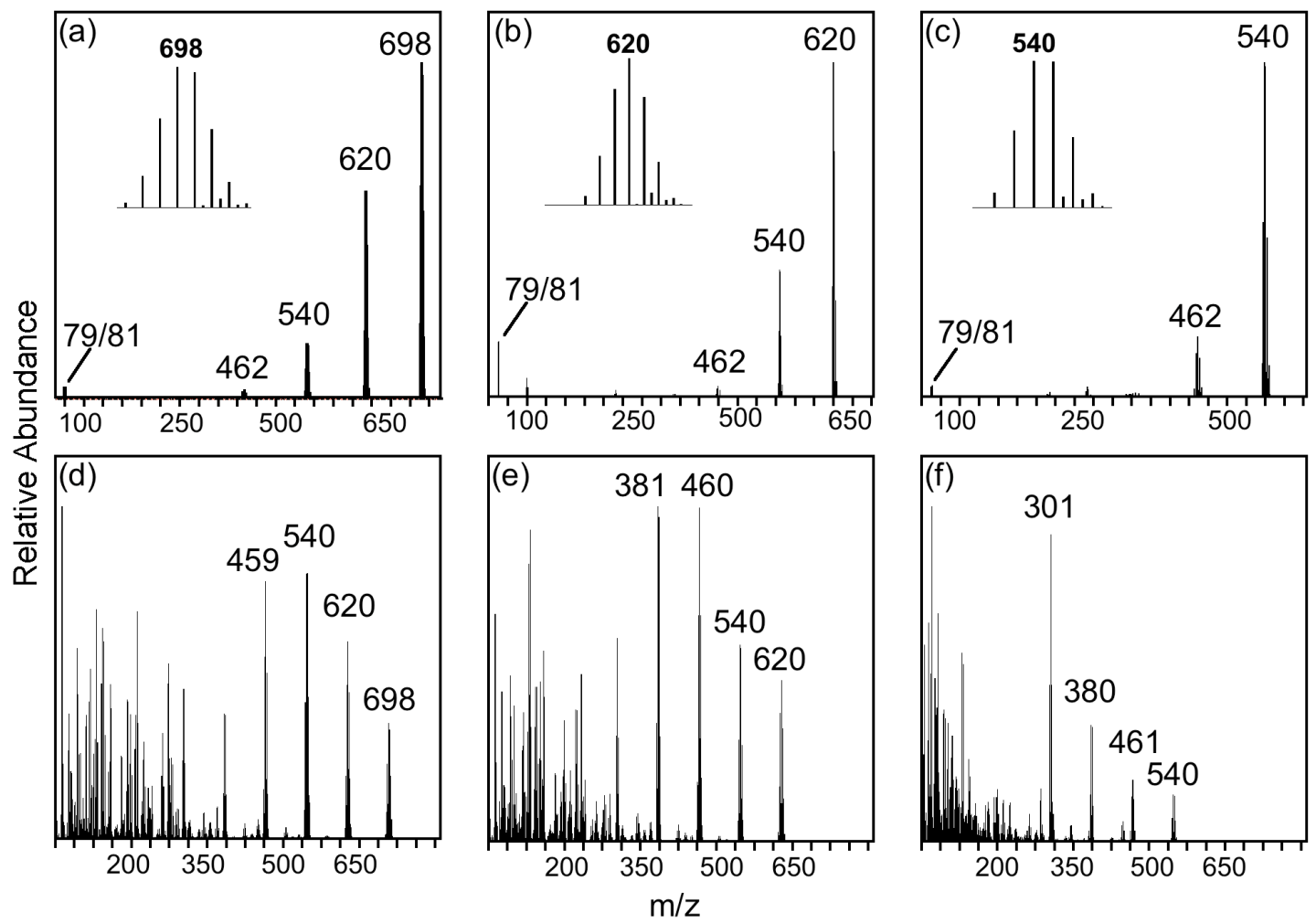

Figure 3. The mass spectra of MBP-Br, $\mathrm{MBP}_{7} \mathrm{HBr}_{6}$ and $\mathrm{MBP}-\mathrm{H}_{2} \mathrm{Br}_{5}$ from both ECNI-MS ( $a, b$ and $c$, respectively) and TOF-MS ( $d$, e and $f$, respectively) are shown. Inset in panels (a), (b) and (c) are enlargements of the molecular ion cluster. The isotope pattern of the molecular ion cluster for MBP-Br7: m/z 698 (100\%), 700 (95.9\%), 696 (63.4\%), 702 (55.5\%), $694(22.5 \%)$, and 704 (18.1\%); for MBP-HBr6: m/z 620 (100\%), 618 (79.1\%), 622 (73.1\%), $616(33.2 \%), 624(28.9 \%)$, and $614(5.8 \%)$; for $\mathrm{MBP}_{-} \mathrm{H}_{2} \mathrm{Br}_{5}: \mathrm{m} / \mathrm{z} 536(10.3 \%), 538(51.5 \%)$, $540(100 \%), 542(98.6 \%), 544(47.7 \%)$, and $546(9.8 \%)$. 


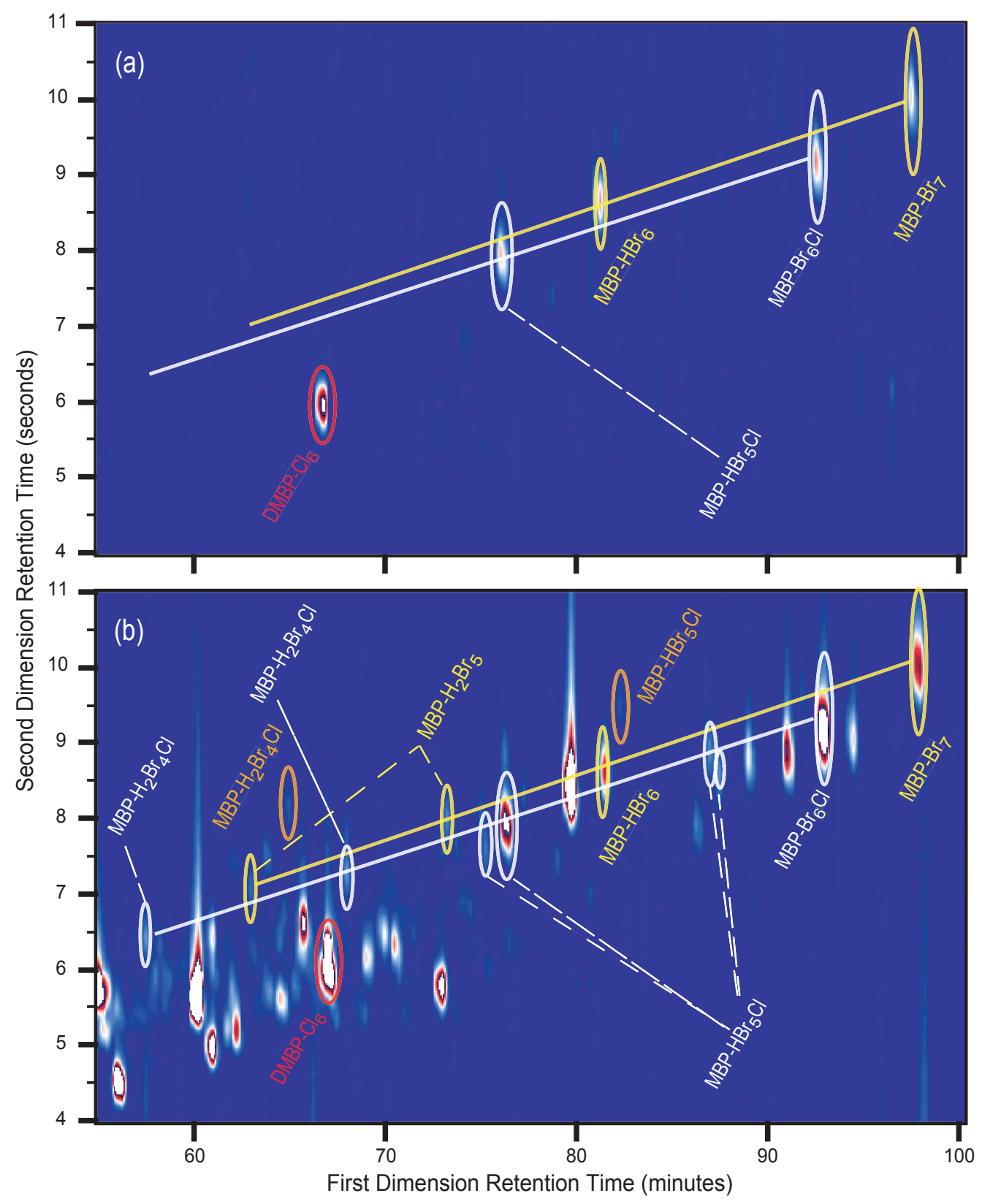

Figure 4. Partial GC $\times$ GC chromatogram of (a) the total ion chromatogram of the MBP standard solution and (b) the MBPs in the D. delphis blubber extract resulting from the summation of the following ions ( \pm 0.5$)$ : 496, 540, 575, 620, 654 and 698. Visible peaks that correspond to MBPs are circled in yellow, white or orange, and the internal standard, $\mathrm{DMBP}_{-} \mathrm{Cl}_{6}$ is circled in red. We have drawn lines representing the MBPs containing only bromine (top, yellow) and MBPs containing one chlorine (bottom, white). The MBPs that elute above these lines, and are proposed to be non- or mono-ortho, are circled in orange. PCBs and chlorinated pesticides elute earlier than the MBPs in the second dimension, and can be seen beneath the MBPs in the lower left corner in the GCxGC chromatogram of the blubber extract in (b). 


\title{
CHAPTER 3
}

This manuscript appeared in:

Environmental Science \& Technology (2009), 43, 122-127

It is reprinted here with permission of the publisher

\section{Distribution patterns suggest biomagnification of halogenated 1'- methyl-1,2'-bipyrroles (MBPs)}

\author{
Kristin C. Pangallo and Christopher M. Reddy
}

\begin{abstract}
The halogenated 1'-methyl-1,2'-bipyrroles (MBPs) are a suite of marine natural products that have been detected in marine mammals worldwide. Although their concentrations are similar to persistent organic pollutants that biomagnify, such as $2,2^{\prime}, 4,4^{\prime}, 5,5^{\prime}$-hexachlorobiphenyl (CB-153), it is not yet clear that these natural products also biomagnify. Here we analyze MBPs and CB-153 isolated from the blubber and liver of marine mammals stranded on the eastern coast of Massachusetts. Four odontocete species (Delphinus delphis, Lagenorhynchus acutus, Phocoena phocoena and Globicephala melas) and two pinniped species (Halichoerus grypus and Phoca groenlandica) were sampled. MBPs were present in all odontocetes, but not detected in pinnipeds; CB-153 was detected in every species. MBP patterns indicative of biomagnification were
\end{abstract}


found, including age-dependent concentration increases and reduced concentrations in adult females. Also explored are the similarities and differences with CB-153, the effects of nutritional state on contaminant distribution, and the maternal transfer of blubber-based organic contaminants.

\section{Introduction}

The halogenated 1'-methyl-1,2'-bipyrroles (MBPs) are a suite of chlorinated and/or brominated congeners (Figure S1) and there is overwhelming evidence that they are natural products (1). The organism or organisms that produces them has yet to be identified, but is likely marine, as these compounds have been found solely in marine samples (2). The first congener found, the perchlorinated congener $\left(\mathrm{MBP}-\mathrm{Cl}_{7}\right)$, was detected in marine mammals in 1999 (3), and its structure was confirmed in 2002 (4). Thus far, 29 primarily chlorinated congeners have been detected in samples from the Pacific (5) and 43 primarily brominated congeners in samples from the Atlantic (6). MBPs have been found in a variety of trophic levels from marine food webs (5-7), as well as in human breast milk (8) and products for human consumption $(9,10)$. Despite their presence in these reservoirs, it is uncertain whether MBPs biomagnify.

Biomagnification is a major concern for many anthropogenic compounds that are classified as persistent organic pollutants (POPs) (11), as well as for some halogenated natural products (HNPs), such as the halogenated 1,1'-dimethyl2,2'-bipyrroles (DMBPs) (12). Man-made halogenated organic compounds 
(HOCs) that biomagnify have been shown to have negative impacts on both human and environmental health $(13,14)$. Some of these health affects can occur at the concentrations detected in environmental samples (15). Despite strict environmental controls that have been placed on the production, use and release of POPs (11), these compounds continue to be measured in an enormous variety of samples from all over the globe and in almost every ecosystem (15). Due to their longevity, the ultimate fate of these compounds has yet to be determined. However, by studying HNPs that share many of the same physical and chemical properties as POPs, we can start to understand and predict their transport and metabolism. Prior to this use, the similarities and differences between individual HNPs and their anthropogenic counterparts must be determined. Ideally, biomagnification should occur in HNPs in order for them to prove useful in elucidating mechanisms that control the environmental concentrations of POPs.

HNPs that have only a marine source, like the MBPs, may also prove useful in tracing the flux of HOCs from marine to terrestrial ecosystems. This pathway is potentially a concern for human consumption of seafood. Indeed, transfers of marine HNPs into human tissues has previously been demonstrated (8). Therefore, marine HNPs may help gauge the seafood-based contribution to human uptake of POPs.

Here we show the presence of MBPs in blubber and liver samples from North Atlantic marine mammals. The MBP patterns are consistent with 
biomagnification, which is not unexpected since MBPs are hydrophobic, as are the POPs, such as polychlorinated biphenyls (PCBs), that biomagnify. For comparison, we also report on the abundance and distribution of the PCB 2,2',4,4',5,5'-hexachlorobiphenyl (CB-153). While the MBPs and CB-153 share some of the same patterns, there are intriguing differences in their distributions and this may be reflective of their different origins.

\section{Experimental}

\subsection{Sampling}

The 25 animals analyzed in this study include both odontocetes (toothed whales) and pinnipeds (earless seals). The odontocete samples consisted of liver and blubber tissue from thirteen common dolphins (Delphinus delphis), three Atlantic white-sided dolphins (Lagenorhynchus acutus), one harbor porpoise (Phocoena phocoena) and one long-finned pilot whale (Globicephala melas). The pinniped samples consisted of liver and blubber tissue from two grey seals (Halichoerus grypus) and five harp seals (Phoca groenlandica). The samples included males and females, adult and youth specimens, and spanned a range of nutritional states from robust to emaciated (Tables 1, S1). All the samples were acquired through the Cape Cod Stranding Network, 23 were fatally stranded on Cape Cod from 2005-2007 and 2 were caught in fishing gear (the harbor porpoise and one grey seal) just south of New England.

\subsection{HOC extraction and purification}


Blubber samples were extracted and HOCs purified following a previously published method (6). Liver samples were kept frozen until ready for use. Upon thawing, liver tissues were chopped into $\sim 1 \mathrm{~cm}^{3}$ pieces and rinsed under cold water to remove excess blood. The samples were freeze-dried, homogenized with mortar and pestle, and extracted using a Dionex ASE200 Accelerated Solvent Extractor (ASE). An ASE cell was packed with $2.5 \mathrm{~g}$ of homogenized, dry tissue and spiked with $25 \mu \mathrm{L}$ of our internal standard, a 50.8 ng $\mu \mathrm{L}^{-1}$ solution of 3,3',4,4',5,5'-hexachloro-1,1'-dimethyl-2,2'-bipyrrole (DMBP$\mathrm{Cl}_{6}$ ). The ASE program extracted each cell three times at $100{ }^{\circ} \mathrm{C}$ and $1000 \mathrm{psi}$ with a dichloromethane/methanol (90:10) solution. The solvent was removed (Zymark TurboVap LV Evaporator) and the mass of the oily residue recorded as the total lipid extract (TLE). Ten-mL of dichloromethane/hexane (50:50) was added to dissolve the TLE and the samples were then centrifuged at $2000 \mathrm{rpm}$ for 10 minutes. The clear solution $(10 \mathrm{~mL})$ was decanted from the insoluble material. The lipids were removed using gel permeation chromatography and the HOCs were purified from the residual lipids with column chromatography as for blubber samples (6).

\subsection{Detection and quantification by GC/ECNI-MS}

Compounds were tentatively identified by gas chromatography mass spectrometry using electron capture negative ion mass spectrometry (GC/ECNIMS) in full scan mode with a previously published method (6). Briefly, on an 
Agilent 6890N series GC interfaced to an Agilent 5973 network mass selective detector, extracts were injected in splitless mode and separated by a J \& W Scientific DB-XLB column ( $60 \mathrm{~m} \times 0.25 \mathrm{~mm}$ i.d., $0.25 \mu \mathrm{m}$ film thickness) using He as a carrier gas at a constant flow rate of $1.1 \mathrm{~mL} \mathrm{~min}^{-1}$. The oven program was: initial temperature of $50^{\circ} \mathrm{C}$, followed by a temperature increase at $20^{\circ} \mathrm{C} \mathrm{min}-1$ to $115{ }^{\circ} \mathrm{C}$ and held for 10 minutes, then a $2{ }^{\circ} \mathrm{C} \mathrm{min}-1$ increase to $320^{\circ} \mathrm{C}$, which was held for 15 minutes. Methane was used as a reagent gas, and the source and transfer lines were maintained at $150^{\circ} \mathrm{C}$.

Each MBP was recognized by its relative retention time and congeners within a homolog series were designated by their halogen content plus a lower case letter (see Table 2 for nomenclature). This nomenclature system is used because the full identification of these congeners has yet to be completed due to the lack of synthetic standards. At this time we have a synthetic quantification standard for only the heptabrominated congener $\left(\mathrm{MBP}-\mathrm{Br}_{7}\right)$. It was provided by Gordon Gribble (Dartmouth College) (16), along with our internal standard that was used to determine recovery percentages, $\mathrm{DMBP}-\mathrm{Cl}_{6}$. Congeners that are unavailable synthetically must be isolated in large quantity from an environmental matrix; we used this technique to isolate $\mathrm{MBP}-\mathrm{Br}_{6} \mathrm{Cl}-\mathrm{b}$, MBP$\mathrm{HBr}_{6}-\mathrm{b}$ and $\mathrm{MBP}-\mathrm{HBr}_{5} \mathrm{Cl}-\mathrm{d}$ for use as quantification standards (6). Recent work has established that the response factors of MBP homologs vary within an order of magnitude (17), which allows us to estimate concentrations (to one significant 
figure) for homologs of the four MBPs for which we have standards. The presence of MBPs not quantified is noted in Tables S4 and S6.

In addition to the MBPs, we also analyzed our samples for the PCB CB153. CB-153 was chosen because it has similar chemical and physical properties to the MBPs; importantly, both have large octanol-water partition coefficients, $10^{6.9}$ for CB-153 and a range of $10^{7.2}$ to $10^{8.3}$ for MBPs (1). Additionally, CB-153 is known to biomagnify and is relatively abundant in environmental samples (18). It has been recommended for monitoring by various international organizations (19). Thus, it has been very well studied in many environmental samples, and has been used previously for comparison with marine halogenated natural products (20). Therefore, it is quite useful for comparison with our relatively newly-discovered MBPs.

The extraction methods and quantification were tested by running blank samples, determining method detection limits for each MBP and CB-153, and by replicate analyses to determine the overall method errors. Details on these protocols can be found in the Supplemental Information.

\section{Results and Discussion}

This study examined six species of marine mammals stranded along the northeast coast of North America for the presence of halogenated MBPs in blubber and liver tissues. To our knowledge, this is the first study to examine MBPs in G. melas and the first to analyze MBPs in liver samples from D. delphis, 
P. phocoena, H. grypus and P. groenlandica. MBPs have been previously detected in liver tissues from L. acutus $(21,22)$. Twenty-seven MBPs were detected, out of which four were quantified and concentrations were estimated for nine (Table S2). From the MBPs measured, $\mathrm{MBP}-\mathrm{Br}_{6} \mathrm{Cl}-\mathrm{b}$ (Table 2) was chosen for direct comparison with CB-153 because it was the most abundant MBP measured in every sample, and it is representative of the MBP and $\Sigma \mathrm{MBP}$ (sum of MBPs for which concentrations were quantified or estimated, Table 2) patterns in our data set. MBPs in odontocete tissues were present at concentrations similar to that of CB-153, suggesting that MBPs may biomagnify throughout the North Atlantic food web. The abundance of MBPs in odontocete blubber relative to CB-153 is orders of magnitude greater than what has been observed for another suite of natural halogenated bipyrroles, the DMBPs (20).

MBPs were present in all odontocetes, though concentrations between individuals varied widely (Tables S3-S6). $\mathrm{MBP}-\mathrm{Br}_{6} \mathrm{Cl}-\mathrm{b}$ was always the most abundant MBP out of those for which concentrations were quantified or estimated; the other MBPs detected (Tables S4 and S6) had very small peaks and, presumably, abundances. MBP individual congener profiles did show a consistent pattern, four congeners dominated the profiles of every sample: MBP$\mathrm{Br}_{7}, \mathrm{MBP}-\mathrm{Br}{ }_{6} \mathrm{Cl}-\mathrm{b}, \mathrm{MBP}-\mathrm{HBr}_{6}-\mathrm{b}$ and $\mathrm{MBP}-\mathrm{HBr}_{5} \mathrm{Cl}-\mathrm{d}$. MBPs were present in similar concentrations $(\Sigma \mathrm{MBP} \sim 2.0 \mu \mathrm{g} / \mathrm{g}$ lipid) in the blubber of all odontocete species investigated (Table 2) and individual variation (Table S3) exceeded the 
variation between species averages (Table 2). There was more variation in the liver concentrations of MBPs (Table 2); the average dolphin $\Sigma \mathrm{MBP}$ concentration $(\sim 2.6 \mu \mathrm{g} / \mathrm{g}$ lipid) far exceeded that of the harbor porpoise and pilot whale $(0.08$ $\mu \mathrm{g} / \mathrm{g}$ lipid and $0.18 \mu \mathrm{g} / \mathrm{g}$ lipid, respectively). The concentration of CB-153 varied between odontocete species, but was present at similar concentrations to MBP$\mathrm{Br}_{6} \mathrm{Cl}-\mathrm{b}$ in blubber $(\sim 1.0 \mu \mathrm{g} / \mathrm{g}$ lipid) and liver $(\sim 2.5 \mu \mathrm{g} / \mathrm{g}$ lipid$)$, with the exception of the liver of the harbor porpoise for which the concentration was below the detection limit (Table 2).

The high concentrations of MBPs in all odontocete samples, and their similarities to the CB-153 concentrations, are consistent with biomagnification, which is the increase of the lipid-normalized concentration of a contaminant with trophic level (23). Previous work has established that biomagnification can occur for hydrophobic compounds with octanol/water partition coefficients exceeding $10^{4}$ (24). Additionally, these compounds must be persistent to avoid any appreciable abiotic or enzymatic degradation. Contaminant concentrations increase in the tissues of each trophic level because the persistent compounds are not significantly metabolized with the rest of the prey and the fugacity of the contaminant increases in the stomach as the prey tissue is digested (25). This increased fugacity during digestion explains how contaminants are transferred against the apparent thermodynamic fugacity gradient.

\subsection{Age dependence of contaminant concentrations}


In addition to high concentrations, the processes that produce biomagnification also result in age-specific patterns within a marine mammal population. (To avoid the complications of interspecies comparison, here we limit our data set to the $13 \mathrm{D}$. delphis samples.) Due to constant exposure, concentrations of biomagnifying compounds increase with age in male mammals. Although the exact age of the individuals was unknown, we are able to categorize them as juvenile or adult, and as male or female. With this information, we can use length as a proxy for age among animals of the same category (juvenile/adult, male/female). Among the D. delphis samples, blubber concentrations for both $\mathrm{MBP}-\mathrm{Br}{ }_{6} \mathrm{Cl}-\mathrm{b}$ and $\mathrm{CB}-153$ increase with length in adult males (Figure 1), implying that these concentrations increase with age.

A different pattern is evident in younger juveniles, their concentrations decrease then increase with increasing length (Figure 1). Due to their small size and milk-based diet, which places them at a higher trophic level, nursing calves tend to have relatively high body burdens of HOCs (26-28). As they grow and switch to a non-milk diet, blubber volume increases and dietary concentrations of HOCs decrease. These changes both result in a characteristic growth dilution pattern for this age group (29). In older individuals, growth dilution is overcome as growth rate slows and blubber concentrations increase (29). These patterns not only match experimental evidence on PCBs, but also show the same features as described by numerical biomagnification models (26-29). 
There is an interesting difference between the MBPs and CB-153 in the age (length) at which the switch from growth dilution to adult accumulation patterns occurs. The concentration of $\mathrm{MBP}-\mathrm{Br}_{6} \mathrm{Cl}-\mathrm{b}$ decreases with increasing length until just past $180 \mathrm{~cm}$, at which point the concentrations in juvenile and adult male samples increase dramatically. However, in CB-153 there is a sharp reduction in concentration after the smallest juvenile, but concentrations then generally increase with length from $160 \mathrm{~cm}$ through the rest of the juvenile and adult male samples. This difference could be due to the limited number of samples, or it may be due to inherent differences between these two types of compounds.

Such differences between natural and anthropogenic compounds may be explained by two different, but not necessarily mutually exclusive, causes. These are their distinctive origins and differences in the ability of degradative enzymes to act upon them. In the first case, we expect that the distribution of natural and anthropogenic compounds in the marine environment to be different. CB-153 is a ubiquitous pollutant, and is present in both terrestrial and marine ecosystems (11); thus, it has multiple inputs to the marine ecosystem. MBPs are natural products that have only been detected in marine samples or samples closely tied to the marine food web $(2,5,6)$. It is likely that they are made by a specific organism or group of organisms, and thus their source is much more limited than that of CB-153. From this source difference, it is likely that MBPs and CB153 enter and move through the marine food web differently. Unlike the 
ubiquitous CB-153, MBPs may have a limited distribution among the species of the North Atlantic food web, though this has yet to be verified. If this were the case it would not be surprising if $\mathrm{MBP}$ concentrations were more variable than those of CB-153 among prey species.

Secondly, the enzymes that degrade both types of compounds have evolved in the presence of HNPs (30). Thus, it would not be surprising if these enzymes could more easily degrade MBPs than the newly introduced CB-153. It is well established that the degree of chlorination and substitution patterns affect enzymatic degradation of PCBs. Dehalogenation studies performed using marine mammal hepatic cells suggest that HOCs can undergo cyctochrome P450 metabolism, and congeners with ortho-meta unsubstituted sites are more available for metabolism (31). CB-153 has both ortho- and meta- chlorine substituents, structural aspects that are consistent with its persistence and tendency to biomagnify. It is likely that these degradation patterns will also apply to MBPs, since the same enzyme systems are likely involved in their dehalogenation and degradation.

In the D. delphis samples, the difference observed between CB-153 and the MBPs may be explained by these differences between natural and anthropogenic compounds. In milk, the dose of lipophilic compounds, such as CB-153 (26-28), is high relative to that of an adult food source, and it is likely that lipophilic MBPs are also relatively enriched in milk. However, both a limited distribution 
of MBPs and an enhanced susceptibility to degradation could lower the dose of MBPs relative to CB-153 for newly weaned dolphins. From this lower dose, we would expect to see a longer transition for MBPs from the growth dilution phase to the age accumulation trend evident in older animals.

\subsection{Maternal transfer of contaminants}

Adult females of our D. delphis data set display significantly reduced MBP blubber concentrations relative to males or to juveniles of similar length (Figure 1). Although females experience similar exposure to males, they have an additional removal process for HOCs. During gestation and lactation, blubberbased contaminants can be mobilized and transferred to offspring $(26-28,32)$. Thus, among adult mammals, females tend to have much lower contaminant body burdens than do males.

Maternal transfer of contaminants can be examined more directly in our data set. An adult female (CCSN06-264Dd) and a male calf (CCSN06-263Dd) D. delphis were found stranded together. Based on observational evidence it is possible that the two are a cow-calf pair. The calf was quite young, the female had three follicular scars - morphology consistent with pregnancy (33), no other dolphins were found in the vicinity, and the HOC concentrations in the female's blubber and liver were indicative of gestational/lactational transfer. Regardless of direct kinship, it is highly probably that these two individuals belonged to the 
same $D$. delphis population and are representative of young juveniles and adult females from that group.

For our presumed cow-calf pair, the concentration of MBPs and CB-153 were much lower in the adult female than in her presumed offspring, though the MBP congener profiles in the blubber of each animal were very similar (Figure 2). As compared to CB-153, the MBPs have a higher juvenile male/adult female ratio. This is surprising since replacement of chlorine substituents with bromine results in higher $\mathrm{K}_{\mathrm{ow}} \mathrm{S}$ in HOCs (34), so highly brominated compounds would be more likely to remain in the blubber than be transferred to milk, and thus, offspring. In fact, past studies have shown that the less lipophilic compounds are mobilized from maternal blubber and transferred to offspring, and the more lipophilic compounds were retained in the maternal blubber $(26,28,35)$. However, there are a few studies that indicate selective mobilization of brominated compounds compared with chlorinated compounds into blood plasma (28) or milk (36). If this is the case, then once mobilized the more brominated MBPs may partition more strongly into the blubber of the offspring than more chlorinated HOCs, such as PCBs. Although this explains our results, it is dependent upon selective MBP mobilization from maternal blubber.

\subsection{Comparison of nutritionally-compromised and healthy individuals}

To further understand how the blubber mobilization affects these compound concentrations, we compared the blubber and liver concentrations of 
MBPs in all odontocete samples. The presence of MBPs in the liver of the odontocete samples was anticipated based on the relatively high lipid content of the liver relative to other body tissues and the presence of detectable levels of MBPs in the blubber of these individuals. Concentrations in liver samples were generally about the same order of magnitude as for the blubber samples (on a lipid-normalized basis). Sorting by body condition (Table 1) results in higher liver MBP concentrations relative to blubber in nutritionally compromised individuals (Table S1). However upon averaging these values, the pattern is overwhelmed by large differences in the absolute concentrations of MBPs and CB-153 among these samples. When this interference is removed (by normalizing the liver concentrations to the blubber concentrations), individuals with body conditions characterized as robust or good have significantly (Wilcoxon-Mann-Whitney rank sum test, $\mathrm{p}=0.001$ ) lower $\mathrm{MBP}-\mathrm{Br}_{6} \mathrm{Cl}-\mathrm{b}$ in their blubber as compared to their liver (Figure 3). Interestingly, CB-153 is statistically the same in both groupings $(p=0.596)$, again showing differences between these two types of HOCs (Figure 3).

This significant difference between liver and blubber samples may be explained by the roles of blubber and liver tissues, and their sensitivity to rapid changes in blood concentrations of contaminants. Blubber is a dynamic reservoir, and in times of energetic need its lipids can be mobilized and its mass reduced (37-39). Since blubber is the major reservoir for lipophilic HOCs, lipid 
mobilization can intensely affect their blubber concentrations. Contaminants can be mobilized into the bloodstream, where they are more susceptible to metabolism, but, potentially, they are also more available to cause toxicity (40). In studies of other animals, nutritional stress has been shown to redistribute HOCs from lipid-storage reservoirs into other tissues $(41,42)$. Liver is more vascularized than blubber and may better reflect changes on a short time-scale.

The distributions of $\mathrm{MBP}-\mathrm{Br}_{6} \mathrm{Cl}-\mathrm{b}$ and $\mathrm{CB}-153$ in nutritionally compromised animals suggests that either $\mathrm{MBP}-\mathrm{Br}_{6} \mathrm{Cl}-\mathrm{b}$ is more efficiently mobilized during times of nutritional stress, or that odontocetes are better able to rid their liver, and/or the bloodstream, of PCBs than of MBPs. The first explanation is consistent with previous evidence presented regarding the maternal transfer of MBPs, other highly brominated organic compounds, and PCBs. The second possibility is not consistent with other evidence presented here, but it cannot be excluded without further study.

\subsection{Interspecies differences}

Finally, there is also a major difference between CB-153 and MBPs in the seal samples. MBP concentrations fell below the detection limit for all pinniped samples (Table 2). However, average concentrations of CB-153 in pinniped blubber $(\sim 0.11 \mu \mathrm{g} / \mathrm{g}$ lipid) were in the same range, though at the low end, as concentrations in odontocete blubber. The average CB-153 concentration in 
pinniped liver samples $(\sim 1.1 \mu \mathrm{g} / \mathrm{g}$ lipid $)$ was higher than pinniped blubber samples, but that average reflects a very large range in values.

These results are consistent with previous studies on other bioaccumulating HNPs. Past work on a set of biomagnifying halogenated bipyrroles has shown that ringed seals (Phoca hispida) had lower blubber concentrations than would be expected based on their trophic position (12). Additionally, harbor seals ( $P$. phocoena) were shown to have lower blubber concentrations of $\mathrm{MBP}_{-} \mathrm{Cl}_{7}$ than do harbor porpoises from the same geographic region, despite sharing comparable concentrations of the POP trans-nonachlor (43). Either differences in diet or in metabolic capabilities could explain the low HNP load of seals as compared with the odontocetes. The presence of CB-153 in the seal samples may indicate that seals share dietary exposure to HOCs but selectively degrade MBPs, or it could indicate different distributions between anthropogenic and natural HOCs in the food web. In either case, there is a distinct difference between the natural MBPs and anthropogenic CB-153 in the seal samples.

The results presented herein suggest that MBPs biomagnify in marine food webs. Our results support previous evidence that there are subtle, but potentially important, differences between anthropogenic and naturally produced compounds that biomagnify in these ecosystems $(12,43)$. In order to prove the biomagnification of MBPs, a full trophic level analysis of these 
compounds must be accomplished. This would also serve to further elucidate the differences found between POPs and HNPs within food webs, particularly clarifying whether prey preference is responsible for the lack of HNPs within seals. In conjunction with the results that we have presented here, future studies will help determine whether MBPs can be high-quality models for understanding the future of POPs.

\section{Acknowledgments}

The authors would like to thank the Cape Cod Stranding Network for the samples provided for this research, and the descriptions of the stranded animals. We are also indebted to Philip Gschwend, John Farrington and Andy Solow for illuminating discussions, and to Matthew Poyton for his dedicated assistance. This work was supported by The Seaver Institute, the J. Seward Johnson Fund, The Virginia Walker Smith Fund, and the National Science Foundation (OCE0550486, the Graduate Research Fellowship Program).

\section{Supplemental Information}

In addition to the data presented here, we have provided a supplemental section that contains the concentrations of each MBP quantified or estimated for each of the 25 mammals, as well as the detection of MBPs for which no concentration can be estimated. Also included are the procedures and calculations performed for quality control, and the general structure of MBPs. 
This information is available free of charge via the Internet at http://pubs.acs.org.

\section{References}

(1) Teuten, E. L.; Reddy, C. M. Halogenated organic compounds in archived whale oil: A pre-industrial record. Environ. Pollut. 2007, 145, 668-671.

(2) Vetter, W. Marine halogenated natural products of environmental relevance. Rev. Environ. Contam. Toxicol. 2006; 188, 1-57.

(3) Vetter, W.; Weichbrodt, M.; Scholz, E.; Luckas, B.; Oelschlager, H. Levels of organochlorines (DDT, PCBs, toxaphene, chlordane, dieldrin, and $\mathrm{HCHs}$ ) in blubber of South African fur seals (Arctocephalus pusillus pusillus) from Cape Cross/Namibia. Mar. Pollut. Bull. 1999, 38, 830-836.

(4) Wu, J.; Vetter, W.; Gribble, G. W.; Schneekloth, J. S.; Blank, D. H.; Gorls, H. Structure and synthesis of the natural heptachloro-1 '-methyl-1,2 '-bipyrrole (Q1). Angew. Chem. Int. Ed. 2002, 41, 1740-1743.

(5) Vetter, W.; Gaul, S.; Olbrich, D.; Gaus, C. Monobromo and higher brominated congeners of the marine halogenated natural product 2,3,3',4,4',5,5'heptachloro-1'-methyl-1,2'-bipyrrole (Q1). Chemosphere 2007, 66, 2011-2018.

(6) Pangallo, K.; Nelson, R. K.; Teuten, E. L.; Pedler, B. E.; Reddy, C. M. Expanding the range of halogenated 1'-methyl-1,2'-bipyrroles (MBPs) using GC/ECNI-MS and GC $\times$ GC/TOF-MS. Chemosphere 2008, 71, 1557-1565.

(7) Teuten, E. L.; Pedler, B. E.; Hangsterfer, A. N.; Reddy, C. M. Identification of highly brominated analogues of Q1 in marine mammals. Environ. Pollut. 2006, $144,336-344$.

(8) Vetter, W.; Alder, L.; Kallenborn, R.; Schlabach, M. Determination of Q1, an unknown organochlorine contaminant, in human milk, Antarctic air, and further environmental samples. Environ. Pollut. 2000, 110, 401-409.

(9) Vetter, W.; Stoll, E. Qualitative determination of bioaccumulative halogenated natural products in food and novel food. Eur. Food Res. Technol. 2002, 215, 523-528.

(10) Haraguchi, K.; Hisamichi, Y.; Endo, T. Bioaccumulation of naturally occurring mixed halogenated dimethylbipyrroles in whale and dolphin products on the Japanese market. Arch. Environ. Contam. Toxicol. 2006, 51, 135-141.

(11) United Nations Environment Program (UNEP). Final Act of the Conference of Plenipotentiaries on the Stockholm Convention on Persistent Organic Pollutants, Stockholm, Sweden, 2001. 
(12) Tittlemier, S. A.; Fisk, A. T.; Hobson, K. A.; Norstrom, R. J. Examination of the bioaccumulation of halogenated dimethyl bipyrroles in an Arctic marine food web using stable nitrogen isotope analysis. Environ. Pollut. 2002, 116, 85-93.

(13) Vasseur, P.; Cossu-Leguille, C. Linking molecular interactions to consequent effects of persistent organic pollutants (POPs) upon populations. Chemosphere 2006, 62, 1033-1042.

(14) Brustad, M.; Sandanger, T. M.; Nieboer, E.; Lund, E. 10th Anniversary Review: when healthy food becomes polluted - implications for public health and dietary advice. J. Environ. Monit. 2008, 10, 422-427.

(15) Ballschmiter, K.; Hackenberg, R.; Jarman, W. M.; Looser, R. Man-made chemicals found in remote areas of the world: The experimental definition for POPS. Environ. Sci. Pollut. Res. Int. 2002, 9, 274-288.

(16) $\mathrm{Fu}, \mathrm{L}$;; Gribble, G. W. A short synthesis of the naturally occuring 2,3,3',4,4',5,5'-heptachloro- ("Q1") and heptabromo-1'-methyl-1,2'-bipyrroles. Org. Prep. \& Proc. Int. 2008, in press.

(17) Gaul, S.; Vetter, W. Photolytic dehalogenation of the marine halogenated natural product Q1. Chemosphere 2008, 70, 1721-1729.

(18) Erickson, M. D. Analytical Chemistry of PCBs; 2 ed.; CRC Press LLC: Boca Raton, 1997.

(19) Duinker, J. C.; Schultz, D. E.; Petrick, G. Selection of chlorinated biphenyl congeners for analysis in environmental samples. Mar. Pollut. Bull. 1988, 19, 1925.

(20) Tittlemier et al. Global distribution of halogenated dimethyl bipyrroles in marine mammal blubber. Arch. Environ. Contam. Toxicol. 2002, 43, 244-255.

(21) Saint-Louis, R.; Pelletier, E. Unsuspected organic pollutants in marine mammals: Halogenated naphthols. Mar. Pollut. Bull. 2005, 50, 889-903.

(22) Teuten, E. L.; Saint-Louis, R.; Pedler, B. E.; Xu, L.; Pelletier, E.; Reddy, C. M. Expanding the range of brominated Q1 analogues. Mar. Pollut. Bull. 2006, 52, 578-582.

(23) Rasmussen, J. B.; Rowan, D. J.; Lean, D. R. S.; Carey, J. H. Food chain structure in Ontario lakes determines PCB levels in Lake Trout (Salvelinus namaycush) and other pelagic fish. Can. J. Fish. Aquat. Sci. 1990, 47, 2030-2038.

(24) Thomann, R. V.; Connolly, J. P.; Parkerton, T. F. An equilibrium model of organic chemical accumulation in aquatic food webs with sediment interaction. Environ. Toxicol. Chem. 1992, 11, 615-629.

(25) Gobas, F. A. P. C.; Wilcockson, J. B.; Russell, R. W.; Haffner, G. D. Mechanism of Biomagnification in Fish under Laboratory and Field Conditions. Environ. Sci. Technol. 1999, 33, 133-141.

(26) Wolkers, H.; Burkow, I. C.; Hammill, M. O.; Lydersen, C.; Witkamp, R. F. Transfer of polychlorinated biphenyls and chlorinated pesticides from mother to pup in relation to cytochrome P450 enzyme activities in harp seals (Phoca 
groenlandica) from the Gulf of St. Lawrence, Canada. Environ. Toxicol. Chem. 2002, 21, 94-101.

(27) Borrell, A.; Aguilar, A. Mother-calf transfer of organochlorine compounds in the common dolphin (Delphinus delphis). Bull. Environ. Contam. Toxicol. 2005, $75,149-156$.

(28) Wolkers, H.; Hammill, M. O.; van Bavel, B. Tissue-specific accumulation and lactational transfer of polychlorinated biphenyls, chlorinated pesticides, and brominated flame retardants in hooded seals (Cistophora cristata) from the Gulf of St. Lawrence: Applications for monitoring. Environ. Pollut. 2006, 142, 476-486.

(29) Hickie, B. E.; Mackay, D.; de Koning, J. Lifetime pharmacokinetic model for hydrophobic contaminants in marine mammals. Environ. Toxicol. Chem. 1999, 18, 2622-2633.

(30) Stegman, J. J.; Hahn, M. E. Biochemistry and molecular biology of monooxygenases: Current directions in forms, functions, and regulation of cytochrome P450 in aquatic species. In Aquatic Toxicology: Molecular, Biochemical and Cellular Perspectives; Malins, D. C., Ostrander, G. K., Eds.; Lewis Publishers, CRC Press: Boca Raton, FL, 1993; pp 87-206.

(31) McKinney, M. A.; De Guise, S.; Martineau, D.; BÈland, P.; Arukwe, A.; Letcher, R. J. Biotransformation of polybrominated diphenyl ethers and polychlorinated biphenyls in beluga whale (Delphinapterus leucas) and rat mammalian model using an in vitro hepatic microsomal assay. Aquat. Toxicol. 2006, 77, 87-97.

(32) Weisbrod, A. V.; Shea, D.; Moore, M. J.; Stegeman, J. J. Species, tissue and gender-related organochlorine bioaccumulation in white-sided dolphins, pilot whales and their common prey in the Northwest Atlantic. Mar. Environ. Res. 2001, 51, 29-50.

(33) Brook, F. M.; Kinoshita, R.; Benirschke, K. Histology of the ovaries of a bottlenose dolphin, Tursiops aduncus, of known reproductive history. Mar. Mamm. Sci. 2002, 18, 540-544.

(34) Puzyn, T.; Suzuki, N.; Haranczyk, M. How do the partitioning properties of polyhalogenated POPs change when chlorine is replaced with bromine? Environ. Sci. Technol. 2008, 42, 5189-5195

(35) Kierkegaard, A.; Asplund, L.; deWit, C. A.; McLachlan, M. S.; Thomas, G. O.; Sweetman, A. J.; Jones, K. C. Fate of higher brominated PBDEs in lactating cows. Environ. Sci. Technol. 2007, 41, 417-423.

(36) Hooper, K.; She, J.; Sharp, M.; Chow, J.; Jewell, N.; Gephart, R.; Holden, A. Depuration of polybrominated diphenyl ethers (PBDEs) and polychlorinated biphenyls (PCBs) in breast milk from California first-time mothers (primiparae). Environ. Health Perspect. 2007, 115, 1271-1275.

(37) Koopman, H. N. Phylogenetic, ecological, and ontogenetic factors influencing the biochemical structure of the blubber of odontocetes. Mar. Biol. 2007, 151, 277-291. 
(38) Hall, A. J.; Gulland, F. M. D.; Ylitalo, G. M.; Greig, D. J.; Lowenstine, L. Changes in blubber contaminant concentrations in California Sea Lions (Zalophus californianus) associated with weight loss and gain during rehabilitation. Environ. Sci. Technol. 2008, 42, 4181-4187.

(39) Montie, E. W.; Garvin, S. R.; Fair, P. A.; Bossart, G. D.; Mitchum, G. B.; McFee, W. E.; Speakman, T.; Starczak, V. R.; Hahn, M. E. Blubber morphology in wild Bottlenose dolphins (Tursiops truncatus) from the southeastern united states: Influence of geographic location, age class, and reproductive state. J. Morphol. 2008, 269, 496-511.

(40) Montie, et al. Cytochrome P4501A1 expression, polychlorinated biphenyls and hydroxylated metabolites, and adipocyte size of bottlenose dolphins from the Southeast United States. Aquat. Toxicol. 2008, 86, 397-412.

(41) Findlay, G. M.; DeFreitas, A. S. W. DDT movement from adipocyte to muscle cell during lipid utilization. Nature 1971, 229, 63-65.

(42) Henriksen, E. O.; Gabrielsen, G. W.; Skaare, J. U. Levels and congener pattern of polychlorinated biphenyls in kittiwakes (Rissa tridactyla), in relation to mobilization of body-lipids associated with reproduction. Environ. Pollut. 1996, 92, 27-37.

(43) Vetter, W.; Jun, W.; Althoff, G. Non-polar halogenated natural products bioaccumulated in marine samples. I. 2,3,3 ',4,4',5,5 '-heptachloro-1 '-methyl-1,2 'bipyrrole (Q1). Chemosphere 2003, 52, 415-422. 
Table 1. Species, gender and maturity distributions for the 25 samples analyzed. Age was determined as the average length at which that species becomes sexually mature. The body condition of the animals was determined during necropsy as robust, good, thin or emaciated. Here we divide the animals into two groupings. A robust classification includes animals stated as in robust and good condition. A compromised classification includes animals in a thin or emaciated condition. Species accompanied by asterisks $\left({ }^{*}\right)$ are pinnipeds (earless seals), the remaining species are odontocetes (toothed whales).

\begin{tabular}{|l|c|c|c|c|c|c|}
\hline & \multicolumn{2}{|c|}{ Gender } & \multicolumn{2}{c|}{ Age } & \multicolumn{2}{c|}{ Body Condition } \\
\hline \multicolumn{1}{|c|}{ Species } & \# male & \# female & \# mature & \# immature & \# robust & \# compromised \\
\hline D. delphis & 9 & 4 & 9 & 4 & 6 & 7 \\
\hline L. acutus & 1 & 2 & 1 & 2 & 2 & 1 \\
\hline H. grypus* & 2 & 0 & 0 & 2 & 0 & 2 \\
\hline P. groenlandica* & 4 & 1 & 1 & 4 & 0 & $5^{*}$ \\
\hline P. phocoena & 1 & 0 & 0 & 1 & 1 & 0 \\
\hline G. melas & 1 & 0 & 0 & 1 & 0 & 1 \\
\hline
\end{tabular}


Table 2. Lipid-normalized concentrations ( $\mathrm{ng} \mathrm{g}^{-1}$ lipid) of individual MBP congeners and CB-153 in the blubber and liver of 6 marine mammal species. Data is grouped by species for the odontocetes; due to similarities the two pinniped species (H. grypus and $P$. groenlandica) were grouped togther. For each compound the mean and a range is given. In categories where $n>1$ the range reflects the variability within the group as the $90 \%$ Confidence Interval. In categories for which $n=1$, the compound-specific standard error is stated. The method measurement error for each compound is lower than 10\% for CB-153 and all MBPs in the blubber (except for MBP- $\mathrm{HBr}_{6}-\mathrm{C}$ and $\mathrm{MBP}-\mathrm{HBr}_{6}-\mathrm{d}$, which were $29 \%$ and $11 \%$, respectively, likely due to their low concentrations). The errors for all MBPs in the liver range from $19 \%-31 \%$, and again are likely high due to the small samples. Compounds for which we have quantification standards are reported to 2 significant figures and are in bold. Concentrations for homologes are estimated to one significant figure.

\begin{tabular}{|c|c|c|c|c|c|c|c|}
\hline Congener & $\begin{array}{l}\text { Rel. } \\
\text { RT }^{*}\end{array}$ & $\begin{array}{c}\text { Detection } \\
\text { Limit }\end{array}$ & $\begin{array}{c}\text { D. delphis } \\
n=13\end{array}$ & $\begin{array}{c}\text { L. acutus } \\
n=3\end{array}$ & $\begin{array}{c}\text { P. phocoena } \\
n=1\end{array}$ & $\begin{array}{c}\text { G. melas } \\
n=1\end{array}$ & $\begin{array}{l}\text { Seals } \\
n=7\end{array}$ \\
\hline \multicolumn{8}{|c|}{ BLUBBER } \\
\hline MBP-Br 7 & 1.754 & 130 & $380 \pm 140$ & $350 \pm 180$ & $470 \pm 20$ & $250 \pm 10$ & $<$ d.1 \\
\hline $\mathrm{MBP}-\mathrm{Br}_{6} \mathrm{Cl}-\mathrm{a}$ & 1.682 & 0.7 & $9 \pm 6$ & $5 \pm 2$ & $7 \pm 0.4$ & $4 \pm 0.2$ & $<$ d.1 \\
\hline MBP-Br 6 Cl-b & 1.685 & 150 & $1000 \pm 300$ & $1100 \pm 500$ & $1100 \pm 100$ & $490 \pm 40$ & $<$ d.1 \\
\hline MBP-HBr 6 -a & 1.543 & 3 & $20 \pm 10$ & $6 \pm 2$ & $9 \pm 1$ & $8 \pm 1$ & $<$ d.1 \\
\hline MBP-HBr ${ }_{6}-\mathrm{b}$ & 1.554 & 59 & $350 \pm 130$ & $250 \pm 100$ & $280 \pm 20$ & $170 \pm 10$ & $<$ d.1 \\
\hline $\mathrm{MBP}-\mathrm{HBr}_{6}-\mathrm{C}$ & 1.637 & 3 & $10 \pm 10$ & $6 \pm 6$ & $20 \pm 5$ & $10 \pm 3$ & $<$ d.1 \\
\hline MBP-HBr ${ }_{6}-\mathrm{d}$ & 1.690 & 2 & $60 \pm 40$ & $30 \pm 10$ & $60 \pm 6$ & $80 \pm 9$ & $<$ d.1 \\
\hline $\mathrm{MBP}-\mathrm{HBr}_{5} \mathrm{Cl}-\mathrm{a}$ & 1.469 & 8 & $80 \pm 30$ & $50 \pm 20$ & $70 \pm 3$ & $40 \pm 2$ & $<$ d.1 \\
\hline MBP-HBr ${ }_{5} \mathrm{Cl}-\mathrm{b}$ & 1.473 & 2 & $100 \pm 200$ & $5 \pm 2$ & $6 \pm 0.4$ & $4 \pm 0.3$ & $<$ d.1 \\
\hline MBP-HBr ${ }_{5} \mathrm{Cl}-\mathrm{c}$ & 1.478 & 1 & $9 \pm 6$ & $2 \pm 1$ & $2 \pm 0.2$ & $2 \pm 0.1$ & $<$ d.1 \\
\hline MBP-HBr 5 Cl-d & 1.483 & 73 & $520 \pm 180$ & $560 \pm 180$ & $650 \pm 40$ & $310 \pm 20$ & $<$ d.1 \\
\hline MBP-HBr ${ }_{5} \mathrm{Cl}-\mathrm{e}$ & 1.565 & 40 & $70 \pm 50$ & $60 \pm 50$ & $100 \pm 40$ & $80 \pm 20$ & $<$ d.1 \\
\hline $\mathrm{MBP}-\mathrm{HBr}_{5} \mathrm{Cl}-\mathrm{f}$ & 1.625 & 10 & $100 \pm 100$ & $30 \pm 10$ & $90 \pm 5$ & $200 \pm 10$ & $<$ d. 1 \\
\hline$\Sigma \mathrm{MBP}$ & & & $3000 \pm 1000$ & $2000 \pm 1000$ & $3000 \pm 200$ & $2000 \pm 100$ & $<$ d.1 \\
\hline CB-153 & 1.380 & 62 & $1000 \pm 400$ & $1400 \pm 500$ & $1200 \pm 100$ & $740 \pm 70$ & $150 \pm 70$ \\
\hline
\end{tabular}

(continued on next page) 
Table 2. (continued)

\begin{tabular}{|c|c|c|c|c|c|c|c|}
\hline \multicolumn{8}{|c|}{ LIVER } \\
\hline MBP-Br $_{7}$ & 1.754 & 100 & $260 \pm 210$ & $570 \pm 610$ & $<$ d.1. & $140 \pm 30$ & $<$ d.l. \\
\hline MBP-Br 6 Cl-b & 1.685 & 1100 & $1500 \pm 1000$ & $1600 \pm 1400$ & $<$ d.1. & $<$ d.1. & $<$ d.1. \\
\hline MBP-HBr $6-b$ & 1.554 & 200 & $250 \pm 190$ & $220 \pm 220$ & $<$ d.1. & $<$ d.l. & $<$ d.1. \\
\hline MBP-HBr ${ }_{5} \mathrm{Cl}-\mathrm{d}$ & 1.483 & 800 & $<$ d.1. & $<$ d.l. & $<$ d.1. & $<$ d.l. & $<$ d.l. \\
\hline MBP-HBr ${ }_{5} \mathrm{Cl}-\mathrm{e}$ & 1.565 & 40 & $50 \pm 50$ & $100 \pm 100$ & $80 \pm 20$ & $40 \pm 10$ & $<$ d.l. \\
\hline$\Sigma \mathrm{MBP}$ & & & $3000 \pm 2000$ & $3000 \pm 3000$ & $80 \pm 20$ & $200 \pm 40$ & $<$ d.l. \\
\hline CB-153 & 1.380 & 53 & $2400 \pm 1600$ & $1500 \pm 500$ & $<$ d.1. & $1400 \pm 300$ & $1100 \pm 1500$ \\
\hline
\end{tabular}

* The relative retention times (Rel. RT) were determined under the conditions described in Experimental section 2.3, and were calculated relative to 2,2',4,6-tetrachlorobiphenyl (CB-50). 


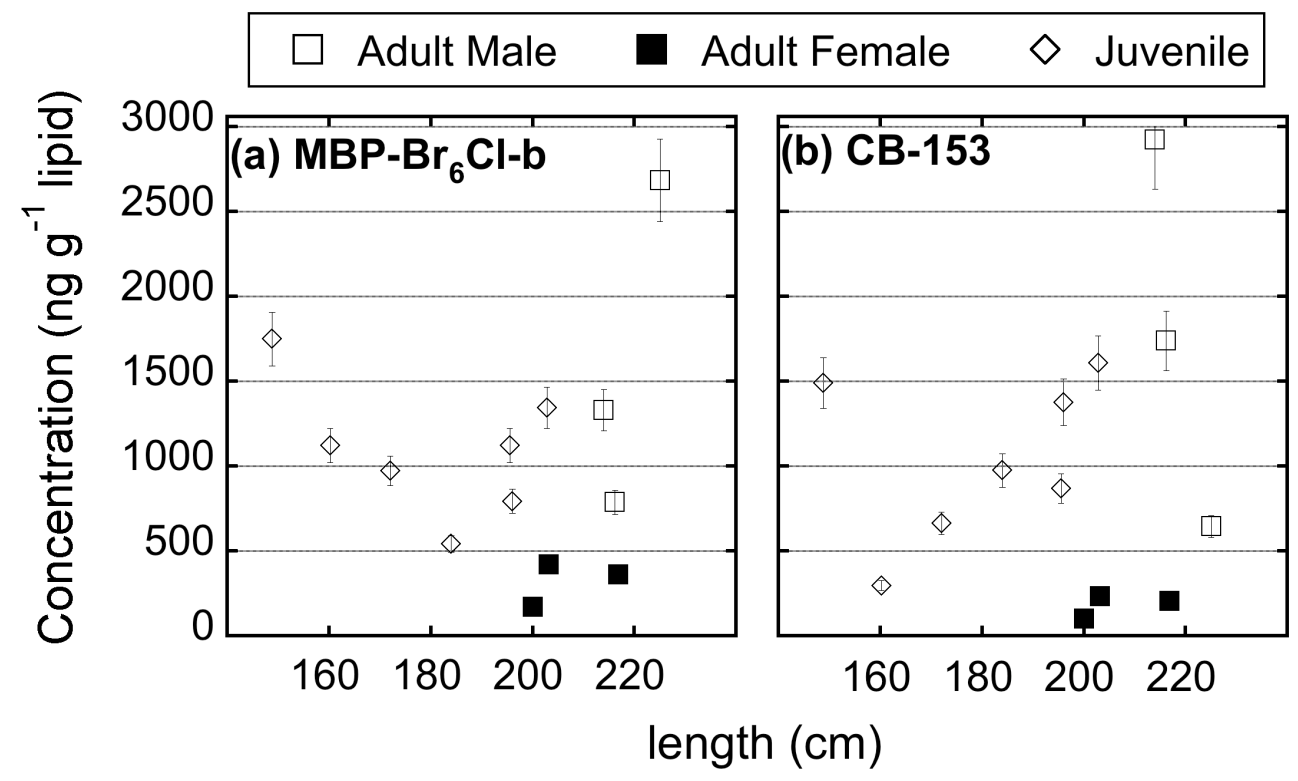

Figure 1. Lipid-normalized concentrations of (a) $\mathrm{MBP}-\mathrm{Br}_{6} \mathrm{Cl}-\mathrm{b}$ and (b) $\mathrm{CB}-153$ in the blubber of 13 common dolphins (D. delphis). Adult females are plotted with solid squares, adult males with open squares, and juveniles of both genders are plotted with open diamonds. Length $(\mathrm{cm})$ is plotted on the x-axis as a proxy for the age of the individuals. Note that there is overlap between adult females and juvenile males on the $x$-axis. This is a function of both sexual dimorphism (the average length of mature females is smaller than that of mature males) and that females attain sexual maturity at a younger age, and therefore shorter length. 


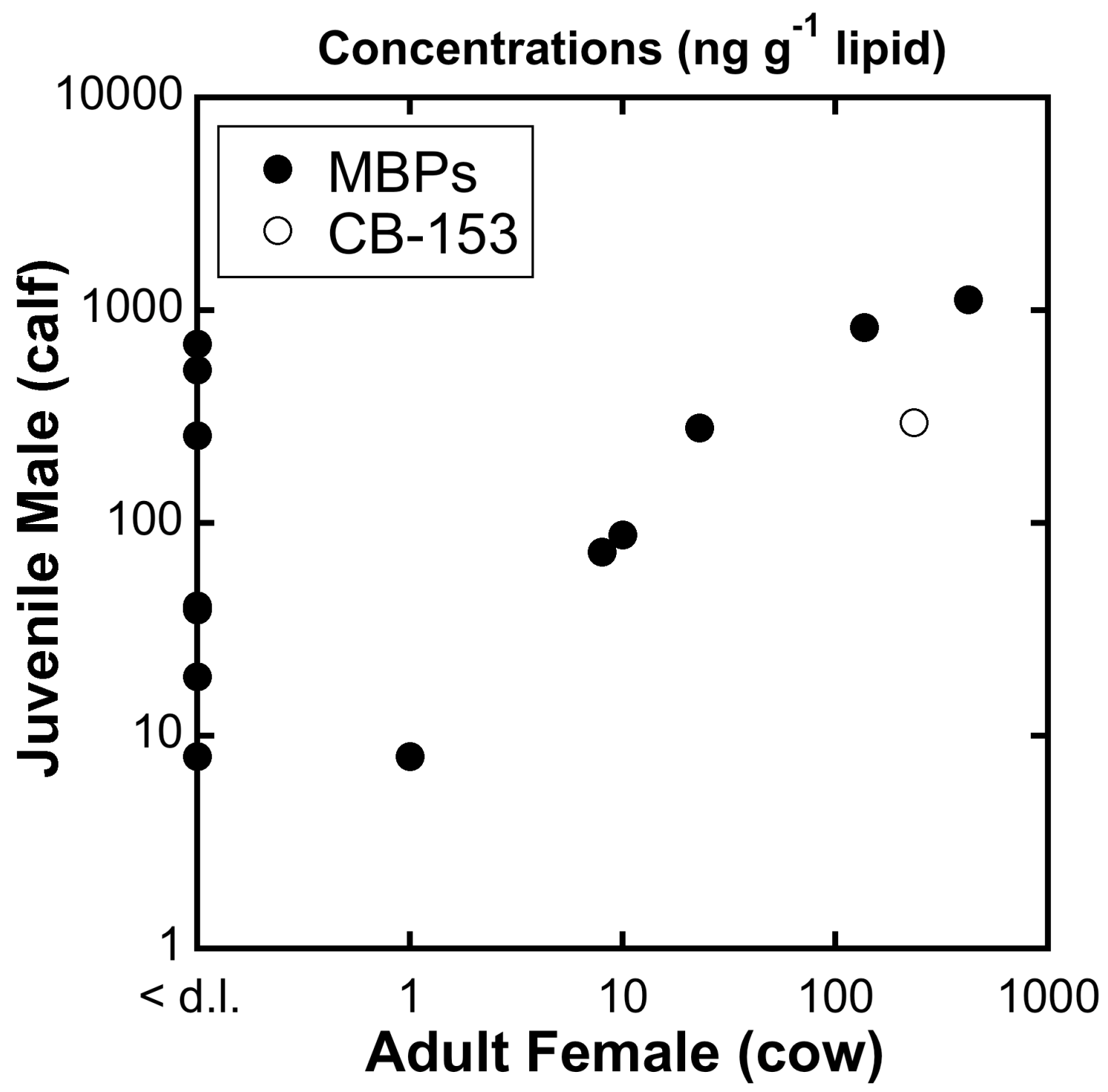

Figure 2. Lipid normalized concentrations of MBPs and CB-153 in the blubber of a pair of common dolphins (D. delphis) found stranded together. MBPs are plotted with solid circles and CB-153 is plotted with an open circle. Error bars are not visible as they are smaller than the circles. Many MBPs were below the detection limit (<d.1.) in the adult female (the presumed cow). However, the detection limits for these compounds fall along the line formed by the measured MBPs, and it is possible that the MBPs below the detection limit continue the trend established by the measured MBPs. 


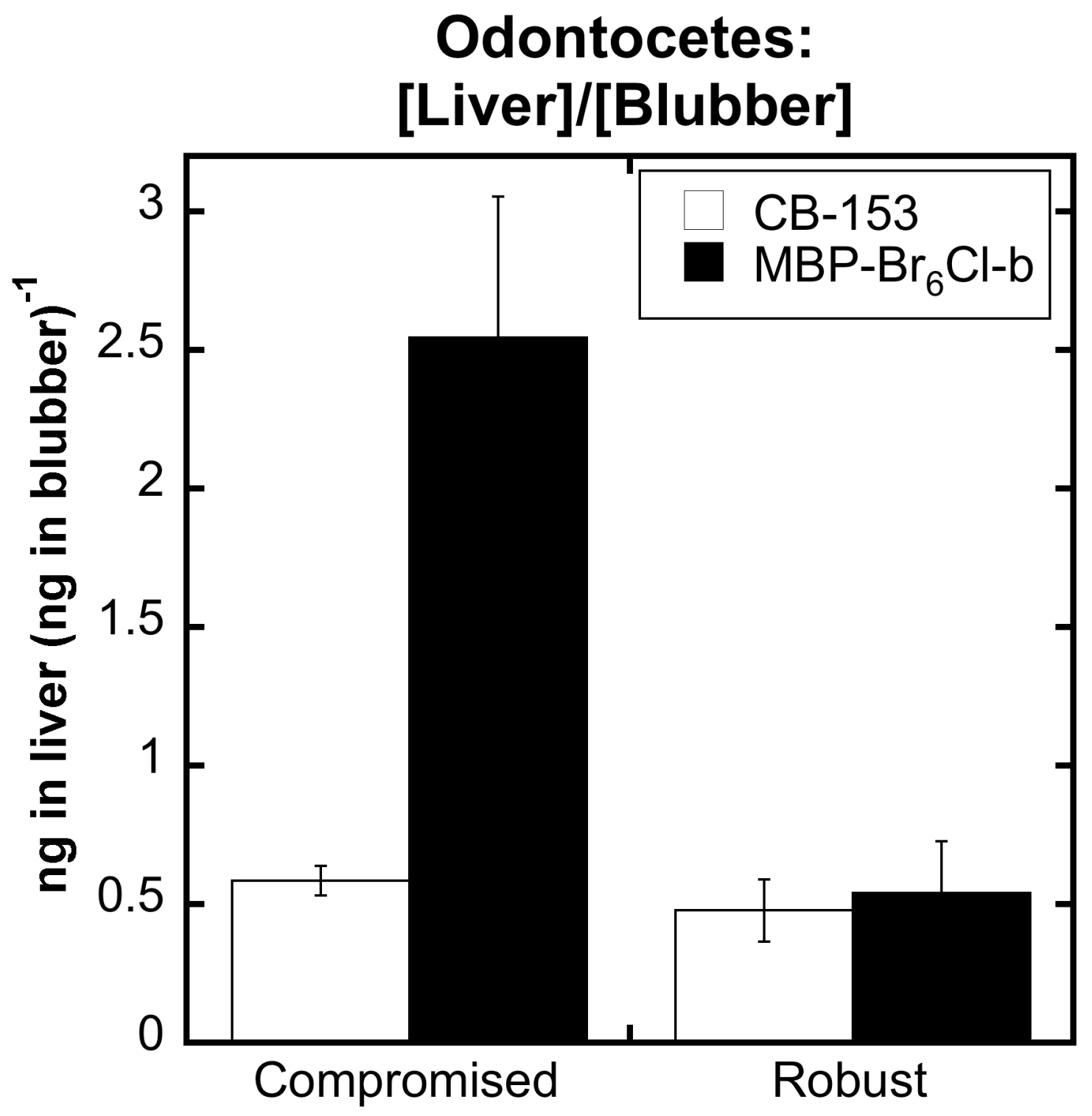

Figure 3. The mean (18 odontocetes) of liver concentrations relative to blubber concentrations (both lipid-normalized) of $\mathrm{MBP}-\mathrm{Br}_{6} \mathrm{Cl}$ (shaded bar) and $\mathrm{CB}-153$ (open bar). Odontocetes are divided into two groups based on their state of health, those in a nutritionally-compromised state and those of robust health (Table 1). 


\section{BRIEF}

Halogenated 1'-methyl-1,2'-bipyrroles were analyzed in liver and blubber tissues of 25 marine mammals; the patterns exhibited are consistent with biomagnification. 


\section{Supplemental Information (SI)}

Paper title: Distribution patterns suggest biomagnification of

halogenated 1'-methyl-1,2'-bipyrroles (MBPs)

Paper authors: $\quad$ Kristin C. Pangallo

Christopher M. Reddy

Pages:

Tables:

Figures:
12

S1-S6

S1 
Quality Controls: blanks, detection limit and error

Blanks were analyzed for both the blubber and liver methods, no MBPs or PCBs were detected in the blanks. The blubber blank consisted of vegetable oil and the liver blank was made of an ASE cell packed with combusted sand. Both types of blanks were spiked with the same internal standard in order to ensure full extraction.

The detection limit of the blubber and liver methods were determined separately. Seven replicates of $10 \%$ of a normal sample $(0.10 \mathrm{~g}$ blubber oil and $0.25 \mathrm{~g}$ dried liver) were extracted and analyzed from a common dolphin (Cape Cod Stranding Network accession number: CCNS06-013Dd). The detection limit was calculated as three times the standard deviation of these seven replicates (1), thus it was positively correlated with the abundance of each congener in this sample. The detection limit had a range of $0.7-150 \mathrm{ng} \mathrm{g}^{-1}$ lipid for blubber samples and 40-1100 $\mathrm{ng} \mathrm{g}^{-1}$ for liver samples (Table 1). For compounds that were not quantified, the detection limit calculation was performed on the relative abundance of the compound compared to the recovery standard, 2,2',4,6tetrachlorobiphenyl (CB-50).

The error associated with the analysis was determined by running replicate samples from five mammals. For each individual mammal, three blubber replicates and two liver replicates were analyzed. The standard error of the mean relative to the mean concentration was calculated for each compound 
of interest in each set of replicates. This relative standard error for each set of replicates was then averaged to give a generalized error for each compound of interest (Tables S3 and S5).

(1) Glaser, J. A.; Foerst, D. L.; McKee, G. D.; Quave, S. A.; Budde, W. L. Trace analyses for wastewaters. Environ. Sci. Technol. 1981, 15, 1426-1435. 
Table S1. Descriptions of the individual mammals sampled in this study are presented. "NA" indicates that a data point was not acquired.

\begin{tabular}{|c|c|c|c|c|c|c|c|c|}
\hline $\begin{array}{l}\text { CCSN ID } \\
\text { number }\end{array}$ & Genus & species & Common name & gender & age & $\begin{array}{l}\text { length } \\
\text { (cm) }\end{array}$ & $\begin{array}{l}\text { weight } \\
\text { (kg) }\end{array}$ & condition \\
\hline CCSN05-316Dd & Delphinus & delphis & Common dolphin & $\mathrm{M}$ & NA & 216.2 & 100 & Robust \\
\hline CCSN06-013Dd & Delphinus & delphis & Common dolphin & M & NA & 195.5 & NA & Robust \\
\hline CCSN06-022La & Lagenorhynchus & acutus & $\begin{array}{l}\text { Atlantic white- } \\
\text { sided dolphin }\end{array}$ & $\mathrm{F}$ & Adult & 205.0 & 135 & Robust \\
\hline CCSN06-024Dd & Delphinus & delphis & Common dolphin & $\mathrm{F}$ & Adult & 216.8 & 110 & NA \\
\hline CCSN06-029Dd & Delphinus & delphis & Common dolphin & $\mathrm{F}$ & Adult & 200.0 & 105 & Robust \\
\hline CCSN06-096Dd & Delphinus & delphis & Common dolphin & M & Subadult & 184.0 & 60 & Thin \\
\hline CCSN06-119La & Lagenorhynchus & acutus & $\begin{array}{l}\text { Atlantic white- } \\
\text { sided dolphin }\end{array}$ & M & Subadult & 193.0 & 100 & Good \\
\hline CCSN06-133Pg & Phoca & groenlandica & Harp seal & M & Male & 160.0 & 91 & Thin \\
\hline CCSN06-137Dd & Delphinus & delphis & Common dolphin & M & NA & 196.0 & 90 & Thin \\
\hline CCSN06-263Dd & Delphinus & delphis & Common dolphin & M & Yearling & 160.2 & 46 & Robust \\
\hline CCSN06-264Dd & Delphinus & delphis & Common dolphin & $\mathrm{F}$ & Adult & 203.2 & 72 & Emaciated \\
\hline CCSN07-022Gm & Globicephala & melas & $\begin{array}{l}\text { Long-finned pilot } \\
\text { whale }\end{array}$ & M & Subadult & 352.0 & 560 & Thin \\
\hline CCSN07-023La & Lagenorhynchus & acutus & $\begin{array}{l}\text { Atlantic white- } \\
\text { sided dolphin }\end{array}$ & $\mathrm{F}$ & Subadult & 182.5 & 64 & Emaciated \\
\hline CCSN07-036Dd & Delphinus & delphis & Common dolphin & M & Adult & 214.0 & 135 & Thin \\
\hline CCSN07-040Dd & Delphinus & delphis & Common dolphin & M & NA & 225.0 & 130 & Robust \\
\hline CCSN07-041Dd & Delphinus & delphis & Common dolphin & M & Adult & 202.8 & NA & Thin \\
\hline CCSN07-063Pg & Phoca & groenlandica & Harp seal & $\mathrm{F}$ & Yearling & 101.2 & 25 & Thin \\
\hline CCSN07-080Pg & Phoca & groenlandica & Harp seal & M & Juvenille & 101.5 & 29 & Thin \\
\hline CCSN07-084Pg & Phoca & groenlandica & Harp seal & M & Yearling & 101.0 & 22 & Thin \\
\hline CCSN07-109Dd & Delphinus & delphis & Common dolphin & M & Subadult & 172.0 & 55 & Emaciated \\
\hline CCSN07-115Dd & Delphinus & delphis & Common dolphin & $\mathrm{F}$ & Subadult & 148.8 & NA & Emaciated \\
\hline CCSN07-116Pg & Phoca & groenlandica & Harp seal & M & Yearling & 98.5 & 25 & Thin \\
\hline CCSN07-129Hg & Halichoerus & grypus & Gray seal & M & Yearling & 104.5 & 142 & Thin \\
\hline D07041 & Phocoena & phocoena & Harbor porpoise & M & Subadult & 126.0 & 35.0 & Robust \\
\hline D08742 & Halichoerus & grypus & Gray seal & M & Juvenille & 105.0 & 25.5 & Thin \\
\hline
\end{tabular}


Table S2. The GC/ECNI-MS relative retention times and quantification ions of the compounds that are discussed in this study. These times are relative to CB50 under the conditions described in the methods section (section 2.3). Concentrations of compounds in the upper section were quantified or estimated (Tables S3 and S5), the detection of those in the lower section is noted in Tables S4 and S5.

\begin{tabular}{|c|c|c|}
\hline Compound & Relative Retention Time & Quantification Ion \\
\hline CB-50 & 1.000 & 257.0 \\
\hline $\mathrm{MBP}-\mathrm{Br}_{7}$ & 1.754 & 697.7 \\
\hline $\mathrm{MBP}-\mathrm{Br}_{6} \mathrm{Cl}-\mathrm{a}$ & 1.682 & 653.7 \\
\hline $\mathrm{MBP}-\mathrm{Br}_{6} \mathrm{Cl}-\mathrm{b}$ & 1.685 & 653.7 \\
\hline $\mathrm{MBP}-\mathrm{HBr}_{6}-\mathrm{a}$ & 1.543 & 619.7 \\
\hline $\mathrm{MBP}-\mathrm{HBr}_{6}-\mathrm{b}$ & 1.554 & 619.7 \\
\hline $\mathrm{MBP}-\mathrm{HBr}_{6}-\mathrm{C}$ & 1.637 & 619.7 \\
\hline MBP-HBr ${ }_{6}-\mathrm{d}$ & 1.690 & 619.7 \\
\hline $\mathrm{MBP}-\mathrm{HBr}_{5} \mathrm{Cl}-\mathrm{a}$ & 1.469 & 575.7 \\
\hline $\mathrm{MBP}-\mathrm{HBr}_{5} \mathrm{Cl}-\mathrm{b}$ & 1.473 & 575.7 \\
\hline $\mathrm{MBP}-\mathrm{HBr}_{5} \mathrm{Cl}-\mathrm{C}$ & 1.478 & 575.7 \\
\hline $\mathrm{MBP}-\mathrm{HBr}_{5} \mathrm{Cl}-\mathrm{d}$ & 1.483 & 575.7 \\
\hline MBP-HBr ${ }_{5} \mathrm{Cl}-\mathrm{e}$ & 1.565 & 575.7 \\
\hline $\mathrm{MBP}-\mathrm{HBr}_{5} \mathrm{Cl}-\mathrm{f}$ & 1.625 & 575.7 \\
\hline CB-153 & 1.380 & 360.0 \\
\hline $\mathrm{MBP}-\mathrm{Br}_{5} \mathrm{Cl}_{2}-\mathrm{a}$ & 1.608 & 609.8 \\
\hline $\mathrm{MBP}-\mathrm{Br}_{5} \mathrm{Cl}_{2}-\mathrm{b}$ & 1.612 & 609.8 \\
\hline $\mathrm{MBP}-\mathrm{H}_{2} \mathrm{Br}_{5}-\mathrm{a}$ & 1.324 & 539.8 \\
\hline $\mathrm{MBP}-\mathrm{H}_{2} \mathrm{Br}_{5}-\mathrm{b}$ & 1.421 & 539.8 \\
\hline $\mathrm{MBP}-\mathrm{H}_{2} \mathrm{Br}_{5}-\mathrm{C}$ & 1.424 & 539.8 \\
\hline $\mathrm{MBP}-\mathrm{H}_{2} \mathrm{Br}_{5}-\mathrm{d}$ & 1.458 & 539.8 \\
\hline $\mathrm{MBP}-\mathrm{HBr}_{4} \mathrm{Cl}_{2}$-a & 1.393 & 531.8 \\
\hline $\mathrm{MBP}-\mathrm{HBr}_{4} \mathrm{Cl}_{2}-\mathrm{b}$ & 1.401 & 531.8 \\
\hline $\mathrm{MBP}-\mathrm{HBr}_{4} \mathrm{Cl}_{2}-\mathrm{C}$ & 1.405 & 531.8 \\
\hline $\mathrm{MBP}-\mathrm{H}_{2} \mathrm{Br}_{4} \mathrm{Cl}-\mathrm{a}$ & 1.248 & 495.8 \\
\hline $\mathrm{MBP}-\mathrm{H}_{2} \mathrm{Br}_{4} \mathrm{Cl}-\mathrm{b}$ & 1.339 & 495.8 \\
\hline 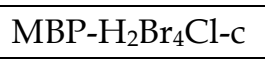 & 1.349 & 495.8 \\
\hline MBP- $\mathrm{H}_{2} \mathrm{Br}_{4} \mathrm{Cl}-\mathrm{d}$ & 1.385 & 495.8 \\
\hline $\mathrm{MBP}-\mathrm{Cl}_{7}$ & 1.225 & 385.7 \\
\hline
\end{tabular}


Table S3. Individual concentrations (ng g-1 lipid) of CB-153 and the MBPs quantified or estimated from blubber are presented. Compounds for which a quantification standard is available were quantified and are given to 2 significant figures. Homologes of these compounds were estimated to one significant figure, as described in section 2.3. The method error for the measurement of each compound is given as $\pm \mathrm{X} \%$, and the calculation is described on page $\mathrm{S} 1$.

\begin{tabular}{|c|c|c|c|c|c|c|c|}
\hline $\begin{array}{l}\text { CCSN ID } \\
\text { number }\end{array}$ & $\begin{array}{c}\text { MBP-Br } \\
\pm 4 \%\end{array}$ & $\begin{array}{c}\text { MBP-Br } 6 \text { Cl-a } \\
\pm 6 \%\end{array}$ & $\begin{array}{c}\text { MBP-Br } 6 \text { Cl-b } \\
\pm 9 \%\end{array}$ & $\begin{array}{c}\text { MBP-HBr } 6-\mathrm{a} \\
\pm 6 \%\end{array}$ & $\begin{array}{c}\text { MBP-HBr }{ }_{6}-\mathrm{b} \\
\pm 5 \%\end{array}$ & $\begin{array}{c}\text { MBP-HBr } 6 \text {-c } \\
\pm 29 \%\end{array}$ & $\begin{array}{c}\text { MBP-HBr } 6-\mathrm{d} \\
\pm 11 \%\end{array}$ \\
\hline CCSN05-316Dd & 200 & 2 & 790 & 3 & 200 & 5 & 10 \\
\hline CCSN06-013Dd & 520 & 9 & 1100 & 10 & 390 & 10 & 50 \\
\hline CCSN06-022La & 550 & 7 & 1700 & 8 & 360 & 10 & 40 \\
\hline CCSN06-024Dd & $<$ d.1. & 1 & 360 & $<$ d.1. & 82 & $<$ d.l. & 9 \\
\hline CCSN06-029Dd & $<$ d.l. & $<$ d.1. & 170 & $<$ d.1. & $<$ d.l. & $<$ d.l. & 3 \\
\hline CCSN06-096Dd & 130 & 2 & 540 & 5 & 190 & 3 & 20 \\
\hline CCSN06-119La & 330 & 4 & 1000 & 6 & 230 & 4 & 30 \\
\hline CCSN06-133Pg & $<$ d.1. & $<$ d.1. & $<$ d.1. & $<$ d.1. & $<$ d.l. & $<$ d.l. & $<$ d.l. \\
\hline CCSN06-137Dd & 250 & 5 & 790 & 10 & 290 & $<$ d.l. & 30 \\
\hline CCSN06-263Dd & 700 & 8 & 1100 & 40 & 520 & 40 & 70 \\
\hline CCSN06-264Dd & $<$ d.1. & 1 & 420 & $<$ d.1. & $<$ d.1. & $<$ d.1. & 9 \\
\hline CCSN07-022Gm & 250 & 4 & 490 & 8 & 170 & 10 & 80 \\
\hline CCSN07-023La & 170 & 2 & 650 & 3 & 150 & $<$ d.l. & 20 \\
\hline CCSN07-036Dd & 690 & 10 & 1300 & 20 & 520 & $<$ d.l. & 40 \\
\hline CCSN07-040Dd & 560 & 50 & 2700 & 100 & 1000 & 60 & 50 \\
\hline CCSN07-041Dd & 690 & 10 & 1300 & 10 & 450 & 4 & 50 \\
\hline CCSN07-063Pg & $<$ d.1. & $<$ d.1. & $<$ d.1. & $<$ d.1. & $<$ d.1. & $<$ d.1. & $<$ d.1. \\
\hline CCSN07-080Pg & $<$ d.1. & $<$ d.l. & $<$ d.1. & $<$ d.1. & $<$ d.l. & $<$ d.1. & $<$ d.l. \\
\hline CCSN07-084Pg & $<$ d.1. & $<$ d.l. & $<$ d.1. & $<$ d.1. & $<$ d.1. & $<$ d.1. & $<$ d.l. \\
\hline CCSN07-109Dd & 260 & 4 & 970 & 10 & 250 & 5 & 70 \\
\hline CCSN07-115Dd & 900 & 20 & 1800 & 40 & 570 & 40 & 300 \\
\hline CCSN07-116Pg & $<$ d.l. & $<$ d.l. & $<$ d.1. & $<$ d.1. & $<$ d.l. & $<$ d.l. & $<$ d.l. \\
\hline CCSN07-129Hg & $<$ d.l. & $<$ d.1. & $<$ d.1. & $<$ d.1. & $<$ d.1. & $<$ d.1. & $<$ d.1. \\
\hline D07041 & 470 & 7 & 1100 & 9 & 280 & 20 & 60 \\
\hline D08742 & $<$ d.l. & $<$ d.l. & $<$ d.l. & $<$ d.l. & $<$ d.l. & $<$ d.l. & $<$ d.l. \\
\hline
\end{tabular}


Table S3. (continued)

\begin{tabular}{|c|c|c|c|c|c|c|c|}
\hline $\begin{array}{l}\text { CCSN ID } \\
\text { number }\end{array}$ & $\begin{array}{c}\text { MBP-HBr }{ }_{5} \mathrm{Cl}-\mathrm{a} \\
\pm 4 \%\end{array}$ & $\begin{array}{c}\text { MBP-HBr }{ }_{5} \mathrm{Cl}-\mathrm{b} \\
\pm 7 \%\end{array}$ & $\begin{array}{c}\text { MBP-HBr }{ }_{5} \mathrm{Cl}-\mathrm{c} \\
\pm 7 \%\end{array}$ & $\begin{array}{c}\text { MBP-HBr }{ }_{5} \mathrm{Cl}-\mathrm{d} \\
\pm 6 \%\end{array}$ & $\begin{array}{c}\text { MBP-HBr }{ }_{5} \mathrm{Cl}-\mathrm{e} \\
\pm 24 \%\end{array}$ & $\begin{array}{c}\text { MBP-HBr }{ }_{5} \mathrm{Cl}-\mathrm{f} \\
\pm 6 \%\end{array}$ & $\begin{array}{c}\text { CB-153 } \\
\pm 10 \% \\
\end{array}$ \\
\hline CCSN05-316Dd & 20 & 5 & 2 & 370 & 40 & 20 & 170 \\
\hline CCSN06-013Dd & 90 & 10 & 4 & 710 & 70 & 70 & 870 \\
\hline CCSN06-022La & 60 & 7 & 2 & 760 & 100 & 40 & 1100 \\
\hline CCSN06-024Dd & 10 & 3 & $<$ d.l. & 190 & $<$ d.l. & 10 & 210 \\
\hline CCSN06-029Dd & $<$ d.1. & $<$ d.1. & $<$ d.1. & 70 & $<$ d.1. & $<$ d.1. & 100 \\
\hline CCSN06-096Dd & 30 & 5 & 2 & 390 & $<$ d.1. & 50 & 980 \\
\hline CCSN06-119La & 50 & 5 & 2 & 560 & 70 & 40 & 1100 \\
\hline CCSN06-133Pg & $<$ d.1. & $<$ d.1. & $<$ d.1. & $<$ d.1. & $<$ d.1. & $<$ d.1. & 100 \\
\hline CCSN06-137Dd & 60 & 10 & 40 & 62 & $<$ d.l. & 60 & 1400 \\
\hline CCSN06-263Dd & 90 & 20 & 8 & 830 & 300 & 300 & 300 \\
\hline CCSN06-264Dd & 10 & $<$ d.1. & $<$ d.l. & 140 & $<$ d.l. & 20 & 240 \\
\hline CCSN07-022Gm & 40 & 4 & 2 & 310 & 80 & 200 & 740 \\
\hline CCSN07-023La & 30 & 3 & $<$ d.1. & 380 & $<$ d.1. & 20 & 2100 \\
\hline CCSN07-036Dd & 100 & 20 & 6 & 930 & 40 & 60 & 2900 \\
\hline CCSN07-040Dd & 200 & 1000 & 40 & 340 & 50 & 400 & 650 \\
\hline CCSN07-041Dd & 90 & 10 & 4 & 810 & 50 & 70 & 1600 \\
\hline CCSN07-063Pg & $<$ d.l. & $<$ d.l. & $<$ d.l. & $<$ d.1. & $<$ d.l. & $<$ d.l. & 250 \\
\hline CCSN07-080Pg & $<$ d.l. & $<$ d.l. & $<$ d.l. & $<$ d.l. & $<$ d.l. & $<$ d.l. & $<$ d.l. \\
\hline CCSN07-084Pg & $<$ d.1. & $<$ d.1. & $<$ d.1. & $<$ d.1. & $<$ d.1. & $<$ d.1. & 130 \\
\hline CCSN07-109Dd & 80 & 9 & 4 & 700 & 80 & 200 & 670 \\
\hline CCSN07-115Dd & 200 & 30 & 10 & 1300 & 400 & 600 & 1500 \\
\hline CCSN07-116Pg & $<$ d.1. & $<$ d.1. & $<$ d.1. & $<$ d.1. & $<$ d.l. & $<$ d.1. & $<$ d.1. \\
\hline CCSN07-129Hg & $<$ d.1. & $<$ d.1. & $<$ d.1. & $<$ d.1. & $<$ d.l. & $<$ d.1. & 270 \\
\hline D07041 & 70 & 6 & 2 & 650 & 100 & 90 & 1200 \\
\hline D08742 & $<$ d.1. & $<$ d.1. & $<$ d.l. & $<$ d.1. & $<$ d.l. & $<$ d.1. & $<$ d.1. \\
\hline
\end{tabular}


Table S4. The detection of compounds in blubber for which concentrations were not quantified or estimated. Compounds above the detection limit (as described in page S1) are indicated with a (+), compounds below the detection limit are unmarked.

\begin{tabular}{|c|c|c|c|c|c|c|}
\hline $\begin{array}{l}\text { CCSN ID } \\
\text { number }\end{array}$ & $\mathrm{MBP}-\mathrm{Br}_{5} \mathrm{Cl}_{2}-\mathrm{a}$ & $\mathrm{MBP}-\mathrm{Br}_{5} \mathrm{Cl}_{2}-\mathrm{b}$ & $\mathrm{MBP}-\mathrm{H}_{2} \mathrm{Br}_{5}-\mathrm{a}$ & $\mathrm{MBP}-\mathrm{H}_{2} \mathrm{Br}_{5}-\mathrm{b}$ & $\mathrm{MBP}-\mathrm{H}_{2} \mathrm{Br}_{5}-\mathrm{C}$ & $\mathrm{MBP}-\mathrm{H}_{2} \mathrm{Br}_{5}-\mathrm{d}$ \\
\hline CCSN05-316Dd & + & + & + & & + & + \\
\hline CCSN06-013Dd & + & + & + & + & + & + \\
\hline CCSN06-022La & + & + & + & + & + & + \\
\hline CCSN06-024Dd & + & & + & + & + & + \\
\hline CCSN06-029Dd & & & + & & + & \\
\hline CCSN06-096Dd & + & + & + & + & + & + \\
\hline CCSN06-119La & + & + & + & + & + & + \\
\hline \multicolumn{7}{|l|}{ CCSN06-133Pg } \\
\hline CCSN06-137Dd & + & + & + & + & + & + \\
\hline CCSN06-263Dd & + & + & + & + & + & + \\
\hline CCSN06-264Dd & + & & + & & + & \\
\hline CCSN07-022Gm & + & + & + & + & + & + \\
\hline CCSN07-023La & + & + & + & & + & + \\
\hline CCSN07-036Dd & + & + & + & + & + & + \\
\hline CCSN07-040Dd & + & + & + & + & + & + \\
\hline CCSN07-041Dd & + & + & + & + & + & + \\
\hline \multicolumn{7}{|l|}{ CCSN07-063Pg } \\
\hline \multicolumn{7}{|l|}{ CCSN07-080Pg } \\
\hline \multicolumn{7}{|l|}{ CCSN07-084Pg } \\
\hline CCSN07-109Dd & + & + & + & + & + & + \\
\hline CCSN07-115Dd & + & + & + & + & + & + \\
\hline \multicolumn{7}{|l|}{ CCSN07-116Pg } \\
\hline \multicolumn{7}{|l|}{ CCSN07-129Hg } \\
\hline D07041 & + & + & + & + & + & + \\
\hline D08742 & & & & & & \\
\hline
\end{tabular}


Table S4. (continued)

\begin{tabular}{|c|c|c|c|}
\hline CCSN ID number & $\mathrm{MBP}-\mathrm{HBr}_{4} \mathrm{Cl}_{2}-\mathrm{a}$ & $\mathrm{MBP}-\mathrm{HBr}_{4} \mathrm{Cl}_{2}-\mathrm{b}$ & $\mathrm{MBP}-\mathrm{HBr}_{4} \mathrm{Cl}_{2}-\mathrm{C}$ \\
\hline CCSN05-316Dd & & + & + \\
\hline CCSN06-013Dd & + & + & + \\
\hline CCSN06-022La & + & + & + \\
\hline CCSN06-024Dd & + & + & + \\
\hline \multicolumn{4}{|l|}{ CCSN06-029Dd } \\
\hline CCSN06-096Dd & + & + & + \\
\hline CCSN06-119La & + & + & + \\
\hline \multicolumn{4}{|l|}{ CCSN06-133Pg } \\
\hline CCSN06-137Dd & + & + & + \\
\hline CCSN06-263Dd & & + & + \\
\hline CCSN06-264Dd & & + & + \\
\hline CCSN07-022Gm & + & + & + \\
\hline CCSN07-023La & + & + & + \\
\hline CCSN07-036Dd & + & + & + \\
\hline CCSN07-040Dd & + & + & + \\
\hline CCSN07-041Dd & + & + & + \\
\hline \multicolumn{4}{|l|}{ CCSN07-063Pg } \\
\hline \multicolumn{4}{|l|}{ CCSN07-080Pg } \\
\hline \multicolumn{4}{|l|}{ CCSN07-084Pg } \\
\hline CCSN07-109Dd & + & + & + \\
\hline CCSN07-115Dd & + & + & + \\
\hline \multicolumn{4}{|l|}{ CCSN07-116Pg } \\
\hline \multicolumn{4}{|l|}{ CCSN07-129Hg } \\
\hline D07041 & + & + & + \\
\hline D08742 & & & \\
\hline
\end{tabular}


Table S4. (continued)

\begin{tabular}{|c|c|c|c|c|c|}
\hline CCSN ID number & $\mathrm{MBP}-\mathrm{H}_{2} \mathrm{Br}_{4} \mathrm{Cl}-\mathrm{a}$ & $\mathrm{MBP}-\mathrm{H}_{2} \mathrm{Br}_{4} \mathrm{Cl}-\mathrm{b}$ & $\mathrm{MBP}-\mathrm{H}_{2} \mathrm{Br}_{4} \mathrm{Cl}-\mathrm{c}$ & $\mathrm{MBP}-\mathrm{H}_{2} \mathrm{Br}_{4} \mathrm{Cl}-\mathrm{d}$ & $\mathrm{MBP}-\mathrm{Cl}_{7}$ \\
\hline CCSN05-316Dd & + & & + & + & + \\
\hline CCSN06-013Dd & + & + & + & + & + \\
\hline CCSN06-022La & + & + & + & + & + \\
\hline CCSN06-024Dd & + & + & + & + & + \\
\hline CCSN06-029Dd & & & + & & \\
\hline CCSN06-096Dd & + & + & + & + & + \\
\hline CCSN06-119La & + & + & + & + & + \\
\hline \multicolumn{6}{|l|}{ CCSN06-133Pg } \\
\hline CCSN06-137Dd & + & + & + & + & + \\
\hline CCSN06-263Dd & + & + & + & + & + \\
\hline CCSN06-264Dd & + & & + & + & + \\
\hline CCSN07-022Gm & + & + & + & + & + \\
\hline CCSN07-023La & + & + & + & + & + \\
\hline CCSN07-036Dd & + & + & + & + & + \\
\hline CCSN07-040Dd & + & + & + & + & + \\
\hline CCSN07-041Dd & + & + & + & + & + \\
\hline \multicolumn{6}{|l|}{ CCSN07-063Pg } \\
\hline \multicolumn{6}{|l|}{ CCSN07-080Pg } \\
\hline \multicolumn{6}{|l|}{ CCSN07-084Pg } \\
\hline CCSN07-109Dd & + & + & + & + & + \\
\hline CCSN07-115Dd & + & + & + & + & + \\
\hline \multicolumn{6}{|l|}{ CCSN07-116Pg } \\
\hline \multicolumn{6}{|l|}{ CCSN07-129Hg } \\
\hline D07041 & + & + & + & + & + \\
\hline D08742 & & & & & \\
\hline
\end{tabular}


Table S5. Individual concentrations (ng g-1 lipid) of CB-153 and the MBPs quantified or estimated from liver are presented. Compounds for which a quantification standard is available were quantified and are given to 2 significant figures. Homologes of these compounds were estimated to one significant figure, as described in section 2.3. The method error for the measurement of each compound is given as $\pm X \%$, and the calculation is described on page $\mathrm{S} 1$.

\begin{tabular}{|c|c|c|c|c|c|c|}
\hline $\begin{array}{l}\text { CCSN ID } \\
\text { number }\end{array}$ & $\begin{array}{c}\text { MBP-Br } \\
\pm 21 \% \\
\end{array}$ & $\begin{array}{c}\text { MBP-Br }{ }_{6} \mathrm{Cl}-\mathrm{b} \\
\pm 22 \% \\
\end{array}$ & $\begin{array}{c}\text { MBP-HBr }{ }_{6}-\mathrm{b} \\
\pm 22 \% \\
\end{array}$ & $\begin{array}{c}\text { MBP-HBr }{ }_{5} \mathrm{Cl}-\mathrm{d} \\
\pm 31 \%\end{array}$ & $\begin{array}{c}\text { MBP-HBr }{ }_{5} \mathrm{Cl}-\mathrm{e} \\
\pm 19 \%\end{array}$ & $\begin{array}{c}\text { CB-153 } \\
\pm 10 \% \\
\end{array}$ \\
\hline CCSN05-316Dd & $<$ d.1. & $<$ d.1. & $<$ d.1. & $<$ d.1. & $<$ d.l. & 630 \\
\hline CCSN06-013Dd & 180 & 1300 & 210 & $<$ d.l. & $<$ d.l. & 1800 \\
\hline CCSN06-022La & 100 & $<$ d.1. & $<$ d.1. & $<$ d.1. & $<$ d.1. & 1000 \\
\hline CCSN06-024Dd & $<$ d.l. & $<$ d.l. & $<$ d.l. & $<$ d.l. & $<$ d.l. & $<$ d.l. \\
\hline CCSN06-029Dd & $<$ d.1. & $<$ d.l. & $<$ d.1. & $<$ d.1. & $<$ d.1. & 93 \\
\hline CCSN06-096Dd & $<$ d.1. & $<$ d.1. & $<$ d.1. & $<$ d.1. & 40 & 820 \\
\hline CCSN06-119La & 300 & 1700 & 210 & $<$ d.1. & 80 & 1500 \\
\hline CCSN06-133Pg & $<$ d.1. & $<$ d.1. & $<$ d.1. & $<$ d.1. & $<$ d.1. & $<$ d.1. \\
\hline CCSN06-137Dd & 550 & 3600 & 640 & 2000 & 100 & 820 \\
\hline CCSN06-263Dd & $<$ d.l. & $<$ d.1. & $<$ d.l. & $<$ d.1. & $<$ d.l. & 2600 \\
\hline CCSN06-264Dd & $<$ d.1. & $<$ d.1. & $<$ d.1. & $<$ d.1. & $<$ d.l. & 920 \\
\hline CCSN07-022Gm & 140 & $<$ d.1. & $<$ d.1. & $<$ d.1. & 40 & 1400 \\
\hline CCSN07-023La & 1300 & 3000 & 460 & 940 & 300 & 2000 \\
\hline CCSN07-036Dd & 860 & 3600 & 750 & 1700 & 40 & 13000 \\
\hline CCSN07-040Dd & $<$ d.l. & $<$ d.1. & $<$ d.1. & $<$ d.1. & $<$ d.l. & 4200 \\
\hline CCSN07-041Dd & 310 & 2100 & 360 & 930 & 40 & 4400 \\
\hline CCSN07-063Pg & $<$ d.1. & $<$ d.1. & $<$ d.1. & $<$ d.1. & $<$ d.1. & 6500 \\
\hline CCSN07-080Pg & $<$ d.1. & $<$ d.1. & $<$ d.1. & $<$ d.1. & $<$ d.1. & 130 \\
\hline CCSN07-084Pg & $<$ d.1. & $<$ d.1. & $<$ d.1. & $<$ d.1. & $<$ d.1. & 890 \\
\hline CCSN07-109Dd & $<$ d.1. & 1100 & $<$ d.1. & $<$ d.1. & 40 & 660 \\
\hline CCSN07-115Dd & 1500 & 7300 & 1300 & 3700 & 400 & 1500 \\
\hline CCSN07-116Pg & $<$ d.1. & $<$ d.1. & $<$ d.1. & $<$ d.1. & $<$ d.l. & $<$ d.1. \\
\hline CCSN07-129Hg & $<$ d.1. & $<$ d.1. & $<$ d.l. & $<$ d.1. & $<$ d.1. & 270 \\
\hline D07041 & $<$ d.l. & $<$ d.1. & $<$ d.l. & $<$ d.1. & 80 & $<$ d.l. \\
\hline D08742 & $<$ d.1. & $<$ d.1. & $<$ d.1. & $<$ d.1. & $<$ d.1. & $<$ d.1. \\
\hline
\end{tabular}


Table S6. The detection of compounds in liver for which concentrations were not quantified or estimated. Compounds above the detection limit (as described in page S1) are indicated with a (+), compounds below the detection limit are unmarked.

\begin{tabular}{|c|c|c|c|c|c|}
\hline CCSN ID number & MBP-H ${ }_{2} \mathrm{Br}_{5}-\mathrm{a}$ & MBP-H ${ }_{2} \mathrm{Br}_{4} \mathrm{Cl}-\mathrm{a}$ & $\mathrm{MBP}-\mathrm{H}_{2} \mathrm{Br}_{4} \mathrm{Cl}-\mathrm{c}$ & MBP-H ${ }_{2} \mathrm{Br}_{4} \mathrm{Cl}-\mathrm{d}$ & $\mathrm{MBP}_{-\mathrm{Cl}_{7}}$ \\
\hline CCSN05-316Dd & + & + & + & + & + \\
\hline CCSN06-013Dd & + & + & + & + & + \\
\hline CCSN06-022La & + & + & + & + & + \\
\hline CCSN06-024Dd & + & + & + & + & + \\
\hline \multicolumn{6}{|l|}{ CCSN06-029Dd } \\
\hline CCSN06-096Dd & + & + & + & + & + \\
\hline CCSN06-119La & + & + & + & + & + \\
\hline \multicolumn{6}{|l|}{ CCSN06-133Pg } \\
\hline CCSN06-137Dd & + & + & + & + & + \\
\hline CCSN06-263Dd & + & & + & & + \\
\hline \multicolumn{6}{|l|}{ CCSN06-264Dd } \\
\hline CCSN07-022Gm & + & + & & & \\
\hline CCSN07-023La & + & + & + & + & + \\
\hline CCSN07-036Dd & + & + & + & + & + \\
\hline CCSN07-040Dd & + & & + & + & + \\
\hline CCSN07-041Dd & + & + & + & + & + \\
\hline \multicolumn{6}{|l|}{ CCSN07-063Pg } \\
\hline \multicolumn{6}{|l|}{ CCSN07-080Pg } \\
\hline \multicolumn{6}{|l|}{ CCSN07-084Pg } \\
\hline CCSN07-109Dd & + & + & + & + & + \\
\hline CCSN07-115Dd & + & + & + & + & + \\
\hline \multicolumn{6}{|l|}{ CCSN07-116Pg } \\
\hline \multicolumn{6}{|l|}{ CCSN07-129Hg } \\
\hline D07041 & + & + & + & + & + \\
\hline D08742 & & & & & \\
\hline
\end{tabular}




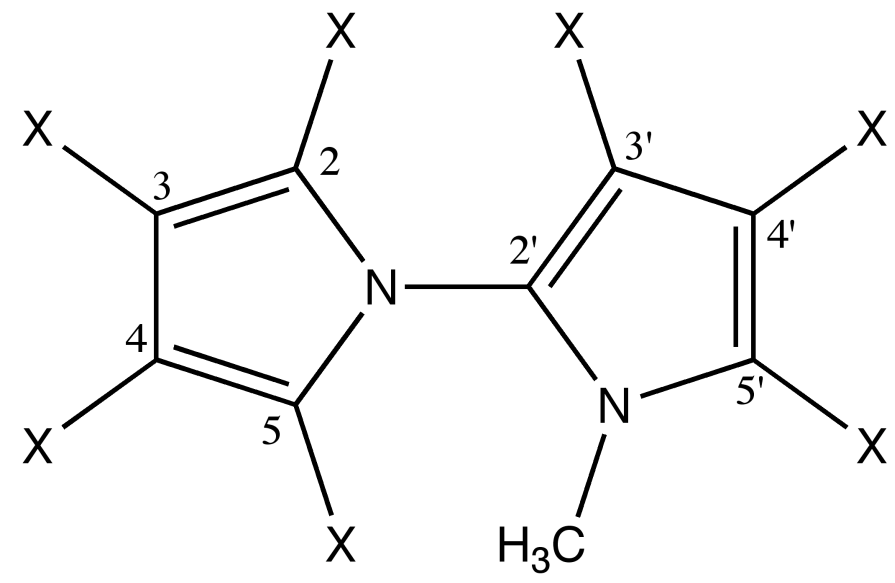

Figure S1. The general structure of the halogenated 1'methyl-1,2'-bipyrroles. Here, the $X$ substituent represents $\mathrm{Br}, \mathrm{Cl}$ or $\mathrm{H}$ atoms. 


\title{
Chapter 4
}

\section{Marine natural products, the halogenated 1'-methyl-1,2'-bipyrroles (MBPs), appear to biomagnify in a Northwestern Atlantic food web}

\begin{abstract}
Halogenated 1'-methyl-1,2'-bipyrroles (MBPs) are putative marine natural products that accumulate in marine mammal blubber in similar concentrations and patterns to biomagnifying pollutants. Here we measure concentrations of MBPs and 2,2',4,4',5,5'-hexachlorobiphenyl (CB-153) in forty samples compromised of eight fish species, two squid species, and six species of marine mammals. To determine their trophic positions, and to further investigate influence of prey preference, we also measured the stable carbon and nitrogen isotopic compositions of all samples. Our results show that lipid-normalized MBP concentrations increase with increasing trophic level, which provides strong evidence that MBPs are another class of biomagnifying marine natural products. The presence of MBPs in pinniped prey and absence in pinniped blubber suggests that these mammals share dietary exposure to MBPs with odontocetes, but have an enhanced ability to metabolize these natural products. Finally, although both MBPs and CB-153 biomagnify in this food web, MBPs do
\end{abstract}


not display the same coupling to $\delta^{13} \mathrm{C}$ as $\mathrm{CB}-153$, further showing their natural origins.

\section{Introduction}

Halogenated 1'-methyl-1,2'-bipyrroles (MBPs) are marine natural products present in the tissues of marine mammals and other species occupying the highest trophic levels of marine food webs [1-3]. They are unusual among the halogenated natural products (HNPs) in their degree of halogenation, they contain up to seven bromines and/or chlorines on the bipyrrole backbone, and their N,C1-linkage, which is not found in other naturally-produced bipyrroles. The MBPs that are the most abundant in environmental samples contain six or seven halogens $[2,3]$. Due to the number of halogens and their structure, MBPs have high estimated octanol-water partition coefficients $\left(\mathrm{K}_{\mathrm{ow}}=10^{\left.7.2-10^{8.3}\right)}[4]\right.$ and preferentially partition into lipid-rich reservoirs, such as blubber. These characteristics make them very similar to the persistent organic pollutants (POPs), and in this respect they are an untapped resource. By studying the pathways and fate of these HNPs through the environment, we can better understand the ultimate fate of the POPs in the marine environment.

POPs are now highly regulated in most countries due to their negative impacts on human and environmental health $[5,6]$. However, due to their recalcitrance, concentrations remain elevated in some reservoirs, especially soil and sediment $[7,8]$. Thus, these compounds continue to circulate within food 
webs and concentrations remain high in top predators [9]. These high concentrations result from biomagnification, which is an increase in their lipidnormalized contaminant concentrations with increasing trophic level that results from a trophic transfer process [10]. Thus, predators have contaminant concentrations that are higher than what would be expected based on equilibrium partitioning between the surrounding environment (i.e., water, soil, or sediment) and biotic tissues [10]. The mechanisms and time-scales for removal of these contaminants from the biosphere are not yet clear [11].

Due to their structural similarities to POPs, it was suspected that some HNPs biomagnify; this has been confirmed for halogenated 1,1'-dimethyl-2,2'bipyrroles (DMBPs) [12] and methoxylated polybrominated diphenyl ethers (MeO-PBDEs) [13]. Biomagnifying HNPs have evolved with their ecosystem and, presumably, have established routes of entry (biosynthesis) and exit (degradation and/or physical removal - e.g., burial). In fact, the enzymes found responsible for POP degradation may have evolved to degrade HNPs [14].

There is strong evidence suggesting that MBPs are another type of biomagnifying natural product. MBPs are present in marine mammal blubber in similar concentrations and in similar patterns to POPs known to biomagnify [3]. Additionally, MBPs have been detected in marine mammal prey (squid) $[15,16]$, fish oil [17], and human breast milk [18], suggesting that these compounds are transferred through food. Here we demonstrate that the lipid-normalized 
concentration of MBPs increase with trophic level in the Northwestern Atlantic Ocean. In doing so, we have identified MBPs in nine additional species, many of which are commonly consumed by humans.

\section{Methods}

\subsection{Sampling}

The 20 marine mammals analyzed in this study consist of both odontocete cetaceans (toothed whales) and pinnipeds (earless seals). The odontocete samples include seven common dolphins (Delphinus delphis), four Atlantic whitesided dolphins (Lagenorhynchus acutus), one harbor porpoise (Phocoena phocoena) and one long-finned pilot whale (Globicephala melas). The pinniped samples are two gray seals (Halichoerus grypus) and five harp seals (Phoca groenlandica). These samples include males and females, and adult and youth specimens (Table 1 and [3]). All the samples were acquired through the Cape Cod Stranding Network, 18 were fatally stranded on Cape Cod from 2004-2007 and 2 were caught in fishing gear (the harbor porpoise and one grey seal) just south of New England. For additional details on the individual marine mammals, including weight, length, age, and nutritional status, see [3].

The 20 fish and squid analyzed in this study were obtained from the 2007 Fall Bottom Trawl Survey conducted by the National Marine Fisheries Ecosystems Survey Branch (Woods Hole, MA). Species were selected based on their role as marine mammal prey: longfin inshore squid (Loligo pealeii), northern 
shortfin squid (Illex illecebrosus), Atlantic herring (Clupea harengus), Atlantic mackerel (Scomber scombrus), white hake (Urophycis tenuis), red hake (Urophycis chuss), silver hake (Merluccius bilinearis), Acadian redfish (Sebastes fasciatus), Atlantic cod (Gadus morhua), and haddock (Melanogrammus aeglefinus). The samples were collected opportunistically during the survey, and approximately 1 $\mathrm{kg}$ (wet weight) of whole fish was collected per species per tow. Two tows were selected per species for analysis, the tow number is listed after the species name in Table 2. Information regarding the date, location, duration, and depth of each tow is available as a Resource Survey Report [19].

Calanus spp. was collected by a vertical tow from the $R / V$ Tioga in Cape Cod Bay on March 30, 2007. The sample was collected in the vicinity of North American Right Whales (Eubalaena glacialis), which feed on Calanus finmarchicus. C. finmarcicus is abundant in this region [20] and it is probable that it made up the majority of our sample. A $0.150 \mu \mathrm{m}$ mesh net was used, and the tow lasted 2.5 minutes (water depth of $30 \mathrm{ft}$ ).

All samples were received and stored frozen. Prior to sub-sampling or initial homogenization they were thawed at room temperature and/or under lukewarm running tap water.

\subsection{HOC extraction and purification}

Blubber samples were extracted and HOCs purified following a previously published method [21]. Fish and squid samples consisted of 1 to $>20$ 
individual animals; all individuals from a sample were homogenized together (whole bodies) to provide sufficient biomass to acquire the $\sim 10 \mathrm{~g}$ of total lipid extract (TLE) necessary to detect MBPs at these trophic levels. The whole bodies were homogenized with a manual, stainless-steel meat-grinder, freeze-dried, and then further homogenized with a mortar and pestle. The dried, homogenized biomass was packed into GreenChem extraction vessels, spiked with $635 \mathrm{ng}$ of 2, $2^{\prime}, 3,4,4^{\prime}, 5,5^{\prime}$-heptabromo-1'-methyl-1,3'-bipyrrole (1,3'-MBP-Br7), then solvent extracted by a CEM MARS Xtraction (with Fiber Optic temperature and pressure control). The microwave program ramped to $100^{\circ} \mathrm{C}$ over 30 minutes, the power was set to $100 \%$ of $1600 \mathrm{~W}$ with a maximum pressure of 200 psi. The temperature was held at $100^{\circ} \mathrm{C}$ for 20 minutes, then the vessels were allowed to cool to approximately $35^{\circ} \mathrm{C}$ before they were vented. The contents of the vessels were filtered, $0.5 \%$ of filtrate was removed for gravimetric analysis to determine the total mass of the extract, and solvent was removed from the remaining extract by rotary evaporation. The masses of the fish sampled (wet and dry weight) and the lipid extracts are presented in the Appendix to this Chapter.

Lipids were removed by gel permeation chromatography (GPC). Our $3 \mathrm{~cm}$ (o.d.) GPC columns were packed with $100 \mathrm{~g}$ of SX-8 BioBeads $(\sim 45 \mathrm{~cm}$, uncompressed). We used a mobile phase of 1:1 dichloromethane:hexane and collected two fractions. The first fraction $(0-150 \mathrm{~mL})$ that contained $\sim 70 \%$ of the lipids was discarded; the second fraction $(150-400 \mathrm{~mL})$, containing the remaining 
lipids and the molecules of interest, was reduced in volume by rotary evaporation. The GPC procedure was repeated until $<0.5 \mathrm{~g}$ lipids remained in the second fraction. The extract was further purified by silica/alumina column chromatography, as described in previous publications (Pangallo 2008, 2009). All samples were spiked with ${ }^{13}$ C-labelled 1,1-bis-(4-chlorophenyl)-2,2dichloroethene (DDE), and analyzed by gas chromatography/electron capture negative ion mass spectrometry (GC/ECNI-MS).

\subsection{Detection and quantification by GC/ECNI-MS}

Compounds were identified by gas chromatography mass spectrometry using electron capture negative ion mass spectrometry (GC/ECNI-MS) in full scan mode with a previously published method [21]. Briefly, extracts were injected in splitless mode and separated by a J \& W Scientific DB-XLB column (60 $\mathrm{m} \times 0.25 \mathrm{~mm}$ i.d., $0.25 \mu \mathrm{m}$ film thickness) on an Agilent $6890 \mathrm{~N}$ series GC interfaced to an Agilent 5973 network mass selective detector operated in full scan mode.

The position of halogens with an MBP homolog series has yet to be determined. Thus, congeners within a homolog series were designated by their halogen content plus a lower case letter. Details on our nomenclature system are available in our prior publications [3, 21], and consistency between the publications allows results to be easily compared. One exception is 2,3,3',4,4',5,5'-heptabromo-1'-methyl-1,2'-bipyrrole, which will be referred to as 
$\mathrm{Br}_{7-M B P-79 .}$ This is consistent with the nomenclature system suggested by Vetter et al. [2, 22] for MBPs with known structures.

In addition to the brominated and chlorinated congeners, the presence of iodinated congeners was also investigated. No iodinated MBPs were identified. However, the mass spectrometer scanned between $\mathrm{m} / \mathrm{z} 50-750$, thus the molecular ions of any congeners with greater than 4 iodine atoms would not be detected in our analysis. The method was not tested for the stability of iodinated congeners, so the absence from our samples is not conclusive evidence against their presence in this food web.

Four MBPs in our samples were identified and quantified by comparison with a synthetic standard $\left(\mathrm{Br}_{7}-\mathrm{MBP}-79\right)$ or with $\mathrm{MBPs}$ isolated from marine mammal blubber and characterized by high resolution mass spectrometry and nuclear magnetic resonance spectroscopy $\left(\mathrm{MBP}-\mathrm{Br}_{6} \mathrm{Cl}-b, \mathrm{MBP}_{-}-\mathrm{Br}_{6}-b\right.$, and $\mathrm{MBP}-$ $\left.\mathrm{Br}_{5} \mathrm{Cl}-d\right)$. Recent work has established that the response factors of MBP homologs vary within an order of magnitude [23], which allows us to estimate concentrations (to one significant figure) for homologs of the four MBPs for which we have standards. These homologs of these congeners were tentatively identified by their relative retention times and mass spectra. For comparison with the MBPs, 2,2',4,4',5,5'-hexachlorobiphenyl (CB-153) was quantified in our samples by comparison with a synthetic standard. A majority of the blubber concentration data has been published previously [3]; MBP and CB-153 
concentrations in the six additional blubber samples (Table 3) and in the fish and squid samples (Table 2) are presented here.

\subsection{Quality Control of MBP quantification}

The extraction methods and quantification were monitored by running blank samples, determining method detection limits (MDLs) for each MBP and CB-153, and by replicate analyses to determine the overall method errors. No MBPs were detected in blanks and recoveries of $1,3^{\prime}-\mathrm{MBP}-\mathrm{Br}_{7}$ were $99 \pm 19 \%$. MDLs were calculated by analyzing seven replicate samples at $10 \%$ of its original concentration; the MDL is defined as three times the standard deviation of this set of measurements [24]. For details on error calculations, see [3].

\subsection{Stable isotope analysis}

Homogenized Calanus, homogenized whole body tissue (fish and squid), and muscle tissue (marine mammals) were each freeze-dried and ground to a fine powder. Nitrogen isotope analyses were performed on unextracted tissue, but extracted tissue was used for the carbon isotope measurements since our samples included lipid-rich tissues. Lipids are depleted relative to cellular biomass [25], and variability in lipid content can obscure the $\delta^{13} \mathrm{C}$ value of lipidrich tissues [26]. Samples were analyzed in duplicate by isotope ratio mass spectrometry (IRMS) at the Stable Isotope Facility at the University of California at Davis. The stable isotope abundances are expressed in $\delta$ notation, which 
measures the deviation of the sample from a standard reference material in parts per thousand (\%o) according to the equation:

$$
\delta^{15} \mathrm{~N} \text { or } \delta^{13} \mathrm{C}=\left[\left(R_{\text {sample }} / R_{\text {standard }}\right)-1\right] \times 1000
$$

where $R$ is the ratio of the more rare isotope $\left({ }^{15} \mathrm{~N}\right.$ or $\left.{ }^{13} \mathrm{C}\right)$ to the more abundant isotope $\left({ }^{14} \mathrm{~N}\right.$ or ${ }^{12} \mathrm{C}$, respectively). The standard reference materials measured for $R_{\text {standard }}$ were atmospheric $\mathrm{N}_{2}$ and PeeDee Belemnite for nitrogen and carbon, respectively.

\section{Results and Discussion}

\subsection{MBP concentrations}

MBPs were present in far lower concentrations in fish and squid (up to 47 ng g $\mathrm{g}^{-1}$ lipid, Table 2) than odontocetes (up to $3700 \mathrm{ng} \mathrm{g}^{-1}$ lipid; Table 3, and [3]). This is consistent with previous research that found concentrations of 2-7 ng g-1 lipid in the squid species L. pealeii [4]. MBPs were consistently below the MDL in the pinniped samples, with only one exception (MBP-Br 5 Cl- $f$ was just above the MDL for one Harp seal). Among the non-mammalian samples, the squid, herring, and mackerel contained detectable levels of MBPs, though orders of magnitude below the concentrations observed in odontocetes. For the most part, MBPs were below the MDL for Acadian redfish, cod and haddock. There was a large amount of variability in MBP content of hake samples, but red hake had 
lower MBP content than white and silver hake. In contrast, the abundance of CB153 was highest in Acadian redfish, cod, haddock, and the hake species, and lowest in the squid, herring, and mackerel species. CB-153 was also present in the odontocete and most pinniped samples, again at abundances far exceeding those of the fish and squid samples.

The non-mammals did display characteristics that were unique from the marine mammals. Three $\mathrm{MBP}-\mathrm{Br}_{6} \mathrm{Cl}$ isomers $\left(\mathrm{MBP}-\mathrm{Br}_{6} \mathrm{Cl}-\mathrm{c},-d\right.$, and $\left.-e\right)$ were present in the fish and squid that have not previously been identified in mammals from this region (Figure 1). These isomers were present at extremely small, but consistent, abundances; and they elute after $\mathrm{MBP}-\mathrm{Br}_{6} \mathrm{Cl}-b$ and prior to $\mathrm{Br}_{7}-\mathrm{MBP}-79$. Because these congeners were not included in our MDL calculations, we can only report their presence in non-mammals and absence from mammalian blubber samples. It is also noteworthy that fewer MBP congeners were detected in the non-mammalian samples. This is likely because many of the MBP congeners detected in marine mammal blubber were found at very low levels. Thus, even if present in the environment, congeners at trace levels in higher trophic level samples would be well below the detection limits for the less contaminated lower trophic level samples.

\subsection{MBP distributions in non-mammalian samples}

The distribution of MBP congeners in non-mammals is similar to that in marine mammals. The most abundant MBP in a majority of the samples was 
MBP-Br${ }_{6} \mathrm{Cl}-b$ (Figure 2), which is consistent with previous studies of MBPs in animals from this region $[15,27,28]$. In five of the fish and squid samples MBP$\mathrm{Br}_{5} \mathrm{Cl}-d$ was the most abundant congener. Aside from the dominance of these congeners, there is a large degree of variability in the abundances of MBPs congeners between species, but within species the patterns are similar. There is no separation geographically or vertically between species with and without MBPs (Table 2 and [29-38]). Therefore, MBPs absence from some species implies that these have a better ability to metabolize or otherwise excrete MBPs, or that MBPs are not present in their diets. This is in contrast to CB-153, which is present in every species, reflecting the ubiquity and persistence of POPs in the environment [39].

\subsection{Stable isotope results}

Both carbon and nitrogen stable isotope ratios were measured for every sample and there was excellent agreement between duplicates (Table 4). The $\delta^{15} \mathrm{~N}$ varied from $+8.01 \%$ o for Calanus $s p$. to $10.4 \pm 0.9 \%$ or squid, $12.6 \pm 0.9$ for fish, and $14.2 \pm 1.2 \%$ or mammals. There was more overlap and a smaller range for the $\delta^{13} \mathrm{C}$ values (-20.4\%o to $-17.5 \%$ o).

\subsection{Trophic level assessment by $\delta^{15} \mathrm{~N}$}

In order to provide evidence that MBPs biomagnify, the trophic position of each sampled organism must be accurately assigned. Photosynthetic organisms occupy TL1, obligate herbivores are at TL2, and carnivores inhabit 
2TL3. However, many consumers are omnivores, preying upon more than one trophic level, and trophic positions are rarely delineated easily. Trophic level has traditionally been assessed by observation of foraging behavior, and/or examination of stomach and scat contents of the organisms of interest. These methods are problematic in that they only give a snapshot of possible predatorprey relationships, and are inconvenient for examining a marine food web due to difficulties in sampling [40]. More recently, stable nitrogen isotopic compositions have been used to examine the bioaccumulation of POPs [40,41] and HNPs [12] within marine food webs. This method takes advantage of nitrogen isotope fractionation during heterotrophy and respiration. For every step up in trophic level, the nitrogen isotopic composition $\left(\delta^{15} \mathrm{~N}\right)$ increases. Unlike identifying stomach contents, it integrates over the many different prey consumed, as well as over time [42]. Additionally, this method can account for dimorphism within a species, be it gender or age related.

We used a calculation modified from Hobson et al. (1995) to determine the trophic levels of our samples:

$$
\mathrm{TL}_{\text {sample }}=2+\left(\frac{\delta^{15} \mathrm{~N}_{\text {sample }}-\delta^{15} \mathrm{~N}_{\text {Calanus }}}{3.6 \%}\right)
$$

where $T L_{\text {sample }}$ is the trophic level of the sample organism, $\delta{ }^{15} \mathrm{~N}_{\text {Calanus }}$ is the nitrogen isotope value of the Calanus sample collected $(8.01 \%$ ), and $3.6 \%$ is the trophic enrichment factor (Fry, 1988). C. finmarchicus species are opportunistic 
omnivores, but their trophic level is generally around 2 [43]. Thus, our TLsample is an estimate with uncertainty introduced by both the trophic enrichment factor $(3.6 \%)$ and the baseline value for TL2 $\left(\delta^{15} \mathrm{~N}=8.01 \%\right)$. This uncertainty does not affect our determination of biomagnification, which is based on a relative, not absolute, determination of trophic level. The trophic level calculated for fish, squid and mammal samples ranged from 2.4-4.4 (Table 4); thus, we analyzed animals from 3 different trophic levels.

\subsection{Evidence for biomagnification of $M B P s$}

In general, $\mathrm{MBP}$ concentrations were found to increase with trophic level (Figure 3), which suggests that MBPs may biomagnify in this food web (samples $<$ MDL were not included). At the $95 \%$ significance level, the slope of the linear regression was significantly larger than zero for $\mathrm{Br}_{7}-\mathrm{MBP}-79, \mathrm{MBP}-\mathrm{Br}_{6} \mathrm{Cl}-b$, MBP$\mathrm{Br}_{6}-b, \mathrm{MBP}-\mathrm{Br}{ }_{5} \mathrm{Cl}-d$, and MBP-Br $5 \mathrm{Cl}_{-}$(Table 5). Biomagnification cannot be confirmed until it is clear this concentration increase results from a trophic transfer process. Our measurements show that CB-153 also appears to biomagnify in this food web.

Food web magnification factors (FWMFs) are used to compare the magnitude of biomagnification and are calculated using the slope of the linear regression of the natural $\log$ of the concentration versus trophic level [41]:

$$
\mathrm{FWMF}=e^{\text {slope }}
$$


(Only samples above the detection limit were used in the calculation of the slope.) The FWMFs calculated for the MBPs are quite high (Table 5), ranging from 15 to 82, while CB-153 has the lowest calculated FMWF (9.0). For comparison, FWMFs for DMBPs in the Arctic vary from 5.2 to 14.6 [12], and POPs also tend to have FWMFs in this range [41, 44, 45]. Polybrominated diphenyl ethers (PBDEs) containing 3-7 bromines have FWMFs that are much lower ( 1.5) [46]. However, PBDE biomagnification factors (concentration in organism relative to the concentration in diet, equivalent to the FWMF but for only two trophic levels) have been shown to extend up to 76 [47]; these values are consistent with our findings. Numerical modeling investigations of POPs in food webs that include mammals demonstrate biomagnification factors of up to 49 [48]. Additionally, the value calculated for CB-153 agrees well with a previous FWMF calculation of this compound in a marine food web (9.8) [41]. It is important to note that because of the exponential relationship between slope and the FWMF, small variations in the slope result in large changes in the FWMF value [44]. For our compounds, high FWMFs are associated with fewer data points and greater uncertainty (Table 5). Regardless, it is clear that MBPs have FWMFs greater than 1, which supports the hypothesis that MBPs biomagnify in this marine food web. 


\subsection{Pinniped anomaly}

Although MBPs and CB-153 are both present in odontocetes and nonmammals, there are distinct differences in their abundances in pinnipeds. Pinnipeds have much lower body burdens of MBPs than would be expected for their trophic level, yet levels of CB-153 are comparable to those of odontocetes (Tables 3 and 4, and [3]). Previous studies have seen this same discrepancy between POPs and naturally produced compounds in pinnipeds $[1,12,13]$. The cause may be in pinniped diets, and/or in their ability to metabolize HNPs. To examine if foraging preference is responsible for the difference in MBP body burdens, we targeted prey species of the mammals included in this study for inclusion in our analyses.

The marine mammals consume a wide variety of prey [49] and their diets likely contain a similar spectrum of the local prey species. However, studies also indicate that they have distinct prey preferences, as observed from foraging behavior, and stomach and scat contents. The dolphins, L. acutus and D. delphis, are known to focus their feeding on squid, mackerel, silver hake, and herring [49, 50]. Harbor porpoises, P. phocoena, have similar preferences, targeting squid, herring, silver hake, and red/white hake [51,52]. Squid make up a large portion of pilot whales' diets ( 75\%, [49]), with the remaining $25 \%$ from pelagic fish such as mackerel and, to a lesser extent, cod and hake [53]. In contrast to the odontocetes, both pinniped species in our study consume relatively small 
amounts of squid $(5 \%,[49])$. Harp seals ( $P$. groenlandica) preferentially target polar cod, capelin, amphipods, halibut and herring [54-56]. Gray seals $(H$. grypus) focus on red/white hake, winter flounder, skate, cusk eel, and sand lance [57].

Although we were unable to analyze all prey species of interest, it is noteworthy that mammals with high MBP body burdens preferentially consume large quantities of the prey species that have high MBP concentrations: squid, mackerel and herring. Pinnipeds also consume herring and squid, and therefore do consume MBP-rich prey, yet MBPs are generally far below detection limits in pinniped blubber. Thus, prey preference is not sufficient to explain the dramatic differences between odontocete and pinniped MBP concentrations.

Differences between odontocetes and pinnipeds in the blubber structure may also play a role. Odontocetes have more highly stratified blubber, resulting in outer layers being much colder and less metabolically active. Pinniped blubber, however, is far less stratified, and thus the depth of the blubber is metabolically active. Thus, contaminants in pinniped blubber may be more available for metabolism and removal from the body, while contaminants in odontocete blubber would likely have longer lifetimes.

The presence of CB-153 in blubber of both groups of marine mammals, however, suggests that blubber morphology alone cannot explain the differences between MBPs and CB-153. This is consistent with previous research showing 
that pinnipeds with low body burdens of HNPs still contain high concentrations of POPs $[1,3,12,13]$. As a result, the data presented here strengthens the hypothesis originally put forward by Tittlemier et al. [12], that pinnipeds have an enhanced capability to degrade HNPs relative to odontocetes. If this is the case, then pinniped enzymes used in HNP metabolism cannot adapt, or have not yet adapted, to degrade CB-153 as efficiently as MBPs. Previous investigations into metabolism of PCB congeners have identified that differences in cytochrome P450 enzymes in cetaceans and phocid seals can help explain differences in the metabolism of different types of PCB congeners between these mammalian orders [58]. Phocid seals have a greater ability to metabolize PCB congeners with vicinal $\mathrm{H}$ atoms ( $\mathrm{H}$ atoms adjacent to each other on an aromatic ring system) in the ortho- and meta-positions, but cetaceans have a greater ability to metabolize PCB congeners with vicinal hydrogens in the meta- and para- positions [58]. However, since these differences relate to the position of vicinal $\mathrm{H}$ atoms, and the MBPs investigated here do not contain vicinal hydrogen atoms, the difference in P450 enzymes between cetaceans and phocid seals cannot explain our results. Thus, investigating differences between the enzymes responsible for MBP metabolism in both groups of marine mammals would provide valuable information on the metabolism of perhalogenated compounds and/or compounds with no vicinal $\mathrm{H}$ atoms.

\subsection{Differences between MBPs and CB-153}


The concentrations of both MBPs and CB-153 both increase with increasing trophic level. On closer examination, however, differences between the PCB and the natural products are apparent. MBPs strongly correlate $(\rho>0.9)$ with each other; the correlation of MBPs with CB-153, while still statistically significant, is weaker (Figure 4, Table 6). (Please note, although the data appear to fall within two groupings, all of the assumptions to statistically test for correlation are met within this data set.) This is consistent with a previous study by Stapleton et al. [59] that showed significant correlations between HNPs, but not between HNPs and POPs. The exception is MBP-Br $5 \mathrm{Cl}-e$, which is not as well correlated with either the MBPs or CB-153. This is likely caused by the large error term for in the quantification of this compound (24\%), which is much larger than those for the other MBP congeners and CB-153 (Tables 2 and 3, and [3]). For these analyses, both compounds are required to be above the MDL, therefore the pinniped samples were excluded and cannot explain this variation. In fact, the pattern is present in both marine mammals and in fish and squid.

In the non-mammalian samples the difference in correlation strength can be partially explained by examining the stable carbon isotope ratios. A wellestablished relationship exists between stable carbon isotope ratios and carbon source: the pelagic food web is depleted $(-22 \%)$ relative to that of the inshore/benthic food web (-17\%) [60-63]. CB-153 is highest in non-mammalian samples that are the most enriched in ${ }^{13} \mathrm{C}$ and lowest in those that are most ${ }^{13} \mathrm{C}$ 
depleted (Figure 5). This pattern is consistent with a terrestrial source of the anthropogenic PCB. In the non-mammalians samples there are two data points for CB-153 that are much higher than those of the other fish, these are for the cod samples. These data points may have disproportionate influence on this trend, but are valid data points in themselves. Thus, we include these points for analysis, but the limitations of this data should be noted. There is no similar relationship between $\delta^{13} \mathrm{C}$ and the MBPs, which is not surprising since they have no terrestrial source. The relationship between $\delta^{13} \mathrm{C}$ and CB-153 is absent in the mammal samples (Figure 5), which reflects mammals diets of both pelagic and benthic prey [49]. Their mixed diets are also evident in their $\delta^{13} \mathrm{C}$ values, which span a more narrow range (relative to non-mammalian samples) from $-19.1 \%$ o to $-17.5 \%$ (Table 4$)$.

By measuring an increase in the lipid-normalized MBP concentrations with increasing trophic level, we present strong evidence for the biomagnification of another class of marine natural products. Thus, there is greater confidence in the use of MBPs as natural analogues for POPs in marine ecosystems. MBPs are present in various fish and squid species, though at much lower concentrations than those found in odontocete blubber. The presence of MBPs in pinniped prey and absence in pinniped blubber suggests that these mammals share dietary exposure to MBPs with odontocetes, but have an enhanced ability to metabolize these natural products. Finally, although both 
MBPs and CB-153 biomagnify in this food web, MBPs do not display the same coupling to $\delta^{13} \mathrm{C}$ as CB-153, which is a further indication of their natural origins.

\section{Acknowledgements}

I thank the Ecosystems Surveys Branch of the NOAA Fisheries Northeast Fisheries Science Center and the officers and crew of the NOAA research vessel Albatross VI for their assistance in securing biological samples utilized during this study. I would also like to thank the Cape Cod Stranding Network for their assistance in acquiring samples. I am grateful to Daniel Montluçon and Sean Sylva for their dedicated assistance with laboratory instrumentation. I am extremely grateful to Matthew Poyton for his assistance with processing the mammal samples. And I thank Sheryl Tittlemier and Mark Hahn who provided valuable feedback. This work was supported by The Seaver Institute, the J. Seward Johnson Fund, The Virginia Walker Smith Fund, the Ocean Ventures Fund and the National Science Foundation (OCE-0550486, and the Graduate Research Fellowship Program). 


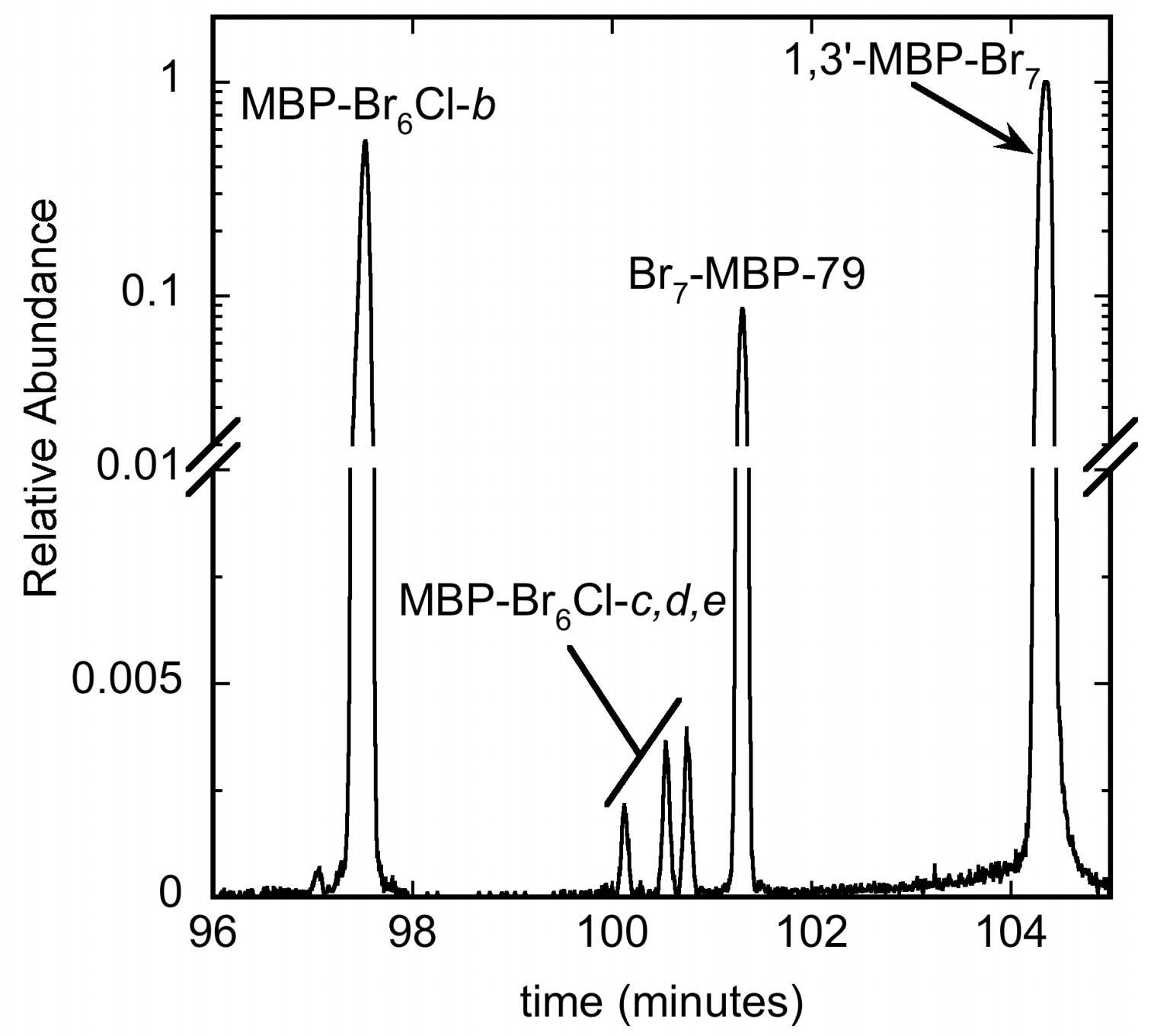

Figure 1. The partial summed ion chromatogram (ions $\pm 0.5: 575.7,619.7,653.7$, and 697.7 ) of the Silver Hake 165 extract. The break in the $\mathrm{y}$-axis highlights the newly identified hexabromochloro-MBP congeners, $\mathrm{MBP}-\mathrm{Br}_{6} \mathrm{Cl}-\mathrm{c}, \mathrm{MBP}-\mathrm{Br} 6 \mathrm{Cl}-d$, and $\mathrm{MBP}-\mathrm{Br} 6 \mathrm{Cl}-e$. Also identified are $\mathrm{MBP}-\mathrm{Br}_{6} \mathrm{Cl}-b$, which is the most abundant $\mathrm{MBP}$ in this sample, $\mathrm{MBP}-\mathrm{Br}_{7}$, and our internal standard, 1,3'-MBP-Br 7 . 


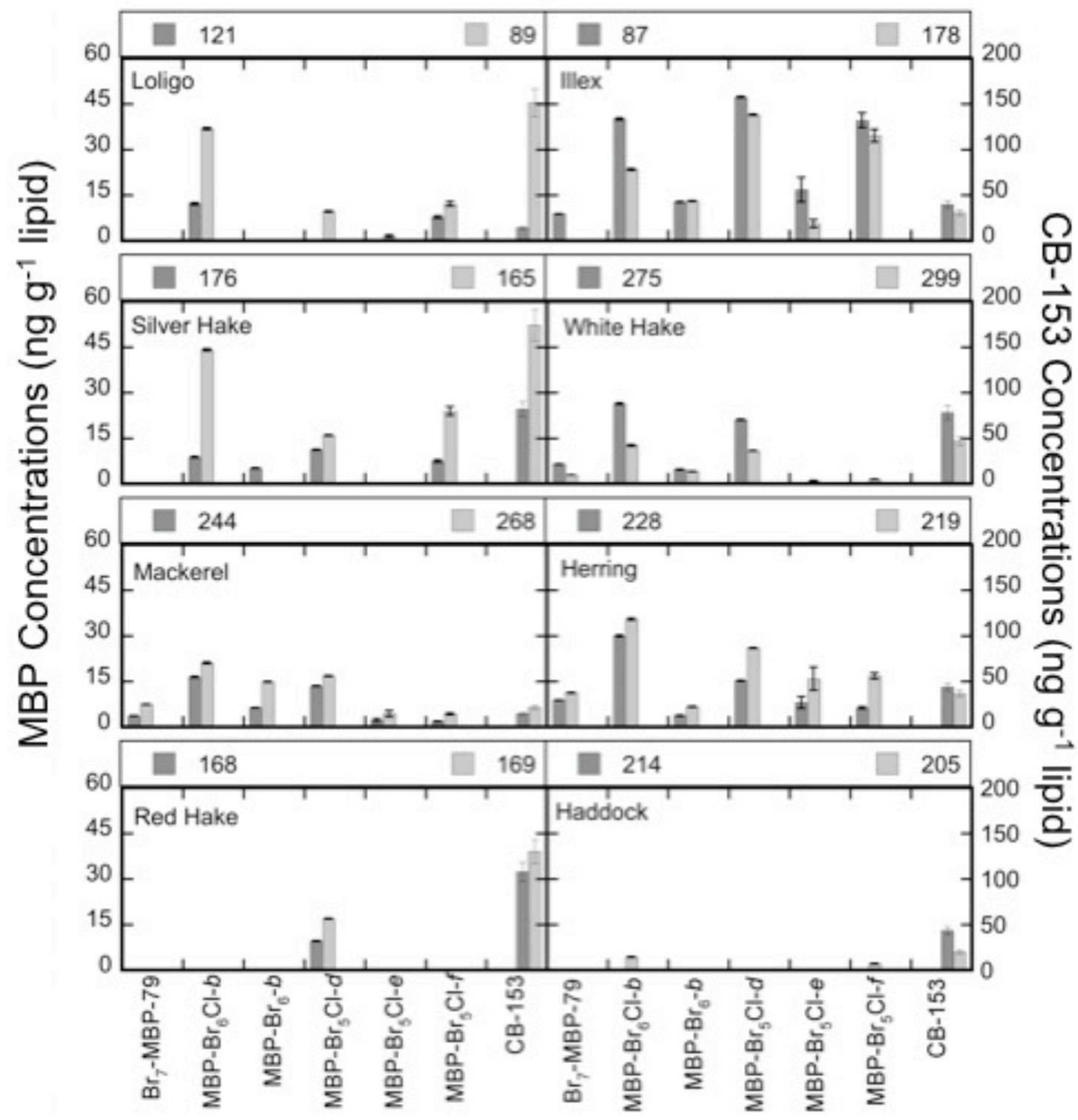

Figure 2. The distribution of MBPs and CB-153 in select non-mammalian samples analyzed in this study (species for which no MBPs were detected - cod and Acadian redfish - are excluded). MBPs are plotted on the left hand axis, and CB-153 concentrations are plotted on the right hand axis. Note the consistent presence of either $\mathrm{MBP}-\mathrm{Br}_{6} \mathrm{Cl}-b$ and $\mathrm{MBP}-\mathrm{Br}_{5} \mathrm{Cl}-d$ in each sample. 


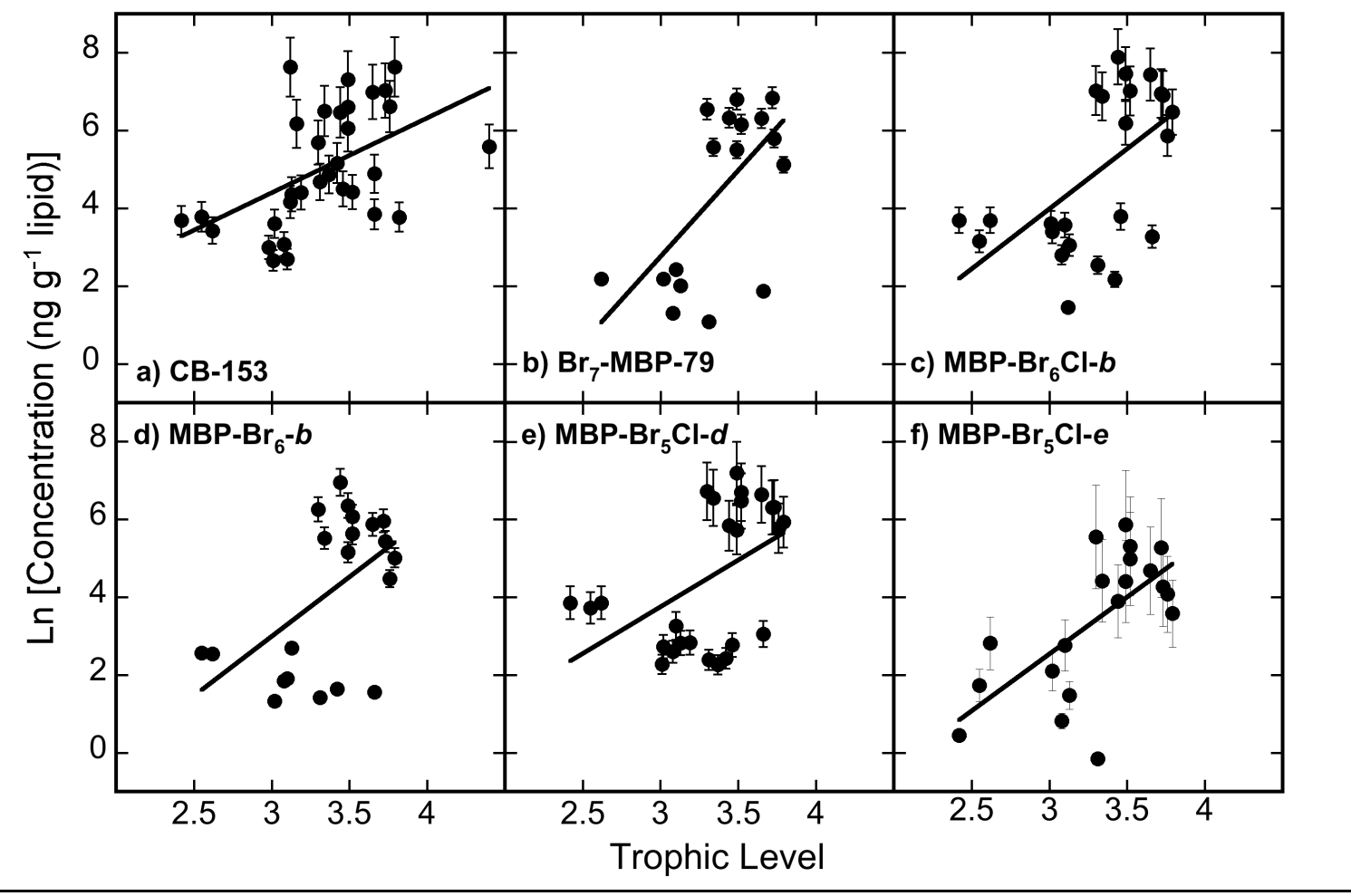

Figure 3. Biomagnification of MBPs and CB-153 is evident by the increase in (lipid-normalized) concentration with increasing trophic level. Here we present the compounds that biomagnify (slopes significantly greater than 0) (a) CB-153, (b) $\mathrm{Br}_{7}-\mathrm{MBP}-79$, (c) $\mathrm{MBP}_{-}-\mathrm{Br}_{6} \mathrm{Cl}-b$, (d) $\mathrm{MBP}_{-} \mathrm{Br}_{6}-b$, (e) $\mathrm{MBP}-\mathrm{Br}_{5} \mathrm{Cl}-d$, and (f) $\mathrm{MBP}-\mathrm{Br}_{5} \mathrm{Cl}-e$. Regression equations and statistical significance are presented in Table 5. 


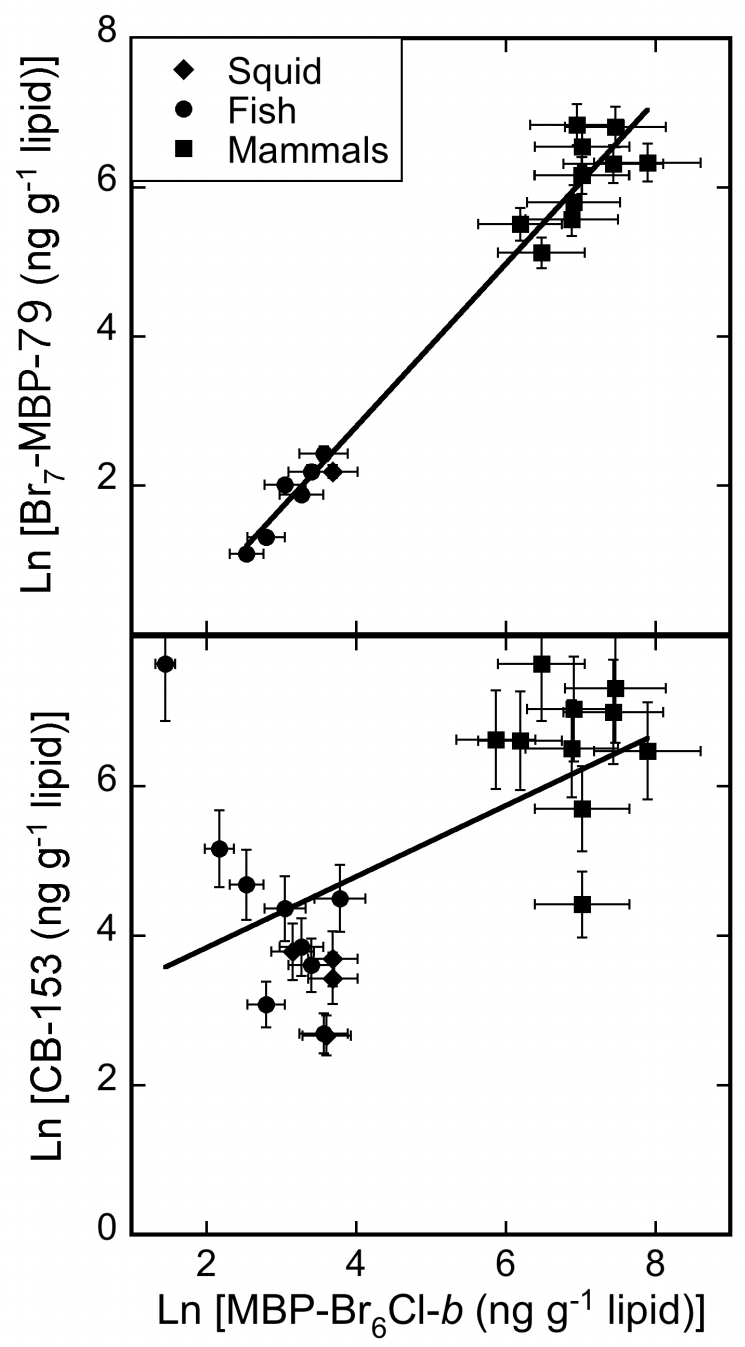

Figure 4. A stronger correlation was found between MBP congeners (top panel) than was found between the MBPs and CB-153 (lower panel). 


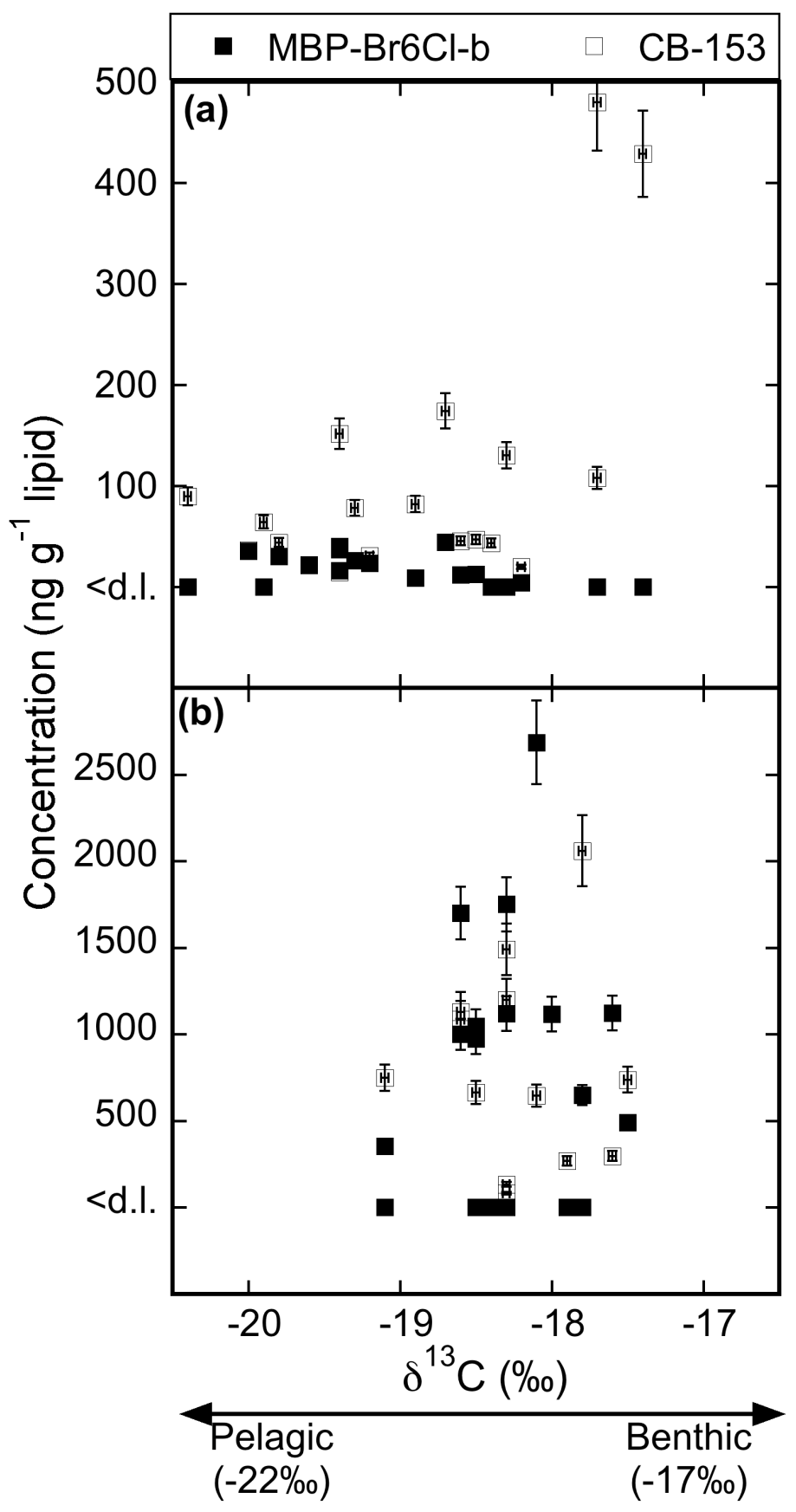

Figure 5. CB-153 and $\mathrm{MBP}-\mathrm{Br}_{6} \mathrm{Cl}-b$ vs. $\delta^{13} \mathrm{C}$ in (a) non-mammals and (b) mammals. More enriched (more positive) stable carbon isotope ratios are indicative of a benthic origin $(-17 \%$ ) , and less enriched (more negative) values are indicative of pelagic origin $(-22 \%)$ [63] 
Table 1. Description of mammals at stranding for the six mammals included in this study and not published previously. For the other mammals in this study, please see [3].

\begin{tabular}{|lccccc|}
\hline CCSN ID number & gender & age & length $\mathbf{( c m )}$ & weight $\mathbf{( k g )}$ & condition \\
\hline CCSN06-019La & male & adult & 280 & 116 & robust \\
CCSN04-218Dd & male & calf & 139.2 & 32 & robust \\
CCSN06-144Dd & male & not recorded & 187 & not recorded & robust \\
CCSN07-074Dd & female & adult & 201.1 & 99.8 & robust \\
CCSN07-066Pg & female & juvenile & 108 & 25 & thin \\
CCSN07-076Pg & female & adult & 104 & 63.5 & thin \\
\hline
\end{tabular}


Table 2. Lipid-normalized whole body concentrations (ng g-1 lipid) of quantifiable MBPs and CB-153 in non-mammilian samples. The three-digit number in the sample ID is the tow from which the sample was collected; <d.l. indicates that a compound was lower than the detection limit in a sample.

\begin{tabular}{|c|c|c|c|c|c|c|c|}
\hline $\begin{array}{l}\text { Sample ID } \\
\qquad M D L\left(n g \mu L^{-1}\right)\end{array}$ & $\begin{array}{c}\mathrm{Br}_{7}-\mathrm{MBP}-79 \\
\pm 4 \% \\
2.0\end{array}$ & $\begin{array}{c}\mathrm{MBP}-\mathrm{Br}_{6} \mathrm{Cl}-\mathrm{b} \\
\pm 9 \% \\
2.2\end{array}$ & $\begin{array}{c}\text { MBP-Br }{ }_{6}-b \\
\pm 5 \% \\
.87\end{array}$ & $\begin{array}{c}\text { MBP-Br }{ }_{5} \mathrm{Cl}-\mathrm{d} \\
\pm 6 \% \\
1.1\end{array}$ & $\begin{array}{c}\mathrm{MBP}-\mathrm{Br}_{5} \mathrm{Cl}-\mathrm{e} \\
\pm 24 \% \\
0.6\end{array}$ & $\begin{array}{c}\mathrm{MBP}-\mathrm{Br}_{5} \mathrm{Cl}-\mathrm{f} \\
\pm 6 \% \\
0.2\end{array}$ & $\begin{array}{c}\text { CB-153 } \\
\pm 10 \% \\
0.26\end{array}$ \\
\hline Loligo 121 & $<$ d.I. & 12 & $<$ d.I. & $<$ d.I. & $<$ d.I. & 8 & 46 \\
\hline Loligo 89 & $<$ d.I. & 37 & $<$ d.I. & 9.7 & 2 & 10 & 150 \\
\hline Illex 87 & 8.9 & 40 & 13 & 47 & 20 & 40 & 40 \\
\hline Illex 178 & $<$ d.l. & 23 & 13 & 41 & 6 & 30 & 31 \\
\hline Herring 228 & 8.9 & 30 & 3.8 & 15 & 8 & 6 & 44 \\
\hline Herring 219 & 11 & 36 & 6.7 & 26 & 20 & 20 & 37 \\
\hline Mackerel 244 & 3.7 & 16 & 6.3 & 13 & 2 & 2 & 15 \\
\hline Mackerel 268 & 7.5 & 21 & 15 & 17 & 4 & 4 & 22 \\
\hline White Hake 275 & 6.5 & 26 & 4.8 & 21 & $<$ d.I. & $<$ d.I. & 78 \\
\hline White Hake 299 & 3.0 & 13 & 4.1 & 11 & .9 & 1 & 47 \\
\hline Red Hake 168 & $<$ d.I. & $<$ d.I. & $<$ d.I. & 9.6 & $<$ d.I. & $<$ d.I. & 110 \\
\hline Red Hake 169 & $<$ d.I. & $<$ d.I. & $<$ d.I. & 17 & $<$ d.I. & $<$ d.l. & 130 \\
\hline Silver Hake 176 & $<$ d.I. & 8.8 & 5.1 & 11 & $<$ d.I. & 8 & 82 \\
\hline Silver Hake 165 & $<$ d.l. & 44 & $<$ d.I. & 16 & $<$ d.l. & 20 & 170 \\
\hline Acadian Redfish 258 & $<$ d.I. & $<$ d.I. & $<$ d.I. & $<$ d.I. & $<$ d.I. & $<$ d.I. & 90 \\
\hline Acadian Redfish 257 & $<$ d.I. & $<$ d.I. & $<$ d.I. & $<$ d.I. & $<$ d.I. & $<$ d.I. & 64 \\
\hline Cod 326 & $<$ d.I. & $<$ d.I. & $<$ d.I. & $<$ d.I. & $<$ d.I. & $<$ d.I. & 480 \\
\hline Cod 324 & $<$ d.I. & $<$ d.I. & $<$ d.I. & $<$ d.I. & $<$ d.I. & $<$ d.I. & 430 \\
\hline Haddock 214 & $<$ d.I. & $<$ d.I. & $<$ d.I. & $<$ d.I. & $<$ d.I. & $<$ d.I. & 43 \\
\hline Haddock 205 & $<$ d.I. & 4.3 & $<$ d.I. & $<$ d.I. & $<$ d.I. & 2 & 20 \\
\hline
\end{tabular}


Table 3. MBP and CB-153 concentrations (ng g-1 lipid) in the blubber of mammals in this study not previously reported. For the other mammals in this study, please see [3].

\begin{tabular}{|c|c|c|c|c|c|c|c|c|}
\hline ID number & $\begin{array}{c}\text { Species } \\
L\left(n g g^{-1} \text { lipid }\right)\end{array}$ & $\begin{array}{c}\mathrm{Br}_{7}-\mathrm{MBP}-79 \\
\pm 4 \% \\
130\end{array}$ & $\begin{array}{c}\mathrm{MBP}-\mathrm{Br}_{6} \mathrm{Cl}-\mathrm{a} \\
\pm 6 \% \\
0.7\end{array}$ & $\begin{array}{c}\mathrm{MBP}-\mathrm{Br}_{6} \mathrm{Cl}-\mathrm{b} \\
\pm 9 \% \\
150\end{array}$ & $\begin{array}{c}{\mathrm{MBP}-\mathrm{Br}_{6}-\mathrm{a}} \\
\pm 6 \% \\
3\end{array}$ & $\begin{array}{c}\mathrm{MBP}-\mathrm{Br}_{6}-\mathrm{b} \\
\pm 5 \% \\
59\end{array}$ & $\begin{array}{c}{\mathrm{MBP}-\mathrm{Br}_{6}-\mathrm{C}} \\
\pm 29 \% \\
3\end{array}$ & $\begin{array}{c}\mathrm{MBP}-\mathrm{Br}_{6}-\mathrm{d} \\
\pm 11 \% \\
2\end{array}$ \\
\hline CCSN06-019La & L. acutus & 940 & 13 & 1000 & 30 & 390 & 40 & 40 \\
\hline CCSN04-218Dd & D. delphis & 68 & $<$ d.I. & 350 & $<$ d.I. & 88 & $<$ d.I. & 5 \\
\hline CCSN06-144Dd & D. delphis & 470 & 4 & 1100 & 30 & 430 & 20 & 4 \\
\hline CCSN07-074Dd & D. delphis & $<$ d.I. & $<$ d.I. & $<$ d.I. & $<$ d.I. & $<$ d.I. & $<$ d.I & $<$ d.I. \\
\hline CCSN07-066Pg & $\begin{array}{c}P . \\
\text { groenlandica }\end{array}$ & $<$ d.I. & $<$ d.I. & $<$ d.I. & $<$ d.I. & $<$ d.I. & $<$ d.I. & $<$ d.I. \\
\hline CCSN07-076Pg & $\begin{array}{c}P . \\
\text { groenlandica }\end{array}$ & $<$ d.I. & $<$ d.I. & $<$ d.I. & $<$ d.I. & $<$ d.I. & $<$ d.I. & $<$ d.I. \\
\hline
\end{tabular}

Table 3. (continued)

\begin{tabular}{|c|c|c|c|c|c|c|c|}
\hline CCSN ID number & $\begin{array}{c}\text { MBP-Br }{ }_{5} \mathrm{Cl}-\mathrm{a} \\
\pm 4 \%\end{array}$ & $\begin{array}{c}\text { MBP- }-\mathrm{Br}_{5} \mathrm{Cl}-b \\
\pm 7 \%\end{array}$ & $\begin{array}{c}\mathrm{MBP}-\mathrm{Br}_{5} \mathrm{Cl}-\mathrm{C} \\
\pm 7 \%\end{array}$ & $\begin{array}{c}\text { MBP-Br }{ }_{5} \mathrm{Cl}-d \\
\pm 6 \%\end{array}$ & $\begin{array}{c}\text { MBP-Br }{ }_{5} \mathrm{Cl}-\mathrm{e} \\
\pm 24 \%\end{array}$ & $\begin{array}{c}\text { MBP-Br }{ }_{5} \mathrm{Cl}-f \\
\pm 6 \%\end{array}$ & $\begin{array}{l}\text { CB-153 } \\
\pm 10 \%\end{array}$ \\
\hline$M D L$ (ng $g^{-1}$ lipid) & 8 & 2 & 1 & 73 & 40 & 10 & 62 \\
\hline CCSN06-019La & 51 & 7 & 9 & 550 & 200 & 200 & not recorded \\
\hline CCSN04-218Dd & 20 & 3 & 1 & 320 & 60 & 100 & 750 \\
\hline CCSN06-144Dd & 70 & 10 & 10 & 810 & 200 & 300 & not recorded \\
\hline CCSN07-074Dd & $<$ d.I. & $<$ d.I. & $<$ d.I. & $<$ d.I. & $<$ d.I. & $<$ d.I. & 83 \\
\hline CCSN07-066Pg & $<$ d.I. & $<$ d.I. & $<$ d.l. & $<$ d.I. & $<$ d.I. & $<$ d.I. & not recorded \\
\hline CCSN07-076Pg & $<$ d.I. & $<$ d.I. & $<$ d.I. & $<$ d.I. & $<$ d.I. & 26 & not recorded \\
\hline
\end{tabular}


Table 4. The stable isotopic ratios (the average of duplicate analyses) and the calculated trophic levels are shown for all samples. *We assume that our Calanus sample occupies TL2.

\begin{tabular}{|c|c|c|c|c|}
\hline Sample ID & Species (Common name) & $\delta^{15} \mathrm{~N}(\%)$ & $\delta^{13} C(\%)$ & TL \\
\hline Calanus sp. & Zooplankton & 8.01 & -19.8 & $2.0^{*}$ \\
\hline Loligo 121 & Longfin inshore squid & 11.6 & -18.6 & 3.0 \\
\hline Loligo 89 & Longfin inshore squid & 9.53 & -19.4 & 2.4 \\
\hline Illex 87 & Northern shortfin squid & 10.3 & -19.4 & 2.6 \\
\hline Illex 178 & Northern shortfin squid & 10.0 & -19.2 & 2.6 \\
\hline Herring 228 & Atlantic herring & 11.7 & -19.8 & 3.0 \\
\hline Herring 219 & Atlantic herring & 12.0 & -20.0 & 3.1 \\
\hline Mackerel 244 & Atlantic mackerel & 11.9 & -19.4 & 3.1 \\
\hline Mackerel 268 & Atlantic mackerel & 12.1 & -19.6 & 3.1 \\
\hline White Hake 275 & White Hake & 14.0 & -19.3 & 3.7 \\
\hline White Hake 299 & White Hake & 12.7 & -18.5 & 3.3 \\
\hline Red Hake 168 & Red Hake & 12.9 & -17.7 & 3.4 \\
\hline Red Hake 169 & Red Hake & 12.3 & -18.3 & 3.2 \\
\hline Silver Hake 176 & Silver Hake & 13.1 & -18.9 & 3.4 \\
\hline Silver Hake 165 & Silver Hake & 13.3 & -18.7 & 3.5 \\
\hline Acadian Redfish 258 & Acadian Redfish & 12.0 & -20.4 & 3.1 \\
\hline Acadian Redfish 257 & Acadian Redfish & 12.2 & -19.9 & 3.2 \\
\hline Cod 326 & Cod & 13.4 & -17.7 & 3.5 \\
\hline Cod 324 & Cod & 14.6 & -17.4 & 3.8 \\
\hline Haddock 214 & Haddock & 11.5 & -18.4 & 3.0 \\
\hline Haddock 205 & Haddock & 12.0 & -18.2 & 3.1 \\
\hline CCSN07-023La & Atlantic white-sided dolphin & 14.5 & -17.8 & 3.8 \\
\hline CCSN06-019La & Atlantic white-sided dolphin & 14.2 & -18.5 & 3.7 \\
\hline CCSN04-218Dd & Common dolphin & 14.3 & -19.1 & 3.8 \\
\hline CCSN07-115Dd & Common dolphin & 13.4 & -18.3 & 3.5 \\
\hline CCSN07-109Dd & Common dolphin & 12.8 & -18.5 & 3.3 \\
\hline CCSN06-119La & Atlantic white-sided dolphin & 14.2 & -18.6 & 3.7 \\
\hline CCSN06-144Dd & Common dolphin & 13.5 & -18.0 & 3.5 \\
\hline CCSN06-263Dd & Common dolphin & 12.7 & -17.6 & 3.3 \\
\hline CCSN06-022La & Atlantic white-sided dolphin & 14.0 & -18.6 & 3.7 \\
\hline CCSN07-040Dd & Common dolphin & 13.2 & -18.1 & 3.4 \\
\hline CCSN07-074Dd & Common dolphin & 13.5 & -18.3 & 3.5 \\
\hline D07041 & Harbor porpoise & 13.5 & -18.3 & 3.5 \\
\hline CCSN07-022Gm & Pilot whale & 13.4 & -17.5 & 3.5 \\
\hline CCSN07-116Pg & Harp seal & 15.6 & -18.5 & 4.1 \\
\hline CCSN07-066Pg & Harp seal & 13.6 & -18.4 & 3.6 \\
\hline CCSN07-129Hg & Gray seal & 16.6 & -17.9 & 4.4 \\
\hline D08742 & Gray seal & 16.7 & -17.8 & 4.4 \\
\hline CCSN07-080Pg & Harp seal & 15.1 & -19.1 & 4.0 \\
\hline CCSN07-084Pg & Harp seal & 14.0 & -18.3 & 3.7 \\
\hline CCSN07-076Pg & Harp seal & 15.4 & -18.3 & 4.1 \\
\hline
\end{tabular}


Table 5. The number of data points $(n)$, regression equation, significance level ( $p$-value), food web magnification factor (FWMF) and $\log \mathrm{K}_{\mathrm{ow}} \mathrm{s}$ are given for each compound in Figure 1.

\begin{tabular}{|c|c|c|c|c|c|}
\hline Compound & $n$ & $\begin{array}{c}\text { Regression Equation } \\
y=\end{array}$ & $p$-value & FWMF & $\log K_{o w}{ }^{b}$ \\
\hline $\mathrm{Br}_{7}-\mathrm{MBP}-79$ & 18 & $4.4 x-11$ & .006 & 82 & 8.3 \\
\hline $\mathrm{MBP}-\mathrm{Br}_{6} \mathrm{Cl}-b$ & 25 & $3.2 x-5.7$ & .003 & 25 & 8.1 \\
\hline $\mathrm{MBP}-\mathrm{Br}_{6}-b$ & 21 & $3.1 x-6.2$ & .014 & 22 & 7.4 \\
\hline $\mathrm{MBP}-\mathrm{Br}_{5} \mathrm{Cl}-\mathrm{d}$ & 25 & $2.7 x-4.4$ & .005 & 15 & 7.2 \\
\hline MBP-Br ${ }_{5} \mathrm{Cl}-\mathrm{e}$ & 20 & $2.9 x-6.3$ & .002 & 18 & 7.2 \\
\hline CB-153 & 33 & $2.2 x-2.1$ & $<.001$ & 9.0 & 6.9 \\
\hline
\end{tabular}

${ }^{a}$ From [4]. 
Table 6. Correlation matrix for the compounds in Table 3, calculated with SPSS, PASW® Statistics. The Pearson correlation coefficient $(\rho)$, significance level ( $p$-value) and number of data points $(n)$ are presented.

\begin{tabular}{|c|c|c|c|c|c|c|c|}
\hline & & $\mathrm{MBP}-\mathrm{Br}_{7}$ & $\mathrm{MBP}-\mathrm{Br}_{6} \mathrm{Cl}-b$ & $\mathrm{MBP}-\mathrm{Br}_{6}-b$ & $\mathrm{MBP}-\mathrm{Br}_{5} \mathrm{Cl}-\mathrm{d}$ & $\mathrm{MBP}-\mathrm{Br}_{5} \mathrm{Cl}-\mathrm{e}$ & CB-153 \\
\hline $\mathrm{MBP}-\mathrm{Br}_{6} \mathrm{Cl}-b$ & $\begin{array}{l}\rho \\
p \text {-value (1-tailed) } \\
n\end{array}$ & $\begin{array}{r}.987 \\
.000 \\
18\end{array}$ & $\begin{array}{r}1 \\
25\end{array}$ & & & & \\
\hline $\mathrm{MBP}-\mathrm{Br}_{6}-b$ & $\begin{array}{l}\rho \\
p \text {-value (1-tailed) } \\
n\end{array}$ & $\begin{array}{r}.977 \\
.000 \\
18 \\
\end{array}$ & $\begin{array}{r}.978 \\
.000 \\
21 \\
\end{array}$ & $\begin{array}{r}1 \\
21 \\
\end{array}$ & & & \\
\hline $\mathrm{MBP}-\mathrm{Br}_{5} \mathrm{Cl}-d$ & $\begin{array}{l}\rho \\
p \text {-value (1-tailed) } \\
n\end{array}$ & $\begin{array}{r}.977 \\
.000 \\
18 \\
\end{array}$ & \begin{tabular}{rr|}
.963 & \\
& .000 \\
& 23 \\
\end{tabular} & $\begin{array}{r}.963 \\
.000 \\
21 \\
\end{array}$ & $\begin{array}{r}1 \\
25 \\
\end{array}$ & & \\
\hline $\mathrm{MBP}-\mathrm{Br}_{5} \mathrm{Cl}-\mathrm{e}$ & $\begin{array}{l}\rho \\
p \text {-value (1-tailed) } \\
n\end{array}$ & $\begin{array}{r}.945 \\
.000 \\
17 \\
\end{array}$ & $\begin{array}{r}.910 \\
.000 \\
20 \\
\end{array}$ & $\begin{array}{r}.895 \\
.000 \\
19 \\
\end{array}$ & $\begin{array}{r}.954 \\
.000 \\
20 \\
\end{array}$ & $\begin{array}{r}1 \\
20 \\
\end{array}$ & \\
\hline CB-153 & $\begin{array}{l}\rho \\
p \text {-value (1-tailed) } \\
n\end{array}$ & $\begin{array}{r}.918 \\
.000 \\
16\end{array}$ & $\begin{array}{r}.908 \\
.000 \\
23\end{array}$ & $\begin{array}{r}.869 \\
.000 \\
19\end{array}$ & $\begin{array}{r}.843 \\
.000 \\
23\end{array}$ & $\begin{array}{r}.788 \\
.000 \\
18\end{array}$ & 33 \\
\hline
\end{tabular}




\section{ChAPTER 4 APPEndiX}

Mass of the total lipid extract (TLE), dry mass, and wet mass for all non-mammalian samples.

\begin{tabular}{cccc} 
Sample ID & \multicolumn{3}{c}{ Mass extracted (g) } \\
\cline { 2 - 4 } & TLE & dry mass & wet mass \\
\hline Loligo 121 & 12.6 & 139.3 & 594.3 \\
Loligo 89 & 12.8 & 164.9 & 761.8 \\
Illex 87 & 14.2 & 119.4 & not recorded \\
Illex 178 & 7.98 & 69.7 & 263.4 \\
Herring 228 & 19.7 & 69.7 & 283.9 \\
Herring 219 & 30.5 & 139.3 & 453.9 \\
Mackerel 244 & 23.1 & 109.5 & 428.3 \\
Mackerel 268 & 19.2 & 129.4 & 907.6 \\
White Hake 275 & 13.9 & 69.7 & 291.6 \\
White Hake 299 & 40.7 & 199.0 & not recorded \\
Red Hake 168 & 8.16 & 89.6 & 376.5 \\
Red Hake 169 & 2.67 & 80.6 & not recorded \\
Silver Hake 176 & 11.2 & not recorded & 162.4 \\
Silver Hake 165 & 4.65 & not recorded & 91.9 \\
Acadian Redfish 258 & 29.5 & 179.4 & 690.5 \\
Acadian Redfish 257 & 33.5 & 207.9 & 794.0 \\
Cod 326 & 6.16 & 181.2 & not recorded \\
Cod 324 & 10.3 & 184.6 & 886.1 \\
Haddock 214 & 11.3 & 199.0 & 990.9 \\
Haddock 205 & 22.2 & 139.3 & 679.0
\end{tabular}




\section{References}

1. Vetter, W.; Jun, W.; Althoff, G., Non-polar halogenated natural products bioaccumulated in marine samples. I. 2,3,3 ',4,4 ',5,5 '-heptachloro-1 '-methyl-1,2 'bipyrrole (Q1). Chemosphere 2003, 52 (2), 415-422.

2. Vetter, W.; Gaul, S.; Olbrich, D.; Gaus, C., Monobromo and higher brominated congeners of the marine halogenated natural product 2,3,3',4,4',5,5'heptachloro-1'-methyl-1,2'-bipyrrole (Q1). Chemosphere 2007, 66, 2011-2018.

3. Pangallo, K. C.; Reddy, C. M., Distribution patterns suggest biomagnification of halogenated 1'-methyl-1,2'-bipyrroles (MBPs). Environmental Science \& Technology 2009, 43 (1), 122-127.

4. Teuten, E. L.; Reddy, C. M., Halogenated organic compounds in archived whale oil: A pre-industrial record. Environmental Pollution 2007, 145 (3), 668-671.

5. Vasseur, P.; Cossu-Leguille, C., Linking molecular interactions to consequent effects of persistent organic pollutants (POPs) upon populations. Chemosphere 2006, 62 (7), 1033-1042.

6. Brustad, M.; Sandanger, T. M.; Nieboer, E.; Lund, E., 10th Anniversary Review: when healthy food becomes polluted - implications for public health and dietary advice. Journal of Environmental Monitoring 2008, 10 (4), 422-427.

7. Jones, K. C.; de Voogt, P., Persistent organic pollutants (POPs): state of the science. Environmental Pollution 1999, 100 (1-3), 209-221.

8. Weber, R.; Gaus, C.; Tysklind, M.; Johnston, P.; Forter, M.; Hollert, H.; Heinisch, E.; Holoubek, I.; Lloyd-Smith, M.; Masunaga, S.; Moccarelli, P.; Santillo, D.; Seike, N.; Symons, R.; Torres, J. P. M.; Verta, M.; Varbelow, G.; Vijgen, J.;

Watson, A.; Costner, P.; Woelz, J.; Wycisk, P.; Zennegg, M., Dioxin- and POPcontaminated sites-contemporary and future relevance and challenges.

Environmental Science and Pollution Research 2008, 15 (5), 363-393.

9. Braune, B. M.; Outridge, P. M.; Fisk, A. T.; Muir, D. C. G.; Helm, P. A.; Hobbs, K.; Hoekstra, P. F.; Kuzyk, Z. A.; Kwan, M.; Letcher, R. J.; Lockhart, W. L.; Norstrom, R. J.; Stern, G. A.; Stirling, I., Persistent organic pollutants and mercury in marine biota of the Canadian Arctic: An overview of spatial and temporal trends. Science of the Total Environment 2005, 351, 4-56.

10. Schwarzenbach, R. P.; Gschwend, P. M.; Imboden, D. M., Environmental Organic Chemistry. Second ed.; John Wiley \& Sons, Inc.: Hoboken, New Jersey, 2003; p 1313.

11. Reddy, C. M.; Stegeman, J. J.; Hahn, M. E., Organic pollutants: presence and effects in humans and marine animals. In Oceans and Human Health, Walsh, P. J.; Smith, S. L.; Fleming, L. E.; Solo-Gabriele, H. M.; Gerwick, W. H., Eds. Academic Press-Elesvier: Boston, 2008; pp 121-144. 
12. Tittlemier, S. A.; Fisk, A. T.; Hobson, K. A.; Norstrom, R. J., Examination of the bioaccumulation of halogenated dimethyl bipyrroles in an Arctic marine food web using stable nitrogen isotope analysis. Environmental Pollution 2002, 116 (1), 85-93.

13. Weijs, L.; Losada, S.; Das, K.; Roosens, L.; Reijnders, P. J. H.; Santos, J. F.; Neels, H.; Blust, R.; Covaci, A., Biomagnification of naturally-produced methoxylated polybrominated diphenyl ethers (MeO-PBDEs) in harbour seals and harbour porpoises from the Southern North Sea. Environment International 2009, 35 (6), 893-899.

14. Wackett, L. P., Questioning our perceptions about evolution of biodegradative enzymes. Current Opinion in Microbiology 2009, In Press, Corrected Proof.

15. Teuten, E. L.; Pedler, B. E.; Hangsterfer, A. N.; Reddy, C. M., Identification of highly brominated analogues of Q1 in marine mammals. Environmental Pollution 2006, 144, 336-344.

16. Unger, M. A.; Harvey, E.; Vadas, G. G.; Vecchione, M., Persistent pollutants in nine species of deep-sea cephalopods. Marine Pollution Bulletin 2008, 56 (8), 1486-1512.

17. Hoh, E.; Lehotay, S. J.; Pangallo, K. C.; Mastovska, K.; Ngo, H. L.; Reddy, C. M.; Vetter, W., Simultaneous quantitation of multiple classes of organohalogen compounds in fish oils with direct sample introduction comprehensive two-dimensional gas chromatography and time-of-flight mass spectrometry. Journal of Agricultural and Food Chemistry 2009, 57 (7), 2653-2660. 18. Vetter, W.; Alder, L.; Kallenborn, R.; Schlabach, M., Determination of Q1, an unknown organochlorine contaminant, in human milk, Antarctic air, and further environmental samples. Environmental Pollution 2000, 110 (3), 401-409. 19. Branch, E. S. http://www.nefsc.noaa.gov/femad/ecosurvey/mainpage. (accessed June 19, 2009).

20. Planque, B.; Battern, S. D., Calanus finmarchicus in the North Atlantic: the year of Calanus in the context of interdecadal change. ICES Journal of Marine Science 2000, 57, 1528-1535.

21. Pangallo, K.; Nelson, R. K.; Teuten, E. L.; Pedler, B. E.; Reddy, C. M., Expanding the range of halogenated 1'-methyl-1,2'-bipyrroles (MBPs) using GC/ECNI-MS and GC $\times$ GC/TOF-MS. Chemosphere 2008, 71, 1557-1565.

22. Vetter, W.; Jun, W., Non-polar halogenated natural products bioaccumulated in marine samples. II. Brominated and mixed halogenated compounds. Chemosphere 2003, 52, 423-431.

23. Gaul, S.; Vetter, W., Photolytic dehalogenation of the marine halogenated natural product Q1. Chemosphere 2008, 70 (9), 1721-1729.

24. Glaser, J. A.; Foerst, D. L.; McKee, G. D.; Quave, S. A.; Budde, W. L., Trace analyses for wastewaters. Environ. Sci. Technol. 1981, 15 (12), 1426-1435. 
25. Hayes, J. M., Fractionation of the isotopes of carbon and hydrogen in biosynthetic processes. In Stable Isotope Geochemistry, Valley, J. W.; Cole, D. R., Eds. Mineralogical Society of America: 2001.

26. Logan, J. M.; Lutcavage, M. E., A comparison of carbon and nitrogen stable isotope ratios of fish tissues following lipid extractions with non-polar and traditional chloroform/methanol solvent systems. Rapid Communications in Mass Spectrometry 2008, 22 (7), 1081-1086.

27. Teuten, E. L.; Saint-Louis, R.; Pedler, B. E.; Xu, L.; Pelletier, E.; Reddy, C. M., Expanding the range of brominated Q1 analogues. Marine Pollution Bulletin 2006, 52, 578-582.

28. Pangallo, K. Biomagnifying natural products in the northwestern Atlantic: halogenated 1'-methyl-1,2'-bipyrroles (MBPs). MIT/WHOI Joint Program in Oceanography/Applied Ocean Science and Engineering, Cambridge, MA, 2009.

29. Brodziak, J. K. T., Essential fish habitat source document: Haddock, Melanogrammus aeglefinus, life history and habitat characteristics. 2 ed.; NOAA National Marine Fisheries Service, N. F. S. C., Ed. NOAA, US Department of Commerce: Woods Hole, MA, 2005; Vol. NMFS-NE-196.

30. Chang, S.; Morse, W. W.; Berrien, P., L., Essential fish habitat source document: Atlantic cod, Gadus morhua, life history and habitat characteristics. 1 ed.; NOAA National Marine Fisheries Service, N. F. S. C., Ed. NOAA, US Department of Commerce: Woods Hole, MA, 1999; Vol. NMFS-NE-136.

31. Hendrickson, L. C.; Holmes, E. M., Essential fish habitat source document: Northern shortfin squid, Illex illecebrosus, life history and habitat characteristics. 2 ed.; NOAA National Marine Fisheries Service, N. F. S. C., Ed. NOAA, US Department of Commerce: Woods Hole, MA, 2004; Vol. NMFS-NE-191.

32. Jacobson, L. D., Essential fish habitat source document: longfin inshore squid, Loligo pealeii, life history and habitat characteristics. 2 ed.; NOAA National Marine Fisheries Service, N. F. S. C., Ed. NOAA, US Department of Commerce: Woods Hole, MA, 2005; Vol. NMFS-NE-193.

33. Lock, M. C.; Packer, D. B., Essential fish habitat source document: silver hake, Merluccius biliearis, life history and habitat characteristics. 2 ed.; NOAA National Marine Fisheries Service, N. F. S. C., Ed. NOAA, US Department of Commerce: Woods Hole, MA, 2004; Vol. NMFS-NE-186.

34. Lough, R. G., Essential fish habitat source document: Atlantic cod, Gadus morhua, life history and habitat characteristics. 2 ed.; NOAA National Marine Fisheries Service, N. F. S. C., Ed. NOAA, US Department of Commerce: Woods Hole, MA, 2004; Vol. NMFS-NE-190.

35. Pikanowski, R. A.; Morse, W. W.; Berrien, P., L.; Johnson, D. L.; McMillan, D. G., Essential fish habitat source document: redfish, Sebastes spp., life history and habitat characteristics. 1 ed.; NOAA National Marine Fisheries Service, N. F. S. C., Ed. NOAA, US Department of Commerce: Woods Hole, MA, 1999; Vol. NMFS-NE-132. 
36. Steimle, F. W.; Morse, W. W.; Berrien, P., L.; Johnson, D. L., Essential fish habitat source document: red hake, Urophycis chuss, life history and habitat characteristics. 1 ed.; NOAA National Marine Fisheries Service, N. F. S. C., Ed. NOAA, US Department of Commerce: Woods Hole, MA, 1999; Vol. NMFS-NE133.

37. Stevenson, D. K.; Scott, M. L., Essential fish habitat source document: Atlantic herring, Clupea harengus, life history and habitat characteristics. 2 ed.; NOAA National Marine Fisheries Service, N. F. S. C., Ed. NOAA, US Department of Commerce: Woods Hole, MA, 2005; Vol. NMFS-NE-192.

38. Studholme, A. L.; Packer, D. B.; Berrien, P., L.; Johnson, D. L.; Zetlin, C. A.; Morse, W. W., Essential fish habitat source document: Atlantic mackerel, Scomber scombrus, life history and habitat characteristics. 1 ed.; NOAA National Marine Fisheries Service, N. F. S. C., Ed. NOAA, US Department of Commerce: Woods Hole, MA, 1999; Vol. NMFS-NE-141.

39. Program, U. N. E., Stockholm Convention on Persistent Organic Pollutants. Program, U. N. E., Ed. Stockholm, Sweden, 2001; p 43.

40. Fisk, A. T.; Tittlemier, S. A.; Pranschke, J. L.; Norstrom, R. J., Using anthropogenic contaminants and stable isotopes to assess the feeding ecology of greenland sharks. Ecology 2002, 83 (8), 2162-2172.

41. Fisk, A. T.; Hobson, K. A.; Norstrom, R. J., Influence of chemical and biological factors on trophic transfer of persistent organic pollutants in the northwater polynya marine food web (vol 35, pg 732, 2001). Environmental Science $\mathcal{E}$ Technology 2001, 35 (8), 1700-1700.

42. Broman, D.; Naf, C.; Rolff, C.; Zebuhr, Y.; Fry, B.; Hobbie, J., Using ratios of stable nitrogen isotopes to estimate bioaccumulation and flux of polychlorinated dibenzo-p-dioxins (PCDDs) and dibenzofurans (PCDFs) in 2 food-chains from the northern Baltic. Environmental Toxicology and Chemistry 1992, 11 (3), 331-345.

43. Saage, A.; Altin, D.; Vadstein, O.; Sommer, U., Trophic position of Calanus finmarchicus (Copepoda, Calanoida) in the Trondheim Fjord. Journal of Sea Research 2008, 59 (3), 162-172.

44. Tomy, G. T.; Pleskach, K.; Ferguson, S. H.; Hare, J.; Stern, G.; MacInnis, G.; Marvin, C. H.; Loseto, L., Trophodynamics of Some PFCs and BFRs in a Western Canadian Arctic Marine Food Web. Environmental Science \& Technology 2009, 43 (11), 4076-4081.

45. Wu, J.; Vetter, W.; Gribble, G. W.; Schneekloth, J. S.; Blank, D. H.; Gorls, H., Structure and synthesis of the natural heptachloro-1 '-methyl-1,2 '-bipyrrole (Q1). Angewandte Chemie-International Edition 2002, 41 (10), 1740-1743.

46. Burreau, S.; Zebuhr, Y.; Broman, D.; Ishaq, R., Biomagnification of PBDEs and PCBs in food webs from the Baltic Sea and the northern Atlantic ocean. Science of The Total Environment 2006, 366 (2-3), 659-672. 
47. Shaw, S. D.; Berger, M. L.; Brenner, D.; Kannan, K.; Lohmann, N.; P\%opke, O., Bioaccumulation of polybrominated diphenyl ethers and hexabromocyclododecane in the northwest Atlantic marine food web. Science of The Total Environment 2009, 407 (10), 3323-3329.

48. Kelly, B. C.; Ikonomou, M. G.; Blair, J. D.; Morin, A. E.; Gobas, F., Food web-specific biomagnification of persistent organic pollutants. Science 2007, 317 (5835), 236-239.

49. Pauly, D.; Trites, A. W.; Capuli, E.; Christensen, V., Diet composition and trophic levels of marine mammals. Ices Journal of Marine Science 1998, 55 (3), 467481.

50. Weisbrod, A. V.; Shea, D.; Moore, M. J.; Stegeman, J. J., Species, tissue and gender-related organochlorine bioaccumulation in white-sided dolphins, pilot whales and their common prey in the Northwest Atlantic. Marine Environmental Research 2001, 51 (1), 29-50.

51. Gannon, D. P.; Craddock, J. E.; Read, A. J., Autumn food habits of harbor porpoises, Phocoena phocoena, in the Gulf of Maine. Fishery Bulletin 1998, 96 (3), 428-437.

52. Read, A. J., Trends in the maternal investment of harbour porpoises are uncoupled from the dynamics of their primary prey. Proceedings of the Royal Society London B 2001, 268 (1467), 573-577.

53. Overholtz, W. J.; Waring, G. T., Diet composition of pilot whales Globicephala sp and common dolphins Delphinus delphis in the Mid-Atlantic Bight during spring 1989. Fishery Bulletin 1991, 89 (4), 723-728.

54. Lawson, J. W.; Anderson, J. T.; Dalley, E. L.; Stenson, G. B., Selective foraging by harp seals Phoca groenlandica in nearshore and offshore waters of Newfoundland, 1993 and 1994. Marine Ecology-Progress Series 1998, 163, 1-10. 55. Lindstrom, U.; Harbitz, A.; Haug, T.; Nilssen, K. T., Do harp seals Phoca groenlandica exhibit particular prey preferences? Ices Journal of Marine Science 1998, 55 (5), 941-953.

56. Haug, T.; Nilssen, K. T.; Lindblom, L., Feeding habits of harp and hooded seals in drift ice waters along the east coast of Greenland in summer and winter. Polar Research 2004, 23 (1), 35-42.

57. Ampela, K. The College of Staten Island, CUNY, Staten Island, NY, 2009.

58. Boon, J. P.; van der Meer, J.; Allchin, C. R.; Law, R. J.; Klungsøyr, J.; Leonards, P. E. G.; Spliid, H.; Storr-Hansen, E.; Mckenzie, C.; Wells, D. E., Concentration-dependent changes of PCB patterns in fish-eating mammals: structural evidence fro induction of cytochrome P450. Archives of Environmental Contamination and Toxicology 1997, 33, 298-311.

59. Stapleton, H. M.; Dodder, N. G.; Kucklick, J. R.; Reddy, C. M.; Schantz, M. M.; Becker, P. R.; Gulland, F.; Porter, B. J.; Wise, S. A., Determination of HBCD, PBDEs and MeO-BDEs in California sea lions (Zalophus californianus) stranded between 1993 and 2003. Marine Pollution Bulletin 2006, 52 (5), 522-531. 
60. Fry, B., Food Web Structure on Georges Bank from Stable C, N, and S Isotopic Compositions. Limnology and Oceanography 1988, 33 (5), 1182-1190.

61. Hobson, K. A.; Ambrose Jr., W. G.; Renaud, P. E., Sources of primary production, benthic-pelagic coupling, and trophic relationships within the Northeast Water Polynya: insigts from $\delta 13 \mathrm{C}$ and $\delta 15 \mathrm{~N}$ analysis. Marine Ecology Progress Series 1995, 128, 1-10.

62. Jarman, W. M.; Hobson, K. A.; Sydeman, W. J.; Bacon, C. E.; McLaren, E. B., Influence of trophic position and feeding location on contaminant levels in the Gulf of the Farallones food web revealed by stable isotope analysis.

Environmental Science \& Technology 1996, 30, 654-660.

63. France, R. L., Carbon-13 enrichment in benthic compared to planktonic algae: foodweb implications. Marine Ecology Progress Series 1995, 124, 307-312. 


\title{
Chapter 5
}

\section{$\delta^{15} \mathrm{~N}$ enrichment suggests possible source for halogenated $1^{\prime}$-methyl-1,2'- bipyrroles (MBPs)}

\begin{abstract}
Highly halogenated 1'-methyl-1,2'-bipyrroles are natural products that bioaccumulate in upper trophic levels of the marine food web. Here we demonstrate that they are dramatically enriched in $\delta^{15} \mathrm{~N}\left(+20-30 \%\right.$ ). This ${ }^{15} \mathrm{~N}-$ enrichment is greater than that seen for other biosynthetic organic compounds measured to date. We argue that this enrichment likely stems from enriched precursors and/or fractionation during biosynthesis, and is not the product of MBP degradation. We also consider possible sources of MBPs in light of these results.
\end{abstract}

\section{Introduction}

Halogenated 1'-methyl-1,2'-bipyrroles (MBPs) are a class of marine natural products. As their name describes, they are made from two pyrrole rings linked by an N,C1-bond, and they have up to seven halogens (bromine or chlorine) on the ring carbons (Figure 1). Originally identified in marine mammal blubber [1-3], they appear to biomagnify through marine food webs to reach the 
concentrations observed in blubber samples [4]. Although recent research has elucidated their geographic and trophic distributions [3-12], the origins and physiological role of MBPs remain a mystery.

MBP structure is especially notable in the N,C1-linkage of the pyrrole rings; this bipyrrole structure has not been previously seen in naturally produced compounds. The novel pyrrole linkage and the highly halogenated nature of MBPs suggest that the biosynthetic organism(s) may have new genes to add to current knowledge of biosynthetic chemistry. With recent advances in genomic sequencing, the genes involved in biosynthesis can be identified and catalogued in 'libraries' [13]. One route of recent drug development is the use of these biosynthetic pathways to replace or assist in the production of complex chemical structures with specific biological activities [14]. Additionally, many organisms that produce secondary metabolites (compounds not required for primary metabolism, but that benefit the producing organism) synthesize more than one type of compound [15]. For example, the marine bacterium that produces hexabromo-2,2'-bipyrrole also generates other brominated pyrrole structures and biosynthetically-unrelated polysaccharides $[16,17]$. Thus, identification of MBPs' producer(s) may result in the discovery of more novel bioactive compounds. To fully realize this potential benefit of MBPs, however, their source must be identified. 
One method to infer the origins of a compound is by measuring its isotopic signature, which is imprinted during biosynthesis. This signature is a combination of the isotopic values of the precursors and the fractionation that occurs during the biosynthetic process. Once released into the environment, a compound's isotope signature can be altered if portions of the original inventory undergo reactions with associated isotopic fractionations. However, compounds that biomagnify should not undergo significant metabolism [18], and, theoretically, there is very little opportunity for isotope fractionation to occur. Hence, the isotopic signal of production should remain unchanged within the tissues of the higher trophic level organisms [19]. By isolating compounds from these higher trophic levels, we can determine the isotopic signature resulting from their biosynthesis. Although the process to isolate sufficient quantities of individual compounds is time and labor intensive, it can be performed without altering the isotopic signature of the targeted molecules [20]. Here we employ compound-specific nitrogen isotope analysis to examine the origin of MBPs isolated from the blubber of three common dolphins (Delphinus delphis). To the best of our knowledge, these are the first compound-specific ${ }^{15} \mathrm{~N}$ isotope analyses of biomagnified compounds.

\section{Methods}

\subsection{Samples}


Blubber samples from three D. delphis (CCSN04-218Dd, CCSN06-013Dd and CCSN07-074Dd) were acquired through the Cape Cod Stranding Network from dolphins stranded on Cape Cod in 2004-2007. CCSN04-218Dd was a maternally-dependent male calf of normal health who stranded with an adult female; the calf was in poor health due to the stress of stranding and was euthanized. CCSN06-013Dd was a male $(195.5 \mathrm{~cm}$ length) in robust health, but was euthanized at the site of stranding due to deteriorating condition. CCSN07074Dd was an adult female in robust health, was lactating at the time of stranding, and died at the stranding site.

\subsection{MBP isolation from blubber}

The blubber was received and was stored as frozen slabs, and thawed prior to processing. It was homogenized with hexane and filtered to a clear, yellow total lipid extract (TLE). The solvent was removed and the oil was stored at $-20^{\circ} \mathrm{C}$.

To isolate large enough quantities of the molecules of interest for compound-specific nitrogen isotope analysis, $250 \mathrm{~g}$ of oil was used for each sample. We employed gel permeation chromatography (GPC) to isolate the small organic compounds and remove the lipids from the samples. Briefly, $10 \mathrm{~g}$ aliquots of each sample was applied to the top of a $3 \mathrm{~cm}$ (o.d.) column, which was packed with 100g of SX-8 BioBeads ( $45 \mathrm{~cm}$, uncompressed). We used a mobile phase of 1:1 dichloromethane:hexane and collected two fractions. The first 
fraction $(0-150 \mathrm{~mL})$ that contained $\sim 70 \%$ of the lipids was discarded; the second fraction $(150-400 \mathrm{~mL})$, containing the remaining lipids and the molecules of interest, was reduced in volume by rotary evaporation. This procedure was repeated with the remaining oil from the initial $250 \mathrm{~g}$ sample, then the second fractions were combined and re-applied to the GPC column in $10 \mathrm{~g}$ aliquots. This was repeated until $<0.5 \mathrm{~g}$ lipids remained in the combined second fraction. The extract was further purified by silica/alumina column chromatography, as described in a previous publication [10].

Although we measured $\delta^{15} \mathrm{~N}$ by gas chromatography isotope-ratio mass spectrometry with a combustion interface (GC-C-IRMS), we chose to first isolate individual MBPs from the concentrated extract by preparative capillary gas chromatography (PCGC) [20]. This choice was determined by MBP structure, where nitrogen is only $\sim 4-5 \%$ percent (by mass) of each compound. To produce the required signal strength in the IRMS (see section 2.5.1), the GC column was overloaded. By isolating the individual compounds prior to GC-C-IRMS, the quality of the chromatography did not limit our ability to make accurate measurements. The quantity of compound isolated was estimated by comparison to a synthetic standard of $2,2^{\prime}, 3,4,4^{\prime}, 5,5^{\prime}$-heptabromo-1'-methyl-1, $3^{\prime}$ bipyrrole using gas chromatography coupled to a flame ionization detector (GC/FID). The identities of the isolated compounds were confirmed with gas chromatography/electron capture negative ion mass spectrometry (GC/ECNI- 
MS). The details of the GC/ECNI-MS method and compound identification have been previously published [10].

\subsection{Bulk stable nitrogen isotope analyses}

The $\delta^{15} \mathrm{~N}_{\text {bulk }}$ of the dolphins was determined by measuring the stable nitrogen isotope ratios of their muscle tissue. Sampling details are provided in a companion study (Chapter 4, [4]). Analyses were conducted at the Stable Isotope Facility at the University of California at Davis.

\subsection{Compound-specific nitrogen isotope analyses}

Compound-specific nitrogen isotope analysis of MBPs was performed following a modified procedure of $\mathrm{N}$ isotope analysis in organic contaminants using GC-C-IRMS [21]. GC-C-IRMS was chosen for the compounds-specific nitrogen isotope analyses because it requires far smaller quantities of each compound per measurement ( $\sim 3$ nmoles $\mathrm{N}$, equivalent to $\sim 2 \mu \mathrm{g}$, see section 2.5.1) than does an elemental analyzer interfaced to an isotope-ratio mass spectrometer (EA/IRMS) (20-150 $\mu \mathrm{g} \mathrm{N}$ [22]).

\subsection{Quality controls}

\subsubsection{GC-C-IRMS}

Due to the high molecular weight (580-700 amu), large number of halogens (6-7), and low nitrogen content (2 nitrogen atoms per compound) of the analytes, we anticipated difficulties in MBP combustion and the reduction of the subsequent $\mathrm{N}$-containing fragments to $\mathrm{N}_{2}$ in the GC/IRMS interface. Indeed, 
such effects were previously reported for the $\delta^{13} \mathrm{C}, \delta^{2} \mathrm{H}$, and $\delta^{15} \mathrm{~N}$ analysis of triazine herbicides with a similar experimental setup [23]. Due to MBPs' high molecular weight, the amount required to achieve the recommended signal intensity of $500 \mathrm{mV}$ [24] is too large to reasonably introduce onto a GC column. Therefore, injections were limited to 3-6 nmoles of each MBP, which produced smaller currents. As shown in Figure 2, accurate and precise $\delta^{15} \mathrm{~N}$ measurements of halogenated bipyrroles are possible at low signal intensities, that is, peak amplitudes between 50 and $500 \mathrm{mV}$. Excellent agreement between the $\delta^{15} \mathrm{~N}$

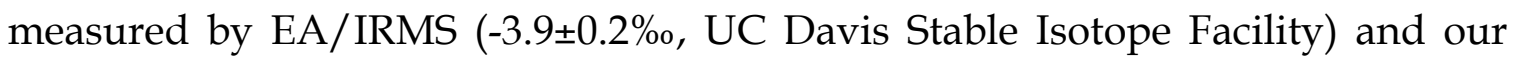
results $(-4.5 \pm 1.1 \%$ o) was observed during this test.

The $\delta^{15} \mathrm{~N}$ values of the synthetic standard $\mathrm{DMBP}-\mathrm{Cl}_{6}$ were monitored after every 3-6 MBP measurements to ensure accuracy. The low abundances used for these measurements resulted in an average of $-2.9 \pm 1.4 \%$, which is $2 \%$ removed from the EA/IRMS measurement. To be conservative, we use an error of $\pm 2 \%$ o to account for this variation. To clarify, this error accounts for the entire method; the instrumental error for low signal strengths is $\pm 1.1 \%$, as described above.

\subsubsection{Extraction and purification procedure}

The purification process to isolate MBPs was lengthy and involved multiple steps. Although no isotopic fractionation would be expected during column chromatography, previous work has shown that PCGC is capable of substantially altering the isotopic signature (up to $9.4 \%$ of for ${ }^{13} \mathrm{C}$ ) of isolated 
compounds if a peak is not captured in its entirety due to cross-peak inhomogeneities [20]. To be cautious, the entire extraction method was assessed to determine if fractionation occurred during the isolation of MBPs from blubber. A $10 \mathrm{~g}$ sample of vegetable oil was spiked with $\mathrm{DMBP}-\mathrm{Cl}_{6}$ and subjected to the isolation procedure (GPC - silica/alumina chromatography - PCGC). The spiked $\mathrm{DMBP}-\mathrm{Cl}_{6}$ recovered from the vegetable oil was analyzed alongside a stock solution of DMBP-Cl 6 . The samples had the same $\delta^{15} \mathrm{~N}$ within the error of the measurement $( \pm 2 \%)$, which indicates that our procedure can be used to determine the compound-specific isotope ratios of halogenated bipyrroles.

\subsection{Nomenclature}

Details on our nomenclature system are available in our prior publications $[10,12]$, and consistency between the publications allows results to be easily compared. The two compounds discussed here are $2,3,3^{\prime}, 4,4^{\prime}, 5,5^{\prime}$-heptabromo-1'methyl-1,2'-bipyrrole (Br7-MBP-79) and the most abundant hexabromochloroMBP congener $\left(\mathrm{MBP}-\mathrm{Br}_{6} \mathrm{Cl}-b\right)$. The acronym for the perbrominated congener is consistent with the nomenclature system developed by Vetter et al. [25] for MBPs of known structure.

\section{Results and Discussion}

\subsection{MBPs enriched in ${ }^{15} \mathrm{~N}$}

The stable nitrogen isotopic ratios of the MBPs measured ranged from $+19-28 \%$ o (Table 1). Four individual compounds were analyzed (in triplicate): 
Br7-MBP-79 in all three blubber samples, and MBP-Br ${ }_{6} \mathrm{Cl}-b$ in CCSN07-074Dd. The Br7-MBP-79 isolated from the female dolphin was enriched relative to MBP$\mathrm{Br}_{6} \mathrm{Cl}-b$ also isolated from the same blubber ( $+28 \%$ and $+22 \%$, respectively). The MBPs are enriched relative to $\delta^{15} \mathrm{~N}_{\text {bulk }}$ of the dolphins from which they were isolated (Table 1). To our knowledge, the extent of this enrichment, even with our conservative consideration of error $( \pm 2 \%)$, is unusual in comparison to other naturally produced compounds.

A thorough literature review of stable nitrogen isotope measurements of organic components in environmental or biological samples (commercially available standards were excluded) shows that most naturally occurring compounds have $\delta^{15} \mathrm{~N}$ values that typically fall from $-10 \%$ to $+10 \%$ o (Figure 3 ). The amino acids are the most analyzed compound class, and the measurements come from a large range of sources: bacteria [26], plankton [27-30], soil [31], plants [32, 33], collagen [34, 35], and human blood plasma [36]. Perhaps not surprisingly, amino acids also span the largest range of isotope ratios. DNA shows the most limited range, but is from only one study measuring soil extracts [37]. The pigment measurements are for chlorophyll and other porphyrins, and they have been measured in multiple studies, including plants [38], phytoplankton [39, 40], lake and marine sediments [41-43], and a saline meromictic lake [44]. Many are tetrapyrroles and thus may share biosynthetic precursors with MBPs. Secondary metabolites show a similar distribution to the 
pigments, which both tend to be depleted in ${ }^{15} \mathrm{~N}$ relative to the cellular inventory of nitrogen [45].

MBPs have much higher $\delta^{15} \mathrm{~N}$ values compared with these other biosynthetic organic compounds (Figure 3). When making this comparison it is important to note that compound-specific $\delta^{15} \mathrm{~N}$ measurements are far less common than those made for $\delta^{13} \mathrm{C}$, which limits our ability to make comparisons. Nevertheless, the $\delta^{15} \mathrm{~N}$ enrichment seen for MBPs is a distinct isotopic signal. MBPs are putative secondary metabolites made of two pyrrole rings. Thus, their enrichment is especially notable compared with the much lower $\delta^{15} \mathrm{~N}$ values measured for secondary metabolites (Figure 3: heroin, morphine, cocaine, nicotine, caffeine and methyl- $\mathrm{N}$-methyl-anthranilate, all isolated from various terrestrial plants [45]) and the tetrapyrrolic pigments.

\subsection{Origin of enrichment}

There are at least three possible explanations for the enrichment we observe in the MBP congeners: enriched precursors, biosynthetic fractionation, and degradative pathways that introduce isotopic fractionation. These three explanations are not mutually exclusive; in fact, all may contribute. MBPs are relatively newly discovered, and details about their synthesis and degradation are still uncertain. Thus, we will examine potential biosynthetic routes of MBPs, including precursors, but first we will discuss the possibility of nitrogen isotope fractionation during degradation of MBPs. 


\subsubsection{Fractionation during degradation}

Although MBPs biomagnify, which indicates that they are resistant to degradation, they are not necessarily immune to degradation. In fact, enzymes involved in the degradation of halogenated organic compounds are ubiquitous, and likely evolved to process HNPs [46, 47]. Such capabilities exist not only in microbes [48], but also in larger organisms, including fish [49] and mammals [50, 51]. In these larger organisms, biotransformation of halogenated organic compounds can proceed via both oxidative pathways and reductive dehalogenation $[49,52]$. Thus, it is reasonable to consider that some fraction of any biomagnifying compound may be metabolized during trophic transfer.

Any metabolism that occurs can have an associated isotopic fractionation, deriving from a kinetic isotope effect. Bond strength is slightly mass dependent, and heavy isotopes form stronger bonds than do light isotopes. Thus, bonds containing the light isotope break more quickly, leading to a faster reaction rate for these compounds. This difference in reaction rates results in enrichment of the heavy isotope in the remaining parent compound. Therefore, if degradation occurs during trophic transfer, we expect to see this enrichment in the remaining compounds, i.e., those that accumulate in the next trophic level. Every link in the food web allows an additional opportunity for fractionation, thus, compounds in the highest trophic levels should show the largest isotopic enrichment. This effect has been observed for 1,1,1-trichloro-2,2-bis( $p$-chlorophenyl)ethane (DDT); 
DDT isolated from the blubber of a grey seal was enriched in ${ }^{37} \mathrm{Cl}$ relative to commercially produced DDT [53].

If MBPs are subject to dehalogenation during trophic transfer, the nitrogen isotopic enrichment would likely be very small. As there are no halogennitrogen bonds in MBPs, dehalogenation is a secondary isotope effect with respect to nitrogen. (I.e., the bond involved in the reaction center is adjacent to nitrogen atom, thus, the nitrogen atom is not directly involved in the reaction.) Since they are not directly involved in the reaction, secondary isotope effects are generally quite small relative to primary isotope effects [54]. This is apparent in the minute secondary isotope effects documented for chlorine in dehalogenation $(0.3 \%$ ) , relative to the primary isotope effects in carbon $(7.2 \%$ ond $8.5 \%$ o for vinyl chloride and cis-1,2-dichloroethane, respectively) [55]; and nitrogen in enzymatic nitrobenzene oxidation $(0.75 \%$ ), again relative to carbon $(3.9 \%)$ [56]. Thus, any fractionation in nitrogen isotopes during MBP dehalogenation is likely to be minor.

The potential for oxidative degradation is more difficult to assess as the degradative pathways of MBPs are as of yet unknown. However, the degradation of halogenated bicyclic ring compounds and nitrogen-containing aromatic compounds have been scrutinized. Oxidative metabolism of polybrominated diphenyl ethers (PBDEs) and polychlorinated biphenyls (PCBs) produces hydroxylated metabolites [50, 52, 57], and PBDE metabolites also 
include brominated phenols [52]. Like dehalogenation, hydroxylation would result in a secondary isotope effect with respect to nitrogen. The production of brominated phenols, however, requires separation of the two aromatic rings in each PBDE at the ether linkage. MBPs have no ether linkage, but are joined through a C-N bond. It is not clear whether the enzymes that produced brominated phenols from PBDEs would similarly act upon the C-N bond in MBPs. Two oxidative paths are suggested by the metabolism of chlorotoluenes: hydroxylation on the aromatic ring (as described for the PBDEs) and at the methyl carbon [58]. The latter results in the formation of a benzyl alcohol, which would produce a secondary isotope effect for the nitrogen atom in position $1^{\prime}$.

Overall, the most probable metabolic pathways for MBPs, dehalogenation and hydroxylation, would result in secondary isotope effects with respect to nitrogen. Keeping in mind the extent of $\delta^{15} \mathrm{~N}$ enrichment in MBPs, it seems unlikely that secondary isotope effects could contribute significantly to their isotopic signature. If we assume that MBPs are initially introduced into the food chain with a $\delta^{15} \mathrm{~N}$ of nitrate $(\sim 5 \%)$ [59] and that secondary isotope effects are responsible for degradation ( $\varepsilon \sim 1 \%$, a conservative estimate), we can calculate the fraction of MBPs remaining ( $f=$ fraction remaining) by Rayleigh distillation of kinetically fractionated isotopes (Eq. 1).

$$
\delta_{\mathrm{MBP} \text { blubber }}=\delta_{\mathrm{MBP} \text { initial }}-\varepsilon \ln (f) \quad \text { (Eq. 1) }
$$


Here, $\delta_{\text {MBP blubber }}$ is the $\delta^{15} \mathrm{~N}$ of MBPs isolated from blubber (here we use $20 \%$ ), and $\delta_{\mathrm{MBP}}$ initial is the $\delta^{15} \mathrm{~N}$ of MBPs when they enter the food web (5\%, as described above). Under these assumptions, this calculation yields $f=0.0000003$, or less than $0.000001 \%$ of the original $\mathrm{MBP}$ remaining. Using a more conservative estimation of $\delta_{\mathrm{MBP}}$ initial $=10 \%$ results in an estimate of $f=0.00005$. This seems unreasonable, as a similar calculation for DDT results in $\sim 10 \%$ of the original DDT remaining [53], and DDT is transformed in the environment relatively quickly to dechlorinated metabolites. Thus, the $\delta^{15} \mathrm{~N}$ enrichment of MBPs isolated from whale blubber is unlikely to be due to degradation.

\subsubsection{Enriched precursors and biosynthesis}

During biosynthesis the isotopic composition of a compound is set and reflects the source of nutrients, the uptake fractionation, and the internal fractionation between the target compound and the cellular biomass [60]. Most important to our investigation are the two pyrrole rings in each MBP, as they contain the nitrogen atoms of interest. Pyrrole biosynthesis is an active area of study, as many secondary metabolites contain pyrroles or pyrrole-derived moieties [61], and a number of pyrrole biosynthetic pathways have been determined (Figure 4). Although there are a few routes to pyrrole synthesis, all derive nitrogen from amino acids [61-65]. Amino acids are synthesized during proteinogenesis, a fraction of which can be drawn off to natural product 
pathways [61]. Amino acids shown to be pyrrole precursors are glycine, proline, alanine, ornithine, serine, and methionine [61-65].

Compound-specific nitrogen isotope analyses have been performed on over 17 amino acids from a variety of sources, for a total of over 360 measurements (Figure 3). Amino acids $\delta^{15} \mathrm{~N}$ values tend to vary from $-10 \%$ o to $+10 \%$, but individual amino acids show distinct patterns. Of those shown to contribute to pyrrole biosynthesis (see above), alanine, ornithine and proline are more enriched, and glycine and methionine are more depleted, relative to the amino acid mean $\delta^{15} \mathrm{~N}$ (Figure 5). For amino acids that are polynitrogeneous, intramolecular isotopic evidence shows that the side-chain nitrogen is consistently enriched relative to the peptide nitrogen [66]. Similarly, nitrogen atoms involved in heteroaromatic binding (such as the nitrogen in pyrroles) are enriched relative to amino acids' peptide nitrogen [45]. Thus, it is possible that part of the enrichment observed in MBPs is due to the incorporation of relatively enriched amino acids (such as alanine, ornithine, and proline) or nitrogen from the side chains of polynitrogeneous amino acids.

Reactions during biosynthesis may also impart associated frationations. The observed enrichment could occur through pyrrole halogenation or during the linkage of the two pyrrole rings. Halogenation of the pyrrole ring would occur by electrophilic aromatic substitution, which would disrupt the aromaticity of the pyrrole. This change in the molecular electronic structure could thus result 
in fractionation for nitrogen atoms. Reaction at the nitrogen atom is a primary isotope effect, and is thus most likely to impart a strong isotopic signature. It seems reasonable that the mechanism linking the two pyrrole rings may be responsible for the enriched nitrogen isotope values we observe.

An alternative possibility for precursor enrichment is $\delta^{15} \mathrm{~N}$ enrichment in the available nitrogen pools. One source of enriched nitrogen is from higher trophic levels. Predators are enriched relative to their prey by $\sim 3 \%$ [67]. Thus, top predators are enriched in ${ }^{15} \mathrm{~N}$, such as the dolphins in this study $\left(\delta^{15} \mathrm{~N} \sim 14 \%\right.$ ). By acquiring nitrogen from top predators by parasitic activity, recycling of carcasses, etc., a very enriched source of nitrogen could be tapped.

Another source of enriched $\mathrm{N}$ could be nitrate. Nitrate is the most abundant source of nitrogen in the oceans, which typically has $\delta^{15} \mathrm{~N}$ values $\sim 5 \%$ o [59]. However, this value can vary widely, especially in regions where denitrification has depleted the pool of nitrate. Denitrification is strongly fractionating, leaving the remaining pool of bioavailable nitrogen enriched in $\delta^{15} \mathrm{~N}$ (e.g., $\delta^{15} \mathrm{~N}_{\text {nitrate }}=12.5 \%$ North Pacific Subtropical Gyre) [68]. Thus, MBP ${ }^{15} \mathrm{~N}$ enrichment may derive from biosynthesis in areas of denitrification, or other areas of ${ }^{15} \mathrm{~N}$-enriched nitrate.

\subsection{A hypothesis for MBPs origins}

Actinomycetes and Pseudoalteromonas species are prolific producers of secondary metabolites $[69,70]$, and are already known to produce halogenated 
bipyrroles [63, 69, 71, 72]. Interestingly, some actinomycete species and Pseudoalteromonas denitrificans are capable of denitrification [67-69] and thus can access nitrogen pools enriched in $\delta^{15} \mathrm{~N}$. Thus, actinomycetes and/or Pseudoalteromonas seem a likely source of MBPs. Although these bacterial orders have been extensively examined for natural product production, MBPs have never been identified $[69,70]$. This is unsurprising, as only a small fraction of existing species have been cultured and examined for secondary metabolite production, and most of these are soil-dwelling species [73]. Future research on the origins of MBPs may want to focus on new strains of marine actinomycetes and Pseudoalteromonas, particularly those isolated from regions where nitrate has high $\delta^{15} \mathrm{~N}$ values.

MBPs are a remarkable class of environmental contaminants. They are highly halogenated, bioaccumulative, natural products, and the research presented here demonstrates that they are dramatically enriched in $\delta^{15} \mathrm{~N}(+20-$ $30 \%$ ). This ${ }^{15} \mathrm{~N}$-enrichment is greater than that seen for other terrestrially produced organic compounds that have been measured. The enrichment likely stems from enriched precursors and/or fractionation during biosynthesis. One source of enriched nitrogen in the oceans is the residual nitrate in areas of denitrification and two bacterial species known to produce halogenated bipyrroles are from genera with denitrifying capabilities. Thus, we hypothesize that marine actinomycetes and/or Pseudoalteromonas produce MBPs. 


\section{Acknowledgements}

I am very grateful to Dr. Thomas Hofstetter and Jakov Bolotin (Institute of Biogeochemistry and Pollutant Dynamics (IBP), ETH, Zürich) for our collaboration on the compound-specific $\delta^{15} \mathrm{~N}$ measurements. I thank Sarah O'Connor for illuminating discussions. I would like to thank the Cape Cod Stranding Network for their assistance in acquiring samples. I am grateful to Daniel Montluçon and Sean Sylva for their dedicated assistance with laboratory instrumentation. I am extremely grateful to Matthew Poyton for his assistance with processing the large volumes of blubber needed for this study. This work was supported by The Seaver Institute, the J. Seward Johnson Fund, The Virginia Walker Smith Fund, the WHOI Ocean Ventures Fund and the National Science Foundation (OCE-0550486, and the Graduate Research Fellowship Program). 


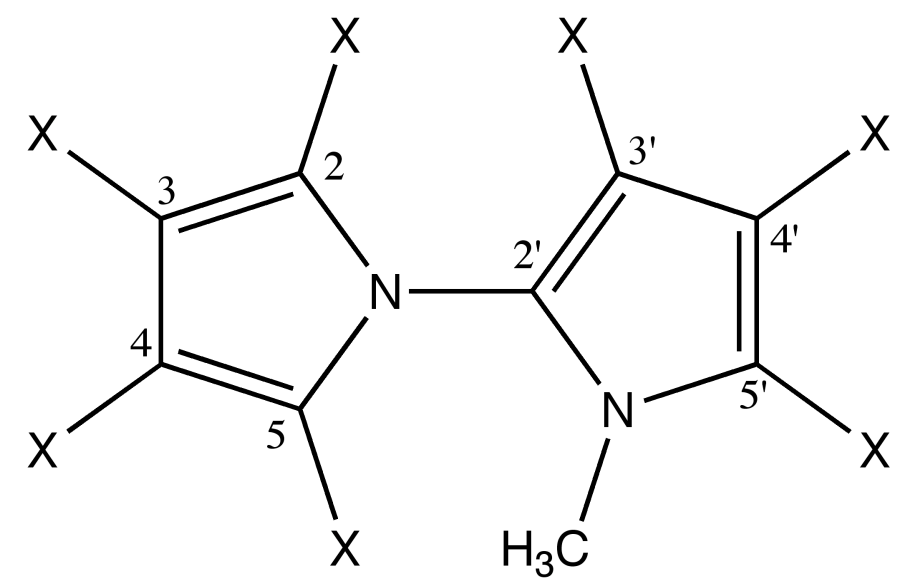

Figure 1. The general structure of MBPs, where $X$ represents $\mathrm{Br}, \mathrm{Cl}$ or $\mathrm{H}$.

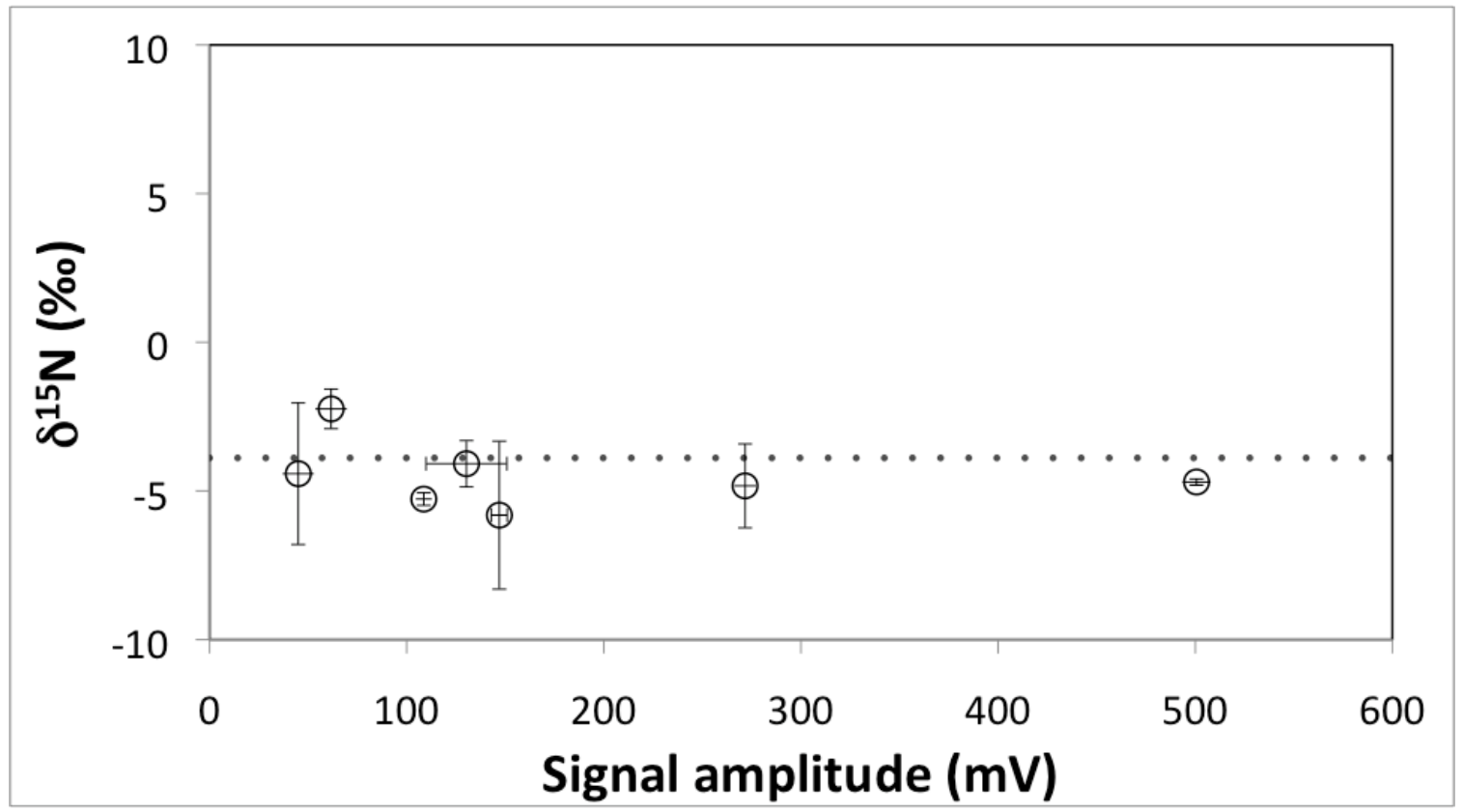

Figure 2. Linearity test of the GC-C-IRMS system for measuring low abundances of halogenated bipyrroles. Each circle represents one measurement on the GC-C-IRMS system (average of $4.5 \pm 1.1 \%$ ) and the dotted line represents the EA/IRMS measured $\delta^{15} \mathrm{~N}$ value of the standard DMBP-Cl $6(-3,9 \pm 0.2 \%$ ). 


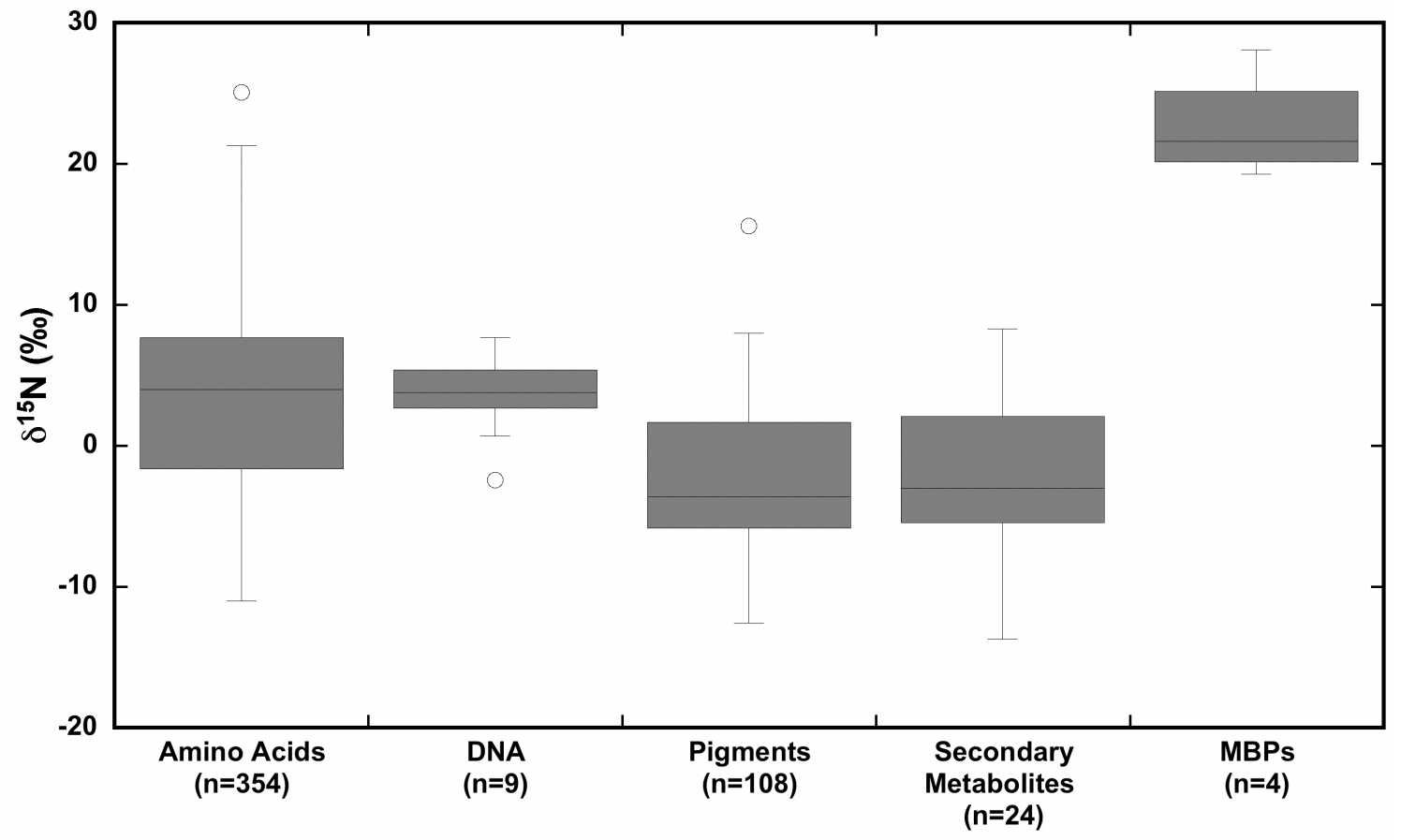

Figure 3. Box plots of selected $\delta^{15} \mathrm{~N}$ ranges from a literature review of compoundspecific nitrogen isotope analyses compared with the MBPs presented in this study. Data from: amino acids [26-31, 33-36, 66, 74], DNA [37], pigments [38-44], secondary metabolites [45]. 


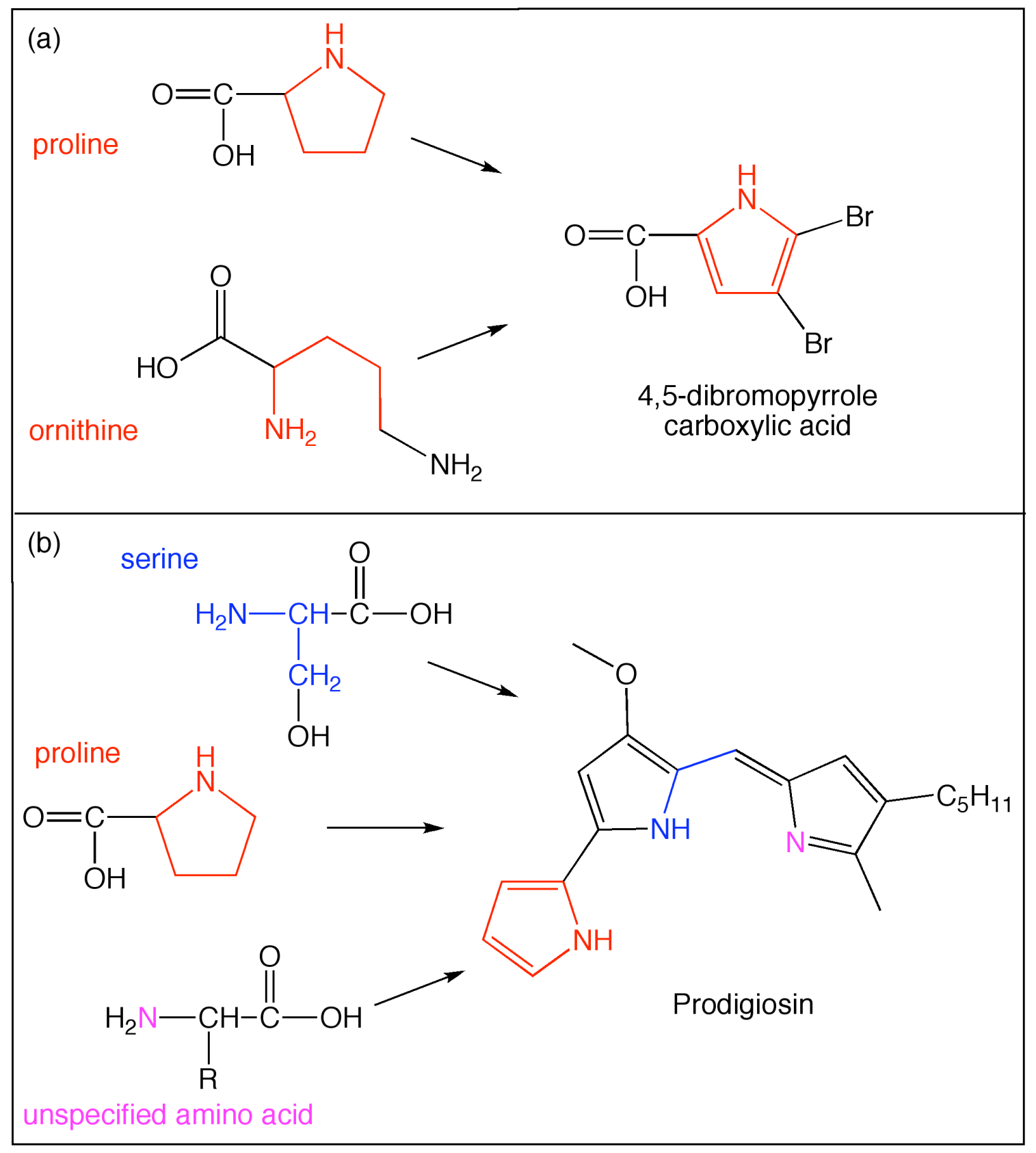

Figure 4. Selected pathways of pyrrole biosynthesis. The pyrrole moiety in the oroidin family of bromopyrrole alkaloids (produced in a number of marine sponge genera) is generated from proline and ornithine [75]. Proline is also the basis for one of the three pyrrole rings (in red) in Prodigiosin biosynthesis, the other nitrogens derive from serine (in blue) and an additional (unidentified) amino acid (in purple) [63]. 


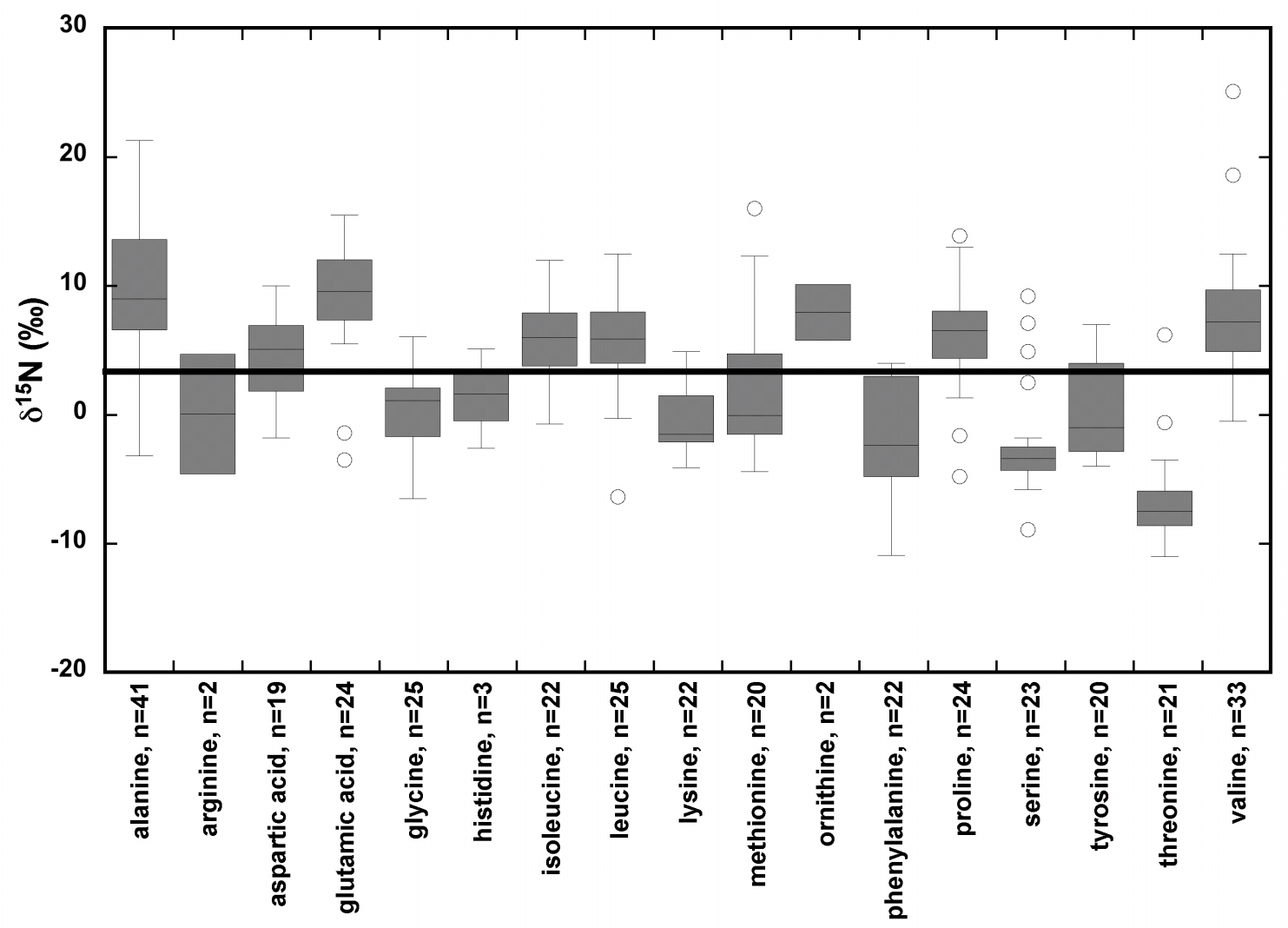

Figure 5. Box plots of the $\delta^{15} \mathrm{~N}$ ranges of selected amino acids (amino acids with only one reported value were not included). The horizontal bar represents the average value of all amino acids from this literature review (+3.4\%). Data from [26-31, 33-36, $66,74]$. 
Table 1. The $\delta^{15} \mathrm{~N}$ of four MBPs isolated from the blubber of three common dolphins, and the gender, age, and $\delta^{15} \mathrm{~N}_{\text {bulk }}$ of the dolphins. Measurements were made in triplicate, all three measurements are presented in italics and the average in bold.

\begin{tabular}{|c|c|c|c|c|c|}
\hline \multirow[b]{2}{*}{ Sample ID } & \multirow[b]{2}{*}{ gender } & \multirow[b]{2}{*}{ age } & \multirow[b]{2}{*}{$\delta^{15} N_{\text {bulk }}$} & \multicolumn{2}{|c|}{$\delta^{15} N(\% 0)( \pm 2 \% 0)$} \\
\hline & & & & $\mathrm{Br}_{7}-\mathrm{MBP}-79$ & MBP-Br${ }_{6} \mathrm{Cl}-b$ \\
\hline \multirow[t]{4}{*}{ CCSN04-218Dd } & male & calf & 14.3 & +19.3 & \\
\hline & & & eplicate 1 & +21.6 & \\
\hline & & & plicate 2 & +20.0 & \\
\hline & & & plicate 3 & +16.2 & \\
\hline \multirow[t]{4}{*}{ CCSN06-013Dd } & male & adult & $13.2^{*}$ & +21.0 & \\
\hline & & & plicate 1 & +21.6 & \\
\hline & & & eplicate 2 & +20.3 & \\
\hline & & & plicate 3 & +21.0 & \\
\hline \multirow[t]{4}{*}{ CCSN07-074Dd } & female & adult & 13.5 & +28.1 & +22.2 \\
\hline & & & plicate 1 & +28.3 & +25.5 \\
\hline & & & plicate 2 & +30.4 & +19.7 \\
\hline & & & plicate 3 & +25.6 & +21.3 \\
\hline
\end{tabular}

${ }^{*}$ Muscle was not sampled, and no bulk $\delta^{15} \mathrm{~N}$ was measured. The value was estimated based on the values of other adult male common dolphins in a companion study (Chapter 4 [4]).

\section{References}

1. Vetter, W.; Alder, L.; Kallenborn, R.; Schlabach, M., Determination of Q1, an unknown organochlorine contaminant, in human milk, Antarctic air, and further environmental samples. Environmental Pollution 2000, 110 (3), 401-409.

2. Wu, J.; Vetter, W.; Gribble, G. W.; Schneekloth, J. S.; Blank, D. H.; Gorls, H., Structure and synthesis of the natural heptachloro-1 '-methyl-1,2 '-bipyrrole (Q1). Angewandte Chemie-International Edition 2002, 41 (10), 1740-1743.

3. Teuten, E. L.; Pedler, B. E.; Hangsterfer, A. N.; Reddy, C. M., Identification of highly brominated analogues of Q1 in marine mammals. Environmental Pollution 2006, 144, 336-344.

4. Pangallo, K. Biomagnifying natural products in the northwestern Atlantic: halogenated 1'-methyl-1,2'-bipyrroles (MBPs). MIT/WHOI Joint Program in Oceanography/Applied Ocean Science and Engineering, Cambridge, MA, 2009. 5. Vetter, W., Marine halogenated natural products of environmental relevance. Reviews of Environmental Contamination and Toxicology 2006, 188, 1-57. 
6. Teuten, E. L.; Saint-Louis, R.; Pedler, B. E.; Xu, L.; Pelletier, E.; Reddy, C. M., Expanding the range of brominated Q1 analogues. Marine Pollution Bulletin 2006, 52, 578-582.

7. Teuten, E. L.; Reddy, C. M., Halogenated organic compounds in archived whale oil: A pre-industrial record. Environmental Pollution 2007, 145 (3), 668-671.

8. Vetter, W.; Gribble, G. W., Anthropogenic persistent organic pollutants lessons to learn from halogenated natural products. Environmental Toxicology and Chemistry 2007, 26 (11), 2249-2252.

9. Gaul, S.; Vetter, W., Photolytic dehalogenation of the marine halogenated natural product Q1. Chemosphere 2008, 70 (9), 1721-1729.

10. Pangallo, K.; Nelson, R. K.; Teuten, E. L.; Pedler, B. E.; Reddy, C. M., Expanding the range of halogenated 1'-methyl-1,2'-bipyrroles (MBPs) using GC/ECNI-MS and GC×GC/TOF-MS. Chemosphere 2008, 71, 1557-1565.

11. Unger, M. A.; Harvey, E.; Vadas, G. G.; Vecchione, M., Persistent pollutants in nine species of deep-sea cephalopods. Marine Pollution Bulletin 2008, 56 (8), 1486-1512.

12. Pangallo, K. C.; Reddy, C. M., Distribution patterns suggest biomagnification of halogenated 1'-methyl-1,2'-bipyrroles (MBPs). Environmental Science \& Technology 2009, 43 (1), 122-127.

13. Walsh, C. T., Natural insights for chemical biologists. Nature Chemical Biology 2005, 1 (3), 122-124.

14. Van Lanen, S. G.; Shen, B., Microbial genomics for the improvement of natural product discovery. Current Opinion in Microbiology 2006, 9 (3), 252-260.

15. Garson, M. J., Ecological perspectives on marine natural product biosynthesis. In Marine Chemical Ecology, McClintock, J. B.; Baker, B. J., Eds. CRC Press LLC: Boca Raton, FL, 2001; pp 71-114.

16. Andersen, R. J.; Wolfe, M. S.; Faulkner, D. J., Autotoxic antibiotic production by a marine Chromobacterium. Marine Biology 1974, 27 (4), 281-285.

17. Gauthier, M. J.; Flatau, G. N., Antibacterial activity of marine violetpigmented Alteromonas with special reference to production of brominated compounds. Canadian Journal of Microbiology 1976, 22 (11), 1612-1619.

18. Vetter, W.; Gleixner, G., Compound-specific stable carbon isotope ratios (delta C-13 values) of the halogenated natural product 2,3,3 ',4,4 ',5,5 'heptachloro-1 '-methyl-1,2 '-bipyrrole (Q1). Rapid Communications in Mass Spectrometry 2006, 20 (20), 3018-3022.

19. Vetter, W.; Schlatterer, J.; Gleixner, G., Experiments directed to the compound-specific determination of the stable carbon isotope ratios of the Toxaphene congener B8-1413 in two technical mixtures and Antarctic Weddell seal. Journal of Chromatography A 2006, 1110 (1-2), 165-170.

20. Eglinton, T. I.; Aluwihare, L. I.; Bauer, J. E.; Druffel, E. R. M.; McNichol, A. P., Gas chromatographic isolation of individual compouds from complex matrices for radiocarbon dating. Analytical Chemistry 1996, 68, 904-912. 
21. Berg, M.; Bolotin, J.; Hofstetter, T. B., Compound-specific nitrogen and carbon isotope analysis of nitroaromatic compounds in aqueous samples using solid-phase microextraction coupled to GC/IRMS. Analytical Chemistry 2007, 79 (6), 2386-2393.

22. Facility, U. D. S. I. http://stableisotopefacility.ucdavis.edu/. (accessed June 22, 2009).

23. Hartenbach, A. E.; Hofstetter, T. B.; Tentscher, P. R.; Canonica, S.; Berg, M.; Schwarzenbach, R. P., Carbon, hydrogen, and nitrogen isotope fractionation during light-induced transformations of atrazine. Environmental Science $\mathcal{E}$ Technology 2008, 42 (21), 7751-7756.

24. Sherwood Lollar, B.; Hirschorn, S. K.; Chartrand, M. M. G.; LacrampeCouloume, G., An approach for assessing total instrumental uncertainty in compound-specific carbon isotope analysis: implications for environmental remediation studies. Analytical Chemistry 2007, 79 (9), 3469-3475.

25. Vetter, W.; Gaul, S.; Olbrich, D.; Gaus, C., Monobromo and higher brominated congeners of the marine halogenated natural product $2,3,3^{\prime}, 4,4^{\prime}, 5,5^{\prime}$ heptachloro-1'-methyl-1,2'-bipyrrole (Q1). Chemosphere 2007, 66, 2011-2018.

26. Takano, Y.; Chikaraishi, Y.; Ogawa, N. O.; Kitazato, H.; Ohkouchi, N., Compound-specific nitrogen isotope analysis of D-alanine, L-alanine, and valine: application of diastereomer separation to delta N-15 and microbial peptidoglycan studies. Analytical Chemistry 2009, 81 (1), 394-399.

27. McClelland, J. W.; Montoya, J. P., Trophic relationships and the nitrogen isotopic composition of amino acids in plankton. Ecology 2002, 83 (8), 2173-2180.

28. McClelland, J. W.; Holl, C. M.; Montoya, J. P., Relating low delta N-15 values of zooplankton to N-2-fixation in the tropical North Atlantic: insights provided by stable isotope ratios of amino acids. Deep-Sea Research Part IOceanographic Research Papers 2003, 50 (7), 849-861.

29. Schmidt, K.; McClelland, J. W.; Mente, E.; Montoya, J. P.; Atkinson, A.; Voss, M., Trophic-level interpretation based on delta N-15 values: implications of tissue-specific fractionation and amino acid composition. Marine Ecology-Progress Series 2004, 266, 43-58.

30. Chikaraishi, Y.; Kashiyamal, Y.; Ogawa, N. O.; Kitazato, H.; Ohkouchi, N., Metabolic control of nitrogen isotope composition of amino acids in macroalgae and gastropods: implications for aquatic food web studies. Marine EcologyProgress Series 2007, 342, 85-90.

31. Bol, R.; Ostle, N.; Chenu, C.; Petzke, K.-J.; Werner, R.; Balesdent, J., Long term changes in the distribution and $\delta 15 \mathrm{~N}$ values of individual soil amino acids in the absence of plant and fertiliser inputs. Isotopes in Environmental and Health Studies 2004, 40 (4), 243-256.

32. Yoneyama, T.; Tanaka, F., Natural abundance of $15 \mathrm{~N}$ in nitrate, ureides, and amino acids from plant tissues. Soil Science and Plant Nutrition (Tokyo) 1999, 45 (3), 751-755. 
33. Zhang, L.; Altabet, M. A., Amino-group-specific natural abundance nitrogen isotope ratio analysis in amino acids. Rapid Communications in Mass Spectrometry 2008, 22 (4), 559-566.

34. Minagawa, M.; Egawa, S.; Kabaya, Y.; Karasawa-Tsuru, K., Carbon and nitrogen isotope analysis for amino acids from biological sample. Shitsuryo Bunseki 1992, 40 (1), 47-56.

35. O'Connell, T. C.; Hedge, R. E. M., Isolation and isotopic analysis of individual amino acids from archaeological bone collagen: A new method using RP-HPLC. Archaeometry 2001, 43, 421-438.

36. Metges, C. C.; Petzke, K. J., Measurement of N-15/N-14 isotopic composition in individual plasma free amino acids of human adults at natural abundance by gas chromatography combustion isotope ratio mass spectrometry. Analytical Biochemistry 1997, 247 (1), 158-164.

37. Schwartz, E.; Blazewicz, S.; Doucett, R.; Hungate, B. A.; Hart, S. C.; Dijkstra, P., Natural abundance $\delta 15 \mathrm{~N}$ and $\delta 13 \mathrm{C}$ of DNA extracted from soil. Soil Biology \& Biochemistry 2007, 39 (12), 3101-3107.

38. Bidigare, R. R.; Kennicutt, M. C.; Keeneykennicutt, W. L.; Macko, S. A., Isolation and purification of chlorophylls $\mathrm{a}$ and $\mathrm{b}$ for the determination of stable carbon and nitrogen isotope compositions. Analytical Chemistry 1991, 63 (2), 130133.

39. Sachs, J. P.; Repeta, D. J.; Goericke, R., Nitrogen and carbon isotopic ratios of chlorophyll from marine phytoplankton. Geochimica Et Cosmochimica Acta 1999, 63 (9), 1431-1441.

40. York, J. K.; Tomasky, G.; Valiela, I.; Repeta, D. J., Stable isotopic detection of ammonium and nitrate assimilation by phytoplankton in the Waquoit Bay estuarine system. Limnology and Oceanography 2007, 52 (1), 144-155.

41. Enders, S. K.; Pagani, M.; Pantoja, S.; Baron, J. S.; Wolfe, A. P.; Pedentchouk, N.; Nunez, L., Compound-specific stable isotopes of organic compounds from lake sediments track recent environmental changes in an alpine ecosystem, Rocky Mountain National Park, Colorado. Limnology and Oceanography 2008, 53 (4), 1468-1478.

42. Kashiyama, Y.; Ogawa, N. O.; Kuroda, J.; Shiro, M.; Nomoto, S.; Tada, R.; Kitazato, H.; Ohkouchi, N., Diazotrophic cyanobacteria as the major photoautotrophs during mid-Cretaceous oceanic anoxic events: Nitrogen and carbon isotopic evidence from sedimentary porphyrin. Organic Geochemistry 2008, 39 (5), 532-549.

43. Kashiyama, Y.; Ogawa, N. O.; Shiro, M.; Tada, R.; Kitazato, H.; Ohkouchi, N., Reconstruction of the biogeochemistry and ecology of photoautotrophs based on the nitrogen and carbon isotopic compositions of vanadyl porphyrins from Miocene siliceous sediments. Biogeosciences 2008, 5 (3), 797-816.

44. Ohkouchi, N.; Nakajima, Y.; Okada, H.; Ogawa, N. O.; Suga, H.; Oguri, K.; Kitazato, H., Biogeochemical processes in the saline meromictic Lake Kaiike, 
Japan: Implications from molecular isotopic evidences of photosynthetic pigments. Environmental Microbiology 2005, 7 (7), 1009-1016.

45. Werner, R. A.; Schmidt, H. L., The in vivo nitrogen isotope discrimination among organic plant compounds. Phytochemistry 2002, 61 (5), 465-484.

46. Stegman, J. J.; Hahn, M. E., Biochemistry and molecular biology of monooxygenases: Current directions in forms, functions, and regulation of cytochrome P450 in aquatic species. In Aquatic Toxicology: Molecular, Biochemical and Cellular Perspectives, Malins, D. C.; Ostrander, G. K., Eds. Lewis Publishers, CRC Press: Boca Raton, FL, 1993; pp 87-206.

47. Wackett, L. P., Questioning our perceptions about evolution of biodegradative enzymes. Current Opinion in Microbiology 2009, In Press, Corrected Proof.

48. Ahn, Y.-B.; Rhee, S.-K.; Fennell, D. E.; Kerkhof, L. J.; Hentschel, U.; Häggblom, M. M., Reductive dehalogenation of brominated phenolic compounds by microorganisms associated with the marine sponge Aplysina aerophoba. Applied and Environmental Microbiology 2003, 69 , 4159-4166.

49. Stapleton, H. M.; Brazil, B.; Holbrook, R. D.; Mitchelmore, C. L.; Benedict, R.; Konstantinov, A.; Potter, D., In vivo and in vitro debromination of decabromodiphenyl ether (BDE 209) by juvenile rainbow trout and common carp. Environmental Science \& Technology 2006, 40, 4653-4658.

50. Malmberg, T.; Athanasiadou, M.; Marsh, G.; Brandt, I.; Bergman, A., Identification of hydroxylated polybrominated diphenyl ether metabolites in blood plasma from polybrominated diphenyl ether exposed rats. Environmental Science \& Technology 2005, 39 (14), 5342-5348.

51. Thuresson, K.; Höglund, P.; Hagmar, L.; Sjödin, A.; Bergman, Å.; Jakobsson, K., Apparent half-lives of hepta- to decabrominated diphenyl ethers in human serum as determined in occupationally exposed workers. Environmental Health Perspectives 2006, 114 (2), 176-181.

52. Stapleton, H. M.; Kelly, S. M.; Pei, R.; Letcher, R. J.; Gunsch, C., Metabolism of polybrominated diphenyl ethers (PBDEs) by human hepatocytes in Vitro. Environmental Health Perspectives 2009, 117 (2), 197-202.

53. Holmstrand, H.; Mandalakis, M.; Zencak, Z.; Andersson, P.; Gustafsson, O., First compound-specific chlorine-isotope analysis of environmentallybioaccumulated organochlorines indicates a degradation-relatable kinetic isotope effect for DDT. Chemosphere 2007, 69 (10), 1533-1539.

54. Hengge, A. C., Secondary isotope effects. In Isot. Eff. Chem. Biol., Amnon, K.; Limbach, H.-H., Eds. CRC Press LLC: Boca Raton, FL, 2006; pp 955-974.

55. Abe, Y.; Aravena, R.; Zopfi, J.; Shouakar-Stash, O.; Cox, E.; Roberts, J. D.; Hunkeler, D., Carbon and chlorine isotope fractionation during aerobic oxidation and reductive dechlorination of vinyl chloride and cis-1,2-dichloroethene. Environmental Science \& Technology 2009, 43 (1), 101-107. 
56. Hofstetter, T. B.; Spain, J. C.; Nishino, S. F.; Bolotin, J.; Schwarzenbach, R. P., Identifying competing aerobic nitrobenzene biodegradation pathways by compound-specific isotope analysis. Environmental Science \& Technology 2008, 42 (13), 4764-4770.

57. Letcher, R. J.; Klasson-Wehler, E.; Bergman, Å., Methyl sulfone and hydroxylated metabolites of polychlorinated biphenyls. In The Handbook of Environmental Chemistry, Passivirta, J., Ed. Springer-Verlag: Berlin, 2001.

58. Pollman, K.; Wray, V.; Pieper, D. H., Chloromethylmuconolactones as critical metabolites in the degradation of chloromethylcatechols: recalcitrence of 2-chlorotoluene. J. Bacteriol. 2005, 187 (7), 2332-2340.

59. Sigman, D. M.; Altabet, M. A.; McCorkle, D. C.; Francois, R.; Fischer, G., The $\delta 15 \mathrm{~N}$ of nitrate in the Southern Ocean: Nitrogen cycling and circulation in the ocean interior. Journal of Geophysical Research 2000, 105.

60. Hayes, J. M., Fractionation of the isotopes of carbon and hydrogen in biosynthetic processes. In Stable Isotope Geochemistry, Valley, J. W.; Cole, D. R., Eds. Mineralogical Society of America: 2001.

61. Walsh, C. T.; Garneau-Tsodikova, S.; Howard-Jones, A. R., Biological formation of pyrroles: nature's logic and enzymatic machinery. Natural Product Reports 2006, 23, 517-531.

62. Garneau, S.; Dorrestein, P. C.; Kelleher, N. L.; Walsh, C. T., Characterization of the formation of the pyrrole moiety during clorobiocin and coumermycin A(1) biosynthesis. Biochemistry 2005, 44 (8), 2770-2780.

63. Williamson, N. R.; Simonsen, H. T.; Ahmed, R. A. A.; Goldet, G.; Slater, H.; Woodley, L.; Leeper, F. J.; Salmond, G. P. C., Biosynthesis of the red antibiotic, prodigiosin, in Serratia: identification of a novel 2-methyl-3-n-amylpyrrole (MAP) assembly pathway, definition of the terminal condensing enzyme, and implications for undecylprodigiosin biosynthesis in Streptomyces. Molecular Microbiology 2005, 56 (4), 971-989.

64. Moore, B. S., Biosynthesis of marine natural products: Microorganisms (Part A). Natural Product Reports 2005, 22 (5), 580-593.

65. Moore, B. S., Biosynthesis of marine natural products: macroorganisms (Part B). Natural Product Reports 2006, 23 (4), 615-629.

66. Sacks, G. L.; Brenna, J. T., N-15/N-14 position-specific isotopic analyses of polynitrogenous amino acids. Analytical Chemistry 2005, 77 (4), 1013-1019.

67. Broman, D.; Naf, C.; Rolff, C.; Zebuhr, Y.; Fry, B.; Hobbie, J., Using ratios of stable nitrogen isotopes to estimate bioaccumulation and flux of polychlorinated dibenzo-p-dioxins (PCDDs) and dibenzofurans (PCDFs) in 2 food-chains from the northern Baltic. Environmental Toxicology and Chemistry 1992, 11 (3), 331-345.

68. Sutka, R. L.; Ostrom, N. E.; Ostrom, P. H.; Phanikumar, M. S., Stable nitrogen isotope dynamics of dissolved nitrate in a transect from the North 
Pacific Subtropical Gyre to the Eastern Tropical North Pacific. Geochimica Et Cosmochimica Acta 2004, 68 (3), 517-527.

69. Bowman, J. P., Bioactive compound synthetic capacity and ecological significance of marine bacterial genus Pseudoalteromonas. Marine Drugs 2007, 5, 220-241.

70. Baltz, R. H., Renaissance in antibacterial discovery from actinomycetes. Current Opinion in Pharmacology 2008, 8 (5), 557-563.

71. Cerdeño, A. M.; Bibb, M. J.; Challis, G. L., Analysis of the prodiginine biosynthesis gene cluster of Streptomyces coelicolor A3(2): new mechanisms for chain initiation and termination in modular multienzymes. Chemistry $\mathcal{E}$ Biology 2001, 8 (8), 817-829.

72. Hughes, C. C.; Prieto-Davo, A.; Jensen, P. R.; Fenical, W., The marinopyrroles, antibiotics of an unprecedented structure class from a marine Streptomyces sp. Organic Letters 2008, 10 (4), 629-631.

73. Williams, P. G., Panning for chemical gold: marine bacteria as a source of new therapeutics. Trends in Biotechnology 2009, 27 (1), 45-52.

74. Yoneyamma, T.; Fujihara, S.; Yagi, K., Natural abundance of $15 \mathrm{~N}$ in amino acids and polyamines from leguminous nodules: unique $15 \mathrm{~N}$ enrichment in homospermidine. Journal of Experimental Botany 1998, 49 (320), 521-526.

75. Andrade, P.; Willoughby, R.; Pomponi, S. A.; Kerr, R. G., Biosynthetic studies of the alkaloid, stevensine, in a cell culture of the marine sponge Teichaxinella morchella. Tetrahedron Letters 1999, 40 (26), 4775-4778. 


\section{CHAPTER 6}

\section{Conclusions and Future Directions}

Halogenated 1'-methyl-1,2'-bipyrroles (MBPs) are a distinctive class of marine organic compounds. They are naturally produced, have a unique carbon structure, are highly halogenated (with bromine and/or chlorine), appear to biomagnify, and are considerably enriched in ${ }^{15} \mathrm{~N}$ relative to other terrestrial and marine naturally produced organic molecules.

When these compounds were initially detected in blubber samples, only a few of the most abundant MBP congeners were identified [1-3]. Specifically, only one $\mathrm{MBP}-\mathrm{Br}{ }_{6} \mathrm{Cl}$ congener was detected (out of a possible five), prompting researchers to speculate that the halogenation process during biosynthesis was regioselective and that congeners with fewer than seven halogens were the dehalogenation products of biosynthetic perhalogenated congeners [3]. However, over twenty perhalogenated MBPs have now been detected [4-6], which diminishes the theory that MBP halogenation is regioselective. The origins of MBPs with fewer than seven halogens are not yet clear. They may be

synthesized concomitantly with their perhalogenated counterparts, they may be products of dehalogenation, or both processes may contribute to their presence in environmental samples. 
One line of evidence for MBPs as marine natural products is their detection only in marine samples. Even the carbon structure (N.C1-linked bipyrrole) had never been reported prior to the identification of MBP-79 [7]. However, it should be noted that a thorough search for MBPs in terrestrial environments has not yet been performed. Since pyrroles are relatively common, as are opportunities for halogenation, a more thorough screening of terrestrial samples would be beneficial supporting evidence. Further, the abiotic condensation of pyrroles in the presence of halogenating agents or enzymes should also be investigated. Unintentional abiotic generation of MBPs may be unlikely (lab-based chemical synthesis of these molecules suffers from very low yields $[2,8])$, but still requires investigation to rule out.

The evidence for MBPs biomagnification is extremely strong. As demonstrated in this dissertation, lipid-normalized MBPs concentrations increase with increasing trophic level. Additionally, MBPs display the biomagnification patterns seen in the environment for persistent organic pollutants (POPs) and that have been demonstrated mathematically by numerical models. In adult males, MBP concentrations increase with age; in juveniles there is a growth dilution pattern; and adult females have much lower body burdens than males, likely due to MBP transfers during lactation and gestation. All of our data is consistent with biomagnification as the process responsible for the environmental distribution of MBPs. Since biomagnification is a critical feature 
of the environmental chemistry of POPs, the data presented here affords greater confidence in the use of MBPs as natural analogues for these anthropogenic contaminants.

It remains to be determined why MBPs and other similar naturally produced compounds are persistent in the environment. Although halogenated natural products are commonly hypothesized to be defensive compounds [9], further hypotheses have also been proposed, such as forms of chemical communication, settling deterrents/anti-fouling agents, and protection from UV radiation $[9,10]$. Persistence is not an obviously desirable attribute for chemicals involved in communication or that might be toxic. However, as proposed by Prof. William Fenical (personal communication) the lipophilicity of many of these persistent chemicals may be the mechanism that prevents them from overaccumulating in the ecosystem in which they are produced.

However, the similarities to POPs are inevitably limited, as demonstrated in this dissertation by the comparison of MBPs and a POP, 2, $2^{\prime}, 4,4^{\prime}, 5,5^{\prime}$ hexachlorobiphenyl (CB-153). POPs and marine halogenated natural products (HNPs), such as MBPs, have very different sources, and this can lead to differences in their distributions. POPs are now ubiquitous [11], but they are produced terrestrially, and their inputs to the ocean are thus tied to their terrestrial sources. MBPs, however, have only a marine source, and have no association with terrestrial inputs. Further, it is likely that just one species or an 
assemblage of species produces them, thus their source is far more limited than POP sources. The differences in the geography and magnitude of sources between MBPs and POPs may lead to variations in the ways that they enter and transit through the food webs. Thus, it takes longer for concentrations to accumulate in blubber because MBPs have a more limited magnitude and distribution relative to PCBs and exposure to MBPs is reduced. This theory is strengthened by the consistent presence of CB-153, and its relative abundance, compared to the more variable, but consistently less abundant, distribution of MBPs in marine species.

The differences between MBPs and POPs are not limited to their sources and geographic distributions. This dissertation presents evidence suggesting that marine mammals process these compounds differently. MBPs appear to be more easily mobilized from blubber during times of nutritional stress, and this may include periods of gestation and lactation in adult females. Further, the pinniped species analyzed in this dissertation (P. groenlandica and H. grypus) have far lower MBP blubber concentrations than would be expected for their trophic positions, yet they still have the expected high levels of CB-153. Such differences between HNPs and POPs were noted in previous studies of pinnipeds [12-14], which suggested that these pinnipeds had enhanced metabolic capabilities to process HNPs. By determining that pinnipeds are exposed to MBPs through their diets, the data presented in Chapter 4 considerably 
strengthens this argument. Investigating the enzymatic mechanisms of HNP and POP metabolism may elucidate which structural features facilitate MBP metabolism.

Finally, MBPs have high $\delta^{15} \mathrm{~N}$ values, enriched relative to other naturally produced organic compounds and to the bulk tissue of the dolphins from which they were isolated. This enrichment appears to be a signature of biosynthesis, and it is unlikely to have been introduced by metabolism or abiotic degradation. Thus, their enrichment is tied to biosynthetic fractionation and/or enriched precursors. Two potential sources of biosynthetic enrichment can be tested rather easily. The isotope effects of halogenation of pyrrole rings can be examined through the abiotic process to determine if changes in aromaticity result in an associated fractionation. The fractionation associated with linking the pyrrole rings could be examined by comparing the $\delta^{15} \mathrm{~N}$ of MBPs and marinopyrroles with that of DMBPs. MBPs and marinopyrroles are both linked through a nitrogen atom from one of the pyrrole rings, while DMBPs are only linked through carbon atoms. Thus, if the enrichment we observe in MBPs is due to formation of the $C 1, N$ bond, than similar enrichment should be observed in the marinopyrroles and no such enrichment would be present in the DMBPs.

The biosynthetic mechanism of MBPs is, of course, unknown, but structurally similar compounds are produced by other marine bacteria, specifically the marinopyrroles from an actinomycete strain (CNQ-418) [15] and 
3,3',4,4',5,5'-hexabromo-2,2'-bipyrrole from Pseudoalteromonas luteoviolacea [16,

17]. A source of enriched nitrogen is common to both groups. Species from both groups are involved in denitrification, a process that strongly fractionates nitrogen isotopes, leaving the residual nitrate enriched in ${ }^{15} \mathrm{~N}$. Consequently, MBP's $\delta^{15} \mathrm{~N}$ signatures suggest that species from the Actinomycetes or Pseudoalteromonas may be responsible for MBP biosynthesis. Future searches for MBP producers may find it most productive to focus on these species.

Much remains to be learned about the controls on MBP cycling and fate, as well as about MBP biosynthesis and chemical ecology. Ultimately, the questions that drive my interest in MBPs have not yet been answered: who make these compounds, how are they made, what function do they serve, and why are they required to be environmentally persistent? The dissertation provides the foundation necessary to find these answers by expanding our understanding of environmental distributions and providing initial constraints on MBP biosynthesis.

\section{References}

1. Vetter, W.; Jun, W., Elucidation of a polychlorinated bipyrrole structure using enantioselective GC. Analytical Chemistry 2002, 74 (16), 4287-4289.

2. Wu, J.; Vetter, W.; Gribble, G. W.; Schneekloth, J. S.; Blank, D. H.; Gorls, H., Structure and synthesis of the natural heptachloro-1 '-methyl-1,2 '-bipyrrole (Q1). Angewandte Chemie-International Edition 2002, 41 (10), 1740-1743. 
3. Teuten, E. L.; Pedler, B. E.; Hangsterfer, A. N.; Reddy, C. M., Identification of highly brominated analogues of Q1 in marine mammals. Environmental Pollution 2006, 144, 336-344.

4. Vetter, W.; Gaul, S.; Olbrich, D.; Gaus, C., Monobromo and higher brominated congeners of the marine halogenated natural product 2,3,3',4,4',5,5'heptachloro-1'-methyl-1,2'-bipyrrole (Q1). Chemosphere 2007, 66, 2011-2018.

5. Pangallo, K.; Nelson, R. K.; Teuten, E. L.; Pedler, B. E.; Reddy, C. M., Expanding the range of halogenated 1'-methyl-1,2'-bipyrroles (MBPs) using GC/ECNI-MS and GC $\times$ GC/TOF-MS. Chemosphere 2008, 71, 1557-1565.

6. Gaul, S.; Vetter, W., Photolytic dehalogenation of the marine halogenated natural product Q1. Chemosphere 2008, 70 (9), 1721-1729.

7. Vetter, W., Marine halogenated natural products of environmental relevance. Reviews of Environmental Contamination and Toxicology 2006, 188, 1-57.

8. $\mathrm{Fu}, \mathrm{L}$.; Gribble, G. W., A short synthesis of the naturally occuring 2,3,3',4,4',5,5'-heptachloro- ("Q1") and heptabromo-1'-methyl-1,2'-bipyrroles. Org. Prep. \& Proc. Int. 2008, Accepted.

9. Avila, C.; Taboada, S.; Nunez-Pons, L., Antarctic marine chemical ecology: what is next? Mar. Ecol.-Evol. Persp. 2008, 29 (1), 1-71.

10. Meinwald, J., The Chemistry of Biotic Interactions in Perspective: Small Molecules Take Center Stage. Journal of Organic Chemistry 2009, 74 (5), 1813-1825.

11. Program, U. N. E., Stockholm Convention on Persistent Organic Pollutants. Program, U. N. E., Ed. Stockholm, Sweden, 2001; p 43.

12. Tittlemier, S. A.; Fisk, A. T.; Hobson, K. A.; Norstrom, R. J., Examination of the bioaccumulation of halogenated dimethyl bipyrroles in an Arctic marine food web using stable nitrogen isotope analysis. Environmental Pollution 2002, 116 (1), 85-93.

13. Vetter, W.; Jun, W.; Althoff, G., Non-polar halogenated natural products bioaccumulated in marine samples. I. 2,3,3 ',4,4 ',5,5 '-heptachloro-1 '-methyl-1,2 'bipyrrole (Q1). Chemosphere 2003, 52 (2), 415-422.

14. Weijs, L.; Losada, S.; Das, K.; Roosens, L.; Reijnders, P. J. H.; Santos, J. F.; Neels, H.; Blust, R.; Covaci, A., Biomagnification of naturally-produced methoxylated polybrominated diphenyl ethers (MeO-PBDEs) in harbour seals and harbour porpoises from the Southern North Sea. Environment International 2009, 35 (6), 893-899.

15. Hughes, C. C.; Prieto-Davo, A.; Jensen, P. R.; Fenical, W., The marinopyrroles, antibiotics of an unprecedented structure class from a marine Streptomyces sp. Organic Letters 2008, 10 (4), 629-631.

16. Andersen, R. J.; Wolfe, M. S.; Faulkner, D. J., Autotoxic antibiotic production by a marine Chromobacterium. Marine Biology 1974, 27 (4), 281-285.

17. Gauthier, G.; Gauthier, M.; Christen, R., Phylogenetic analysis of the genera Alteromonas, Shewanella, and Moritella using genes-coding for smallsubunit ribosomal-RNA sequences and division of the genus Alteromonas into 2 
genera, Alteromonas (emended) and Pseudoalteromonas Gen-Nov, and proposal of 12 new species combinations. International Journal of Systematic Bacteriology 1995, 45 (4), 755-761. 


\section{APPENDIX}

The lipid content of mammalian samples. Blubber percentages are given on a wet weight basis, liver percentages are given on a dry weight basis. The abbreviations are: 'n.r.' - not recorded; 'n/a' - not applicable because no liver samples were available.

\begin{tabular}{ccc} 
& \multicolumn{2}{c}{$\%$ lipid } \\
\cline { 2 - 3 } CCSN number & blubber & liver \\
\hline CCSN07-023La & 83.3 & 13.4 \\
CCSN06-119La & 77.6 & 12.5 \\
CCSN06-022La & 75.5 & 19.8 \\
CCSN06-264Dd & 69.3 & 10.5 \\
CCSN07-109Dd & 57.3 & 10.0 \\
CCSN07-115Dd & 56.7 & 11.0 \\
CCSN05-316Dd & n.r. & 12.6 \\
CCSN06-013Dd & n.r. & 13.6 \\
CCSN06-029Dd & 80.5 & 8.73 \\
CCSN06-263Dd & 85.2 & 7.23 \\
CCSN07-040Dd & 71.5 & 6.00 \\
CCSN06-024Dd & 79.0 & 23.1 \\
CCSN06-096Dd & 83.8 & 19.6 \\
CCSN06-137Dd & 63.6 & 12.1 \\
CCSN07-036Dd & $n . r$. & 7.35 \\
CCSN07-041Dd & 53.8 & 11.1 \\
D08742 & n.r. & 9.94 \\
CCSN07-129Hg & 78.0 & 11.0 \\
D07041 & 63.1 & 15.7 \\
CCSN07-063Pg & 81.4 & 22.8 \\
CCSN07-080Pg & 84.3 & 5.66 \\
CCSN07-084Pg & 79.5 & 16.3 \\
CCSN07-116Pg & 85.5 & 5.34 \\
CCSN06-133Pg & 67.3 & 15.2 \\
CCSN07-022Gm & n.r. & 9.48 \\
CCSN06-019La & 80.0 & $n / a$ \\
CCSN04-218Dd & 59.9 & $n / a$ \\
CCSN06-144Dd & 72.9 & $n / a$ \\
CCSN07-074Dd & $n . r$. & $n / a$ \\
CCSN07-066Pg & 77.5 & $n / a$ \\
CCSN07-076Pg & 76.3 & $n / a$
\end{tabular}

